\title{
Development of an immunosensor for on-line continuous measurement of cardiac injury
}

Citation for published version (APA):

van der Voort, D. (2003). Development of an immunosensor for on-line continuous measurement of cardiac injury. [Doctoral Thesis, Maastricht University]. Universiteit Maastricht. https://doi.org/10.26481/dis.20040130dv

Document status and date:

Published: 01/01/2003

DOI:

$10.26481 /$ dis.20040130dv

Document Version:

Publisher's PDF, also known as Version of record

\section{Please check the document version of this publication:}

- A submitted manuscript is the version of the article upon submission and before peer-review. There can be important differences between the submitted version and the official published version of record. People interested in the research are advised to contact the author for the final version of the publication, or visit the DOI to the publisher's website.

- The final author version and the galley proof are versions of the publication after peer review.

- The final published version features the final layout of the paper including the volume, issue and page numbers.

Link to publication

\footnotetext{
General rights rights.

- You may freely distribute the URL identifying the publication in the public portal. please follow below link for the End User Agreement:

www.umlib.nl/taverne-license

Take down policy

If you believe that this document breaches copyright please contact us at:

repository@maastrichtuniversity.nl

providing details and we will investigate your claim.
}

Copyright and moral rights for the publications made accessible in the public portal are retained by the authors and/or other copyright owners and it is a condition of accessing publications that users recognise and abide by the legal requirements associated with these

- Users may download and print one copy of any publication from the public portal for the purpose of private study or research.

- You may not further distribute the material or use it for any profit-making activity or commercial gain

If the publication is distributed under the terms of Article $25 \mathrm{fa}$ of the Dutch Copyright Act, indicated by the "Taverne" license above, 
Development of an immunosensor for on-line continuous measurement of cardiac injury 
Development of an immunosensor for on-line continuous measurement of cardiac injury / Daniëlle van der Voort

Thesis Maastricht University - With summary in Dutch ISBN 90-9017700-0

Printed by: Datawyse, Maastricht

C D. van der Voort, Maastricht, The Netherlands, 2003. All rights reserved 
Development of an immunosensor for on-line continuous measurement of cardiac injury

\title{
Proefschrift
}

\author{
ter verkrijging van de graad van doctor aan \\ de Universiteit Maastricht, \\ op gezag van Rector Magnificus, \\ Prof.mr. G.P.M.F. Mols,
} volgens het besluit van het College van Decanen, in het openbaar te verdedigen op vrijdag 30 januari 2004 om 16.00 uur

door

Daniëlle van der Voort 


\section{Promotores}

Prof.dr. J.F.C. Glatz

Prof.dr. J. Korf (Rijksuniversiteit Groningen)

Prof.dr. W.T. Hermens

Beoordelingscommissie

Prof.dr. H.J.G.M. Crijns (voorzitter)

Prof.dr. P. Bergveld (Universiteit Twente)

Prof.dr. W.A. Buurman

Dr. J.G. Maessen

Prof.dr. R Renneberg (Hong Kong University)

Financial support by the Dutch Technology Foundation for the project (GGN4860) described in this thesis is gratefully acknowledged 
Writing a thesis is like trying to fly, you just need truth, trust and pixydust 


\section{Contents}

1. General introduction and outline of the thesis

2. Marker proteins in the detection and quantification of myocardial injury

2.1 Cardiac injury 15

2.2 Myocardial infarction 16

2.2.1 Current diagnosis 16

2.2.2 Biochemical markers for the detection of AMI 17

Creatine Kinase 18

Lactate dehydrogenase $\quad 19$

Troponins 20

Myoglobin 21

Fatty acid-binding protein 22

2.3 The ideal marker for cardiac injury 22

2.4 Biosensors 23

2.5 On-line monitoring of circulating analytes 24

2.5.1 Microdialysis 24

2.5.2 Ultrafiltration 24

2.5.3 Comparison of microdialysis and ultrafiltration 25

2.5.4 Continuous sampling in plasma 26

2.5.5 Displacement 27

2.6 References 27

3. Fatty acid-binding protein as the earliest available plasma marker for acute myocardial infarction $\quad 33$

$\begin{array}{lll}3.1 & \text { Abstract } & 34\end{array}$

3.2 Introduction 34

3.3 FABP is abundantly expressed in cardiac myocytes 35

3.4 Immunochemical assay of FABP in plasma 36

3.5 FABP and myoglobin show similar plasma release curves upon muscle injury 36

3.6 FABP shows a relatively low plasma reference concentration 38

3.7 Discrimination of cardiac from skeletal muscle injury 38

$\begin{array}{lll}3.8 & \text { Early diagnosis of AMI } & 39\end{array}$

3.9 FABP and the detection of minor myocardial injury 41

3.10 Other established applications of the plasma marker FABP 42

3.11 New developments in the application of FABP as plasma marker 43

3.12 Conclusions 45

3.13 References 45

4 Biosensors for fatty acid-binding protein, an early plasma marker of myocardial injury 
4.1 Abstract $\quad 52$

4.2 Introduction $\quad 52$

4.3 Immunoassays 53

4.4 Biosensors based on antigen/antibody interactions 54

4.5 Biosensors and their potential for clinical application 54

4.6 Biochemical on-line monitoring 55

4.7 Displacement 55

Fatty acid-binding protein $\quad 56$

4.8 Biosensors for the quantification of fatty acid-binding protein $\quad 57$

$\begin{array}{ll}\text { 4.8.1 The first FABP biosensor } & 57\end{array}$

4.8.2 A direct optical immunosensor for FABP 58

4.8.3 The first FABP biosensor applicable in plasma 58

4.8.4 Grating coupler sensors for the detection of FABP 60

4.8.5 The first FABP biosensor for quantification in whole blood 60

4.8.6 on-line continuous displacement assays for FABP 61

$4.9 \quad$ Future outlook 61

4.10 References $\quad 62$

5. Development of a displacement immunoassay for human heart-type fatty acid-binding protein in plasma: the basic conditions $\quad 67$

$\begin{array}{lll}5.1 & \text { Abstract } & 68\end{array}$

$\begin{array}{lll}5.2 & \text { Introduction } & 68\end{array}$

$\begin{array}{lll}5.3 & \text { Materials and methods } & 69\end{array}$

5.3.1 The assay principle $\quad 69$

5.3.2 Preparation of immobilized FABP 69

5.3.3 Coupling of labeled antibody to Sepharose-bound FABP 70

$\begin{array}{lll}5.3 .4 & \text { Displacement experiments } & 70\end{array}$

$\begin{array}{ll}\text { 5.3.5 FABP assay } & 70\end{array}$

$\begin{array}{lll}5.3 .6 & \text { Ab-HRP assay } & 70\end{array}$

$\begin{array}{lll}5.3 .7 & \text { Statistics } & 71\end{array}$

$\begin{array}{lll}5.4 & \text { Results } & 71\end{array}$

5.4.1 Binding of FABP to the Sepharose matrix 71

5.4.2 Binding of Ab-HRP to the matrix-bound FABP 71

5.4.3 Displacement of Ab-HRP by FABP in buffer 72

5.4.4 Displacement of Ab-HRP by FABP in plasma 73

5.5 Discussion $\quad 74$

$\begin{array}{lll}5.6 & \text { References } & 76\end{array}$

6. A displacement immunoassay for human heart-type fatty acid-binding protein in plasma

6.1 Abstract $\quad 80$

6.2 Introduction 80

6.3 Materials and methods 81

6.3.1 Human plasma $\quad 81$

From healthy donors $\quad 81$ 
From AMI patients $\quad 81$

6.3.2 Preparation of immobilized FABP 81

6.3.3 Coupling of labeled antibody to Sepharose-bound FABP 82

6.3.4 Assay principle $\quad 82$

6.3.5 Displacement experiments $\quad 82$

6.3.6 Ab-HRP assay $\quad 82$

6.3.7 FABP assay $\quad 83$

$\begin{array}{lll}6.3 .8 & \text { Statistics } & 83 \\ & & 83\end{array}$

6.4 Results 83

6.4.1 Preparation of displacement columns 83

6.4.2 Binding of Ab-HRP to the matrix-bound FABP 83

6.4.3 Displacement of Ab-HRP from matrix-bound FABP 83

6.4.4 Studies with plasma from patients $\quad 86$

$\begin{array}{lll}6.5 & \text { Discussion } & 87\end{array}$

6.5.1 Characteristics of the immunoassay 88

6.5.2 Clinical application $\quad 89$

$\begin{array}{lll}6.6 & \text { References } & 89\end{array}$

7. Development of other rapid immunoassays for FABP based on electrochemical or optical transduction methods

7.1 Foreword 93

7.2 FABP quantification by use of an $\mathrm{AC}$ impedance detection technique

7.2.1 Background

7.2.2 Sensor principle 94

$\begin{array}{ll}7.2 .3 \text { Human plasma } & 94\end{array}$

$\begin{array}{lll}7.2 .4 & \text { Results } & 95\end{array}$

7.2.5 Conclusions 95

$\begin{array}{lll}7.3 \text { CardioDetect } & \\ & \text { (B.3. } & 96\end{array}$

$\begin{array}{ll}\text { 7.3.1 Background } & 96\end{array}$

7.3.2 Test principle $\quad 96$

$\begin{array}{ll}\text { 7.3.3 Human samples } & 97\end{array}$

$\begin{array}{lll}\text { 7.3.4 Preliminary results } & 97\end{array}$

7.3.5 Conclusions and future studies 97

$\begin{array}{lll}7.4 & \text { References } & 98\end{array}$

8. General discussion $\quad 99$

8.1 The relevance of rapid diagnosis of cardiac injury 99

8.2 Apoptosis and necrosis may go together 100

8.3 The optimal marker for cardiac injury 102

8.4 The continuous measurement of FABP 103

8.5 Optimization of the FABP displacement sensor 104

$\begin{array}{ll}8.6 & \text { Future perspectives } \\ 8.7 & 107\end{array}$

$\begin{array}{lll}8.7 & \text { References } & 109\end{array}$ 
Samenvatting

Dankwoord 121

Curriculum Vitae 123

Publicaties 


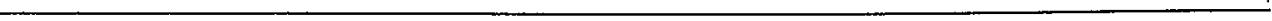




\section{General introduction and outline of the thesis}

Major causes of death and disabilities of adults include infarctions of the heart (acute myocardial infarction, AMI) and of the brain (stroke). For patients presenting in hospital with symptoms suggesting AMI, rapid decision making is mandatory to ascertain the correct diagnosis and treatment. To further optimize therapeutic interventions of patients in the coronary care unit, monitoring of the patient should be performed. Nowadays, this monitoring includes measuring blood pressure, carbon dioxide and oxygen levels in blood, electrocardiogram (ECG) and pulse rate. Although electrocardiography is the unquestioned standard method for the diagnosis of acute myocardial infarction and the initiation of thrombolytic therapy, not all AMI patients can be diagnosed with ECG. In patients without ST-elevation and in patients with unstable angina, other methods are needed to determine their diagnosis. ${ }^{(1-3)}$ These methods can also be helpful in detecting myocardial injury in other cases, for instance in patients who undergo cardiac surgery. These other methods are based on measuring certain cardiac enzymes or proteins, which show increased plasma concentrations after myocardial injury.

The history of biochemical markers for acute myocardial infarction goes back to the nineteenfifties. Karmen et $a^{(4)}$ described aspartate aminotransferase (AST) as the first marker for AMI in 1954. To compensate for the lack of AST specificity for cardiac diseases, the rapid discovery of other markers and the development of enzymatic assays for these newer markers were of great importance. Other markers included lactate dehydrogenase ( $\mathrm{LDH}$, heart isoform), creatine kinase (CK-MB, isoform predominantly in heart), myoglobin, heart type fatty acid-binding protein (H-FABP) and the troponins (late and organ specific protein). These markers will be described in detail in Chapter 2. In that chapter, the basic principles of cardiac injury, the current definition of AMI, the most important aspects for an ideal marker of AMI and the way in which these markers can be continuously measured, will also be described.

Today, the troponins and $\mathrm{CK}-\mathrm{MB}$ are the most accepted biochemical markers used in the coronary care unit. However, the use of troponin measurements is hampered by their slow release into the circulation following cardiac injury, taking a few hours before troponin concentrations in plasma become measurable. Newly developed bedside kits that provide a qualitative result within 15 to 20 minutes were presented recently as a major advance in decision making in emergency rooms, but their acceptance so far has been slow. Apparently, more quantitative indicators are preferred by the attending physicians. Because changes in plasma concentration are often more informative than the concentrations themselves, frequent monitoring is desirable. Moreover, in case the biochemical markers are frequently determined they allow estimation of the size of the infarction and thus may be of prognostic value. Monitoring of marker molecules in plasma is achieved by frequent blood sampling and off-line, time-consuming laboratory analysis. To enable quicker and better decision making, the development of on-line quantification methods became desirable. In this thesis the development of a new method is described. 
In collaboration with the university of Groningen, the Netherlands, the project entitled "Intravenous biosensor systems for the continuous biochemical monitoring of heart and brain damage" was started in 1999. In this thesis the part of this project concerning the development of an immunosensor for the on-line continuous monitoring of H-FABP release in patients will be outlined.

The first step in this development was the fact that we had chosen to use an earlier appearing marker in plasma instead of troponin. Both myoglobin and fatty acid-binding protein are such earlier markers and are released within 1 to 3 hours after onset of symptoms, but H-FABP (hereafter indicated as FABP) is superior to myoglobin in a number of aspects and was therefore chosen as the marker to be used in the new quantification method. Chapter 3 presents a detailed review on FABP as an early plasma marker of AMI with special attention to the comparison between FABP and myoglobin.

Although several laboratory methods are commercially available for the measurement of FABP, they are neither feasible for on-line measurements, or their assay time is longer than 50 minutes. In Chapter 4 a review of all reported methods and measuring devices for the quantification of FABP in buffer, plasma or whole blood is given. Also the definition of biosensors, immunosensors and several general aspects of continuous on-line monitoring of proteins (the principle of displacement) will be mentioned.

Chapter 5 presents the first developments of the new FABP immunosensor. As explained in Chapter 4, displacement is the only method applicable for the continuous measurement of large proteins. The aim of our first study was to further investigate the principles underlying the displacement assay of FABP, both in buffer and in plasma. The results of that study show the feasibility of a sensor based on the displacement principle to be used for the diagnosis of AMI in emergency medicine.

To further investigate the principle of displacement, we developed a continuous flow system, as described in Chapter 6. Although the sensor is not yet sensitive enough to measure small myocardial infarctions, a first attempt for semi-on-line measurements of FABP in plasma of AMI patients was successful. As far as we know this is the first reporting of this kind of immunosensor.

Chapter 7 describes two other devices for the rapid measurement of FABP. The group of dr. C. McNeil (University of Newcastle upon Tyne, Newcastle, United Kingdom) developed a biosensor based on impedance measurements for FABP quantification. The principle of this sensor is explained and preliminary results are given. The second device was developed by the Company 8 sens.diagnostic AG (Berlin, Germany), the so-called Cardio-Detect ${ }^{(\theta)}$ card, and this card was tested in our laboratory. These cards contain a qualitative measuring device for FABP. The mechanism underlying this method as well as the first results are given.

Chapter 8 comprises the general discussion of this thesis and provides suggestions for future investigations. Finally, Chapter 9 provides the summary of this thesis. 


\section{References}

1. Katz IA, Irwig L, Vinen JD, March L, Wyndham LE, et al. Biochemical markers of acute myocardial infarction: strategies for improving their clinical usefulness. Ann Clin Biochem 1998;35:393-9.

2. Newby LK, Storrow AB, Gibler WB, Garvey JL, Tucker JF, et al. Bedside multimarker testing for risk stratification in chest pain units: the chest pain evaluation by creatine kinase-MB, myoglobin, and troponin I (CHECKMATE) study. Circulation 2001;103:1832-7.

3. Hamm CW, Katus HA. New biochemical markers for myocardial cell injury. Curr Opin Cardiol 1995;10:355-60.

4. Karmen A, Wroblewski F, LaDue JS. Transaminase activity in human blood. J Clin Invest 1954;34:126-33. 
Chapter 1 


\section{Marker proteins in the detection and quantification of myocardial injury}

\subsection{Cardiac injury}

Cellular injury can be caused by chemical, microbial and physical agents, trauma, and deprivation of normal nutritional requirements (e.g., anoxia or ischemia).$^{(1,2)}$ The time course of a dying cell, including ischemic cell death, is often slow and contains a substantial reversible pre-lethal phase. Cellular injury may lead to either necrosis (normal cell death, including membrane rupture) and/or apoptosis (programmed cell death) (see also Chapter 8 ). They have different characteristics and can simultaneously be induced by myocardial cell injury. ${ }^{(3-5)}$ In most mammals, myocardial ischemia of less than 15 minutes is tolerated and the myocytes will recover. However, ischemia lasting more than 20 minutes will usually cause irreversible cell injury. ${ }^{(2,6)}$ Myocardial ischemia occurs when coronary arterial flow doesn't supply sufficient oxygen to meet the demands of the myocardium. Anoxia will develop when blood flow is completely impeded, whereas severe hypoxia will occur when there is some residual flow, either through the occluded segment of the coronary artery, or through collateral vessels. Generally, the injurious consequences of ischemia are related to the degree of reduction in blood flow or to the duration of reduced blood flow, or both. The consequences of myocardial ischemia include (i) cessation of contraction, (ii) the onset of anaerobic glycolysis and (iii) possible ECG changes as a result of localized hyperpolarization. ${ }^{(2,6)}$ Early micro-structural changes in the reversible phase of ischemia include edema, condensed and swollen mitochondria, disappearance of glycogen granules, and nuclear chromatin condensation. ${ }^{(7)}$ The ischemic metabolism within cardiomyocytes results in the accumulation of osmotically active substances. This accumulation creates an osmotic load, and, as a consequence, water enters the cardiomyocyte. ${ }^{(8)}$ If ischemia persists, many affected myocytes become irreversibly injured and die. Dying cells are characterized by disruption of the cell membrane and leakage of several cellular constituents, such as protons, lactate, phosphate, potassium, and many proteins, into the interstitial space and, finally, into the circulation. This is a sudden "all-or-none process" and the cellular proteins are, irrespective of their molecular weight or size, released simultaneously. From the cardiac interstitial space, most proteins reach the circulation by direct diffusion through the inter-endothelial clefts into the micro-vessels. This diffusion is strongly dependent on their molecular size. ${ }^{(1)}$ The remainder of the proteins will reach the circulation by lymphatic transport (Figure 2.1 ). The proteins will finally be eliminated from the circulation by e.g., hepatic endocytosis or renal clearance. Some proteins are used as "marker" proteins and their appearance in plasma indicates specific diseases or damage to specific organs. The time course of marker protein concentrations in plasma, i.e., the time-concentration curve, is not only dependent on the time course of the disease, but also on the molecular size and distribution of the protein over extravascular compartments, and on the rate of the protein elimination from plasma. ${ }^{(1,9)}$ After the 
introduction of the first sensitive assays in the 1950's, the appearance of these proteins in plasma has been used as a diagnostic tool for assessment of organ damage. ${ }^{(10)}$

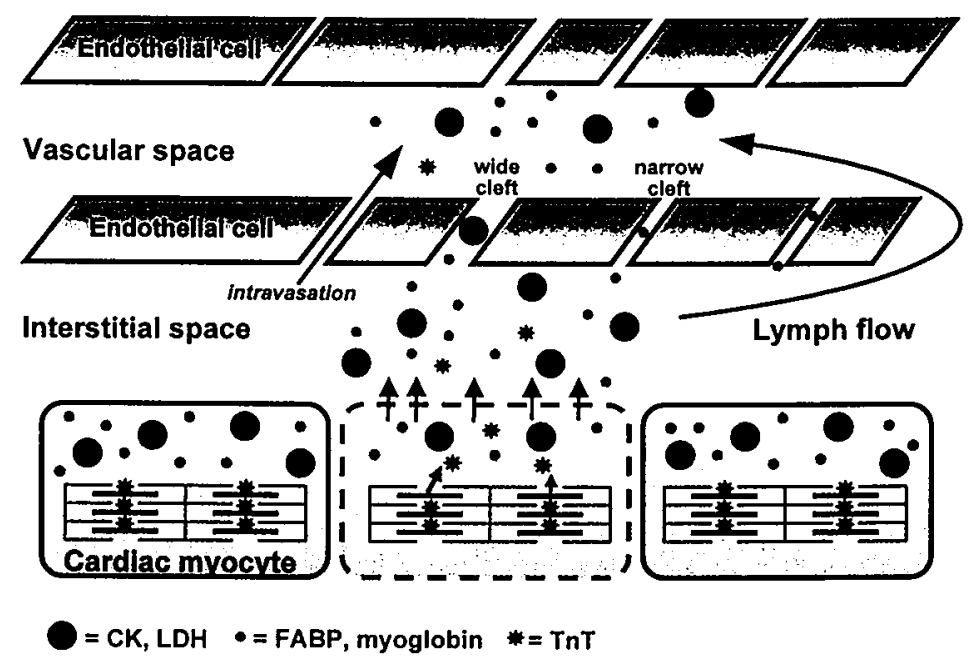

\section{Figure 2.1 Mechanism of protein release after AMI}

Schematic presentation of the possible transport routes of protein released from damaged cardiac myocytes to the plasma compartment. Proteins can either directly cross the endothelial cell barrier (predominant route for small proteins such as FABP and myoglobin) or they can be transported through lymph drainage (predominant route for larger proteins such as creatinekinase (CK) and lactate dehydrogenase (LDH). Structurally bound proteins (such as the troponins) first must be dissociated from the myofibrillar strucutures before they can be released into the interstitial space. (Adapted from reference 9, with permission)

\subsection{Myocardial Infarction}

\subsubsection{Current diagnosis}

Myocardial infarction (MI), which reflects a loss of cardiac myocytes caused by prolonged ischemia, can be defined from a number of different perspectives related to clinical, electrocardiographic (ECG), biochemical and pathological characteristics. ${ }^{(11)}$ In 1979, The World Health Organization (WHO) defined a general consensus for the clinical entity designated as MI. ${ }^{(12)} \mathrm{MI}$ was defined by a combination of two of three characteristics: typical symptoms (i.e., chest pain), enzyme rise and a typical ECG pattern involving the development of $Q$ waves. ${ }^{(12)}$ However, using this definition, microinfarctions could not always be detected and therefore, it was difficult to discriminate between acute myocardial infarction and unstable angina pectoris. It appeared that current clinical practice, health care delivery systems, clinical trials, and epidemiological studies called for a more precise definition of MI. ${ }^{(12)}$ Besides, development of imaging techniques (i.e., myocardial perfusion imaging, ECG, contrast ventriculography), enabled the identification of patients with myocardial necrosis weighing less than $1 \mathrm{~g}$. Therefore, 
re-evaluation of the definition was necessary. It is known that any amount of myocardial damage, due to spontaneous events or events associated with coronary procedures, and indicated by increased cardiac troponin levels, implies a worsened long-term outcome for the patient, ${ }^{(13-16)}$ although this outcome is less well predictable when the patient is suffering from renal insufficiency. ${ }^{(17.18)}$ In 2000 , MI was re-defined and since then, for diagnosing acute or evolving MI, either one of the following two criteria are required $(12,19)$.

1) A typical rise and gradual fall (troponins) or more rapid rise and fall (creatine kinase, creatine kinase subforms or myoglobin) of biochemical markers of myocardial necrosis with at least 1 of the following:

* development of pathologic Q waves in the ECG,

* ischemic symptoms, such as chest pain,

* ECG changes indicative of ischemia (ST segment elevation/depression),

* coronary artery occlusion as demonstrated by intervention.

(e.g. recent reperfusion therapy)

2) Histologic evidence of an acute MI, found at autopsy

This update on the definition of MI introduces several problems on two areas. Since the definition states that any degree of myocardial necrosis is indicative of MI, more patients will be diagnosed of having MI. Similarly, it will identify more infarcts and more episodes of reinfarction in patients with progressive coronary artery disease. Furthermore, biomarkers may be elevated in the absence of coronary artery disease and may indicate other forms of cellular injury, different from MI. Secondly, practical problems and questions appeared such as which markers should be tested and what should be the frequency of blood-collections. Depending on the marker, the frequency of blood sampling should differ. ${ }^{(20)}$

Despite the new definition of myocardial injury, it's still difficult to rapidly diagnose all patients admitted to the hospital with chest pain. In most patients with typical early ECG changes, the diagnosis of AMI is easy and rapidly made. However, at least $40 \%$ of AMI patients have non-diagnostic ECG changes on admission. ${ }^{(21-23)}$ Due to the new definition, this percentage is even increased, because nowadays also minor cardiac injury is defined as MI. In patients without diagnostic ECG changes, but with clinical symptoms (such as chest pain), the diagnosis must be based on biomarkers alone. The advantages of an early diagnosis for these patients first include a better selection of patients for interventions aimed at reducing morbidity and mortality, such as reperfusion by thrombolysis, or acute percutaneaous transluminal coronary

angioplasty. Secondly, other tests or procedures for establishing a definite or alternative diagnosis can be initiated earlier or avoided in appropriate circumstances. Finally, considerable economic gains might be achieved by identifying patients, who are at sufficiently low risk of AMI and its complications, early after admission, so they can be transferred from the coronary care unit (CCU). ${ }^{(23)}$

\subsubsection{Biochemical markers for the detection of AMI}

The history of biochemical markers for acute myocardial infarction goes back to the fifties. In 1954, Karmen et al. ${ }^{(24)}$ described that patients with AMI develop elevated 
plasma concentration of aspartate aminotransferase (AST, formerly glutamate oxalacetate transaminase) during the first hours after onset of symptoms. This established AST as the first marker for acute myocardial infarction. Due to the lack of its cardio-specificity and the rapid discovery of other markers, together with the development of enzymatic assays for these new markers, AST became of less importance as a diagnostic tool in acute myocardial infarction. Therefore, this marker will not be described in further detail here.

Other cytosolic cardiac markers, such as creatine kinase (CK) and its isoforms (CK-MM and CK-MB), lactate dehydrogenase (LDH), myoglobin and cardiac structural proteins like troponin are now more commonly used in the CCU. Fatty acid-binding protein (FABP), another cytosolic cardiac marker, is only used in an experimental set-up, and not yet in the CCU. A brief description of each of these markers is presented below. Table 2.1 presents the overview of relevant plasma markers for AMI.

Table 2.1 Comparison of some plasma markers of cardiac injury

\begin{tabular}{|l|c|c|c|c|c|c|}
\hline $\begin{array}{c}\text { Cardiac } \\
\text { marker }\end{array}$ & $\begin{array}{c}\text { Molec. } \\
\text { Mass } \\
(\mathrm{kD})\end{array}$ & $\begin{array}{c}\text { Plasma } \\
\text { reference } \\
\text { concentration }\end{array}$ & $\begin{array}{c}\text { Cutt off } \\
\text { value for } \\
\text { AMl }\end{array}$ & $\begin{array}{c}\text { Time from chest pain } \\
\text { onset to measurable } \\
\text { raise in plasma }\end{array}$ & $\begin{array}{c}\text { Time needed to reach } \\
\text { plasma peak } \\
\text { concentrations }\end{array}$ & $\begin{array}{c}\text { Time needed to return } \\
\text { to baseline (normal) } \\
\text { concentrations }\end{array}$ \\
\hline CKMB & 86 & $5 \mathrm{ng} / \mathrm{L}$ & $8 \mathrm{ng} / \mathrm{L}$ & $3-6 \mathrm{~h}$ & Within $24 \mathrm{~h}$ & $1.5-3$ days \\
\hline $\begin{array}{l}\mathrm{LDH} \\
(\mathrm{HBDH})\end{array}$ & 136 & $\begin{array}{c}120 \mathrm{U} / \mathrm{L} \mathrm{LDH} \\
80 \mathrm{U} / \mathrm{HBDH}\end{array}$ & $\begin{array}{c}200 \mathrm{U} / \mathrm{L} \mathrm{LDH} \\
120 \mathrm{U} / \mathrm{HBDH}\end{array}$ & $3-6 \mathrm{~h}$ & $1-3 \mathrm{~h}$ & $6-14$ days \\
\hline $\mathrm{CTn}-\mathrm{T}$ & 37 & $<0.01 \mu \mathrm{\mu g} / \mathrm{L}$ & $0.05 \mu \mathrm{g} / \mathrm{L}$ & $3-12 \mathrm{~h}$ & $12-24 \mathrm{~h}$ & $8-21$ days \\
\hline $\mathrm{CTn}-\mathrm{I}$ & 24 & $<0.01 \mu \mathrm{g} / \mathrm{L}$ & $0.05 \mu \mathrm{h} / \mathrm{L}$ & $3-12 \mathrm{~h}$ & $12-24 \mathrm{~h}$ & $7-14$ days \\
\hline Myo & 18 & $32 \mu \mathrm{L} / \mathrm{L}$ & $80 \mu \mathrm{g} / \mathrm{L}$ & $2-6 \mathrm{~h}$ & Within $12 \mathrm{~h}$ & Within $24 \mathrm{~h}$ \\
\hline FABP & 15 & $1.6 \mu \mathrm{g} / \mathrm{L}$ & $6 \mu \mathrm{g} / \mathrm{L}$ & $1-3 \mathrm{~h}$ & $5-10 \mathrm{~h}$ & Within $24 \mathrm{~h}$ \\
\hline
\end{tabular}

Abbreviations: $\mathrm{CK}=$ creatine kinase, $\mathrm{LDH}=$ lactate dehydrogenase, $\mathrm{HBDH}=$ hydroxybutyrate dehydro-genase, $c T n-T=$ cardiac troponin $\mathrm{T}, \mathrm{cTn}-\mathrm{I}=$ cardiac troponin $\mathrm{I}$, Myo = myoglobin,

$\mathrm{FABP}=$ fatty acid-binding protein, $h=$ hours.

\section{Creatine kinase}

CK $(84 \mathrm{kD})$ is a dimeric protein, consisting of muscle $(\mathrm{M})$ and brain (B) subunits and is located in the soluble cytoplasm and in mitochondria of the cells in most tissues. It catalyses the transfer of a high-energy phosphate residue from adenosine triphosphate (ATP) to creatine, producing creatine phosphate and adenosine diphosphate (ADP). Creatine phosphate functions as a temporary energy buffer and contributes to the energy transfer from the mitochondria to the soluble cytoplasm. It has been found that $\mathrm{CK}$ is modified by circulating carboxy-peptidase which cleaves the carboxy-terminal lysine from the M- and B-subunits. ${ }^{(25)}$ The ratio of uncleaved CK over cleaved CK was used as a measure for AMI. When this ratio was high, it indicated a recent AMI. Dreyfus et al. introduced the enzyme creatine kinase (CK) as a marker that became elevated in the blood after AMI. ${ }^{(26)}$ In the next few years, Rosalki et al. modified the first enzymatic assay, which was developed by Oliver et al., for determining CK in AMI patients. ${ }^{(27,28)}$ In an attempt to improve the specificity of total enzyme measurements, researchers started the measurement of iso-forms. There are three CK isoforms: CK-MM, CK-MB and CK-BB. The first assays for CK iso-forms were based on electrophoresis. ${ }^{(29)}$ Due to these time-consuming and difficult to automate assays, immuno-inhibition assays were soon developed. ${ }^{(30)}$ Nowadays, CK-MM, CK-MB and CK-BB concentrations $(\mu \mathrm{g} / \mathrm{L})$ can 
be measured by immunoassays ${ }^{(10)}$, in contrast to the early assays in which the biological activity of the enzyme was measured. The former assays were unable to distinguish the CK-isoforms, and measurements of enzyme activities in plasma were not as stable as the current CK-MB mass determinations.

The high myocardial CK content and the cardiac specificity of CK-MB (15-30\% of $\mathrm{CK}$ in myocardium, compared to $1-3 \% \mathrm{CK}-\mathrm{MB}$ in normal striated muscle ${ }^{(3))}$, made $\mathrm{CK}-\mathrm{MB}$ the most widely used enzyme in confirming or excluding acute myocardial infarction in the eighties and nineties. CK-MB exhibits a monophasic release after AMI and is also detectable in some, but not all cases of irreversible minor myocardial damage. It takes 3 to 6 hours from the onset of myocardial injury before blood levels of CK and $\mathrm{CK}-\mathrm{MB}$ begin to rise, and peak values appear within 24 hours from AMI onset. Within 1.5 to 3 days plasma CK returns to baseline levels. Due to the development of CK-MB mass assays, which are more robust than activity assays, ${ }^{(10)}$ this marker became more appropriate as a diagnostic tool. Within 3 hours after onset of coronary occlusion, $56 \%$ of the patients have abnormal CK-MB mass levels, this percentage is even raised with another $40 \%$ in the following 3 hours. ${ }^{(32)}$ Furthermore, normal CK-MB mass concentrations over a period of 6 to 8 hours have a negative predicting value of about $95 \%$. $^{(33)}$

Unfortunately, CK-MB is not absolutely restricted to myocardial tissue and this leads often to false positive results in patients with muscular- and renal-diseases. ${ }^{(2)}$ Furthermore, using CK and CK-MB as cardiac markers, it is impossible to detect minor myocardial damage. ${ }^{(34)}$

However, in most hospitals, CK-MB is still considered the "gold standard" as a biochemical marker for AMI.

\section{Lactate dehydrogenase}

The enzyme lactate dehydrogenase ( $\mathrm{LDH}, 135 \mathrm{kD}$ ) was first described as a marker for AMI in 1955 by Wroblewski et al. ${ }^{(35)}$ LDH activity is measured enzymatically and the International Federation of Clinical Chemistry (IFCC) recommended a methodology in $1994{ }^{(36)} \mathrm{LDH}$ is an important enzyme of glucose metabolism and catalyses the reversible transfer of 2 electrons and one hydrogen ion from lactate to $\mathrm{NAD}^{+}$, resulting in pyruvate and $\mathrm{NADH}^{(2)}$ The enzyme is a tetramer, which is composed of muscle $(\mathrm{M})$ and heart $(\mathrm{H})$ subunits. These subunits are encoded by different genes and give rise to 5 different isoenzymes, each with a different organ distribution. The iso-enzymes are designated $\mathrm{LD}_{1}$ (H4), $\mathrm{LD}_{2}(\mathrm{H} 3 \mathrm{M}), \mathrm{LD}_{3}(\mathrm{H} 2 \mathrm{M} 2), \mathrm{LD}_{4}$ (HM3) and $\mathrm{LD}_{5}(\mathrm{M} 4){ }^{(37)}$ Following acute myocardial infarction, LDH activity in plasma starts to rise 3 to $6 \mathrm{~h}$ after onset of symptoms, peaks at 1 to 3 days, and returns to normal by 6 to 14 days. ${ }^{(37)}$ The latter is due to clearance by the liver. ${ }^{(38)}$ The iso-enzyme $\mathrm{LD}_{1}$, for which immunoassays ${ }^{(39,40)}$ as well as chemical assays ${ }^{(41.42)}$ have been developed, also increases within 10 to 12 hours and returns to normal in approximately 10 days after AMI. After AMI, $L_{1}$ activity exceeds $L D_{2}$ activity. This altered $L D_{1} / L D_{2}$ ratio is specific for myocardial damage. However, LDH is not heart specific, and LDH activities may also be elevated in case of germ cell tumours, ${ }^{(43)}$ hemolysis, diseases from the pancreas, kidney and stomach or after release from brain or erythrocytes. ${ }^{(2)}$ 


\section{Troponins}

Cardiac troponins are regulatory proteins tightly fixed as a complex to the contractile apparatus of muscle cells (Figure 2.2) ${ }^{(44)}$ Troponin consists of three polypeptide chains; $^{(45)}$ (i) Troponin $\mathrm{T}$ (TnT), a $37 \mathrm{kD}$ binding protein which binds the troponin $\mathrm{C}-\mathrm{I}$ complex to tropomyosin, ${ }^{(46)}$ (ii) TnI, a basic globular $24 \mathrm{kD}$ protein, which modulates the interaction of actin and myosin by acting as an inhibitor of actomyosin ATPase activity, and (iii) $\mathrm{TnC}$, the $18 \mathrm{kD}$ calcium-binding subunit of the troponin complex. TnC is responsible for regulating the process of thin filament activation during skeletal and heart muscle contraction. ${ }^{(47)}$ Different isoforms encoded by separate genes are found in cardiac and skeletal muscle for both $\mathrm{TnT}$ and $\mathrm{TnI}$; the cardiac forms are designated cTnT and cTnI, respectively. These cardiac troponins are unique and completely specific for the myocardium. Because TnC has an identical amino acid sequence in both skeletal and cardiac tissues, it is not used as a cardiac specific marker. In this thesis, $\mathrm{TnC}$ will not further be discussed.

The first assays for cTnT and cTnI were developed in the late 1980 's. ${ }^{(48,49)}$ Enzyme-linked immunosorbent assays are used for troponin testing, ${ }^{(50)}$ however, due to patent restrictions, assays for cTnT are available only from one manufacturer, whereas assays for cTnI are available from multiple companies. There is still an ongoing debate on which troponin (T or I) is most specific for myocardial injury. ${ }^{(51,52)}$

Marked changes in blood levels from small amounts of cellular injury are easily measured and identified as abnormal due to the very low levels of TnT and TnI circulating in the blood of healthy people. ${ }^{(31)}$ This is due to the fact that plasma concentrations of both TnT and TnI are below the detection limit of the assays in healthy individuals. Although the proteins are small, they first have to be released from the myosin complex. Therefore, both cTnT and cTnI require 3 to 12 hours to rise above detectable limits after onset of acute ischemia. Moreover, the total $\operatorname{TnT}$ release from the myocytes is much lower and less complete, than that of other marker proteins. For these reasons, troponin is not the earliest marker of necrosis available. Troponin peaks at 12 to 24 hours; cTnT remains elevated for 8 to 21 days and cTnI remains elevated for 7 to 14 days. $^{(31)}$

Troponins are widely used as "late" specific biochemical marker for acute myocardial infarction. However, several studies also revealed the usefulness of troponins, especially cTnI, as predictor for reinfarction, ${ }^{(53-55)}$ detector of reperfusion, ${ }^{(56,57)}$ detector of peri-operative myocardial infarction, ${ }^{(58)}$ detector of myocyte injury due to myocarditis, ${ }^{(59.60)}$ and to differentiate patients with and without cardiac injury after blunt chest trauma. ${ }^{(61)}$ 


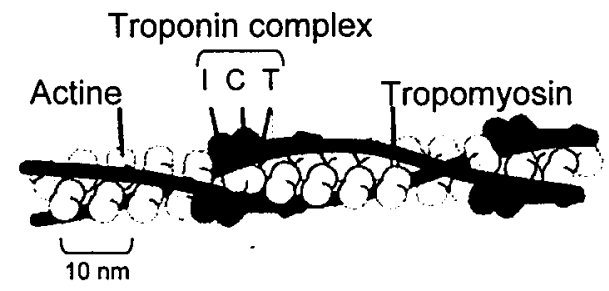

\section{Figure 2.2 Schematic presentation of the Troponin complex}

Troponins are myofibrillar proteins located at the contractile apparatus of striated muscle. This apparatus is composed of thick filaments, who contain the contractile myosin, and thin filaments, consisting of actin, tropomyosin and the troponin complex (consisting of troponin $1, \mathrm{C}$ and T). Troponin $\mathrm{T}$ binds the troponin complex to the tropomyosin strand, troponin $\mathrm{C}$ binds calcium and initiates contraction and troponin I inhibits contraction in the resting state.

\section{Myoglobin}

Myoglobin is an $18 \mathrm{kD}$ oxygen-binding heme protein located in the cytoplasm of both cardiac and skeletal muscle cells. Myoglobin binds oxygen reversibly and facilitates oxygen diffusion in striated muscle fibres. It also serves as an oxygen reservoir. ${ }^{(65)}$ Myoglobin is located close to the sarcolemma, to the contractile apparatus and to the intracellular membranous or fibrillar structures. ${ }^{(66)}$ After cardiac necrosis, myoglobin is released into the plasma, where it can be measured within 2 to 6 hours after onset of symptoms. The highest level is mostly reached within 12 hours. It is rapidly cleared from the plasma by the kidneys and returns to the normal reference interval within 24 hours after the onset of AMI. The rapid disappearance of myoglobin in uncomplicated AMI makes this analysis very suitable to detect a reinfarction in patients with recurring chest pain. ${ }^{(67)}$

Although myoglobin was demonstrated to be elevated in blood and urine in the course of AMI already in $1956,{ }^{(62)}$ enzyme determinations for LDH and CK received more attention at that time. In 1975 the first radioimmunoassay (RIA) for myoglobin was developed. ${ }^{(63)}$ This assay led to the first non-enzymatic protein marker investigated for AMI. However, the RIA methodology was not convenient and there was no clinical interest for this protein until automated non-isotopic immunoassays were developed and became available in the early 1990 's. ${ }^{(64)}$ At that time it was proven that myoglobin appeared in the circulation relatively soon after onset of AMI symptoms, and made early diagnosis of AMI possible. Therefore, measurements of myoglobin became more important.

Myoglobin is not heart-specific and false positive myoglobin levels can be the result of trauma, skeletal muscle injury, chronic disease states or renal failure. ${ }^{(31)}$ However, myoglobin is the earliest appearing biochemical marker that is routinely available for assessment of the acute coronary syndrome patient. 


\section{Fatty acid-binding protein (FABP)}

FABP, a $14.5 \mathrm{kD}$ protein, functions as intracellular fatty acid carrier. In 1988 it was suggested as plasma marker of AMI. ${ }^{(68)}$ The protein is not cardio-specific but in skeletal muscles it is expressed in relatively low amounts. The release and plasma kinetics of FABP closely resemble those of myoglobin, i.e., a rise is detectable as early as 2 to 4 hours after AMI onset, peak values are reached at 6 to 8 hours, and the plasma level returns to normal within 24 to 36 hours. In chapter 3, a complete review about FABP as plasma marker of cardiac injury, is given.

\subsection{The ideal marker for cardiac injury}

An optimal marker for cardiac injury cannot be defined. According to the circumstances, the required properties may vary. The marker's performance in early versus late diagnosis or in monitoring of reinfarction, including prognosis, infarct size, detection of reperfusion etc., will generally depend on different properties. ${ }^{(69-72)}$

The most perfect marker for the diagnosis of heart damage or estimation of the severity of heart damage and possible guidance of therapy should fulfil several requirements. ${ }^{(73)}$

The marker should be:

- heart-specific,

- highly concentrated in the myocardium,

- released in direct proportion to the extent of myocardial injury,

- homogeneously distributed within the myocardium,

- rapidly and completely released after myocardial injury,

- have low normal plasma values in healthy subjects,

- stable and easily measured, quantitative, cost-effective and, most desirable, on-line.

The requirement of high cardiac specificity is self-evident. Many metabolic and circulatory processes can be altered during acute myocardial infarction, and protein release from other than cardiac sources should preferably not interfere with the primary diagnosis. But, specificity alone is not enough to make an early unambiguous diagnosis. The loss of enzymes or proteins from damaged cells at the early onset may still be limited. In order to detect such minimal damage, the concentration of the marker protein in the cardiomyocytes should be high, and the normal plasma concentration should be low. In that way, low values can be used for diagnosis. Therefore, the marker protein assay should be sufficiently sensitive for accurate detection of these small elevations and the assay time should be sufficiently short to allow early diagnosis.

It is generally believed that the optimal marker for infarct timing and diagnosis would be the combination of the earliest cytosolic marker available (FABP or myoglobin) with a cardiac troponin (slowly released but cardio-specific). Indeed, the troponins are recognized as the most specific and sensitive late marker for AMI. However, FABP is not yet generally accepted as an early marker, which is probably due to the relative small amount of patients with chest pain in which FABP has been tested. ${ }^{(74,75)}$ In addition, the 
assay time of the commercially available tests for FABP quantification is relatively high. In order to take full advantage of the characteristics of this early maker, a biosensor, aiming at fast continuous on-line monitoring of FABP levels in patients was developed.

\subsection{Biosensors}

A biosensor can be generally defined as a device that consists of a biological recognition system, often called a bioreceptor, and a transducer. The interaction of the analyte with the bioreceptor is designed to produce an effect measured by the transducer, which converts the information into a measurable effect, such as an electrical signal.

Biosensors can be classified by their type of bioreceptor or by their type of transducer (Figure 2.3). ${ }^{(76)}$ The bioreceptors are responsible for binding the analyte of interest to the sensor for subsequent measurement. Therefore, they are the key to specificity. Biosensors that detect the binding of an antigen to its specific antibody are called immunosensors. Since clinical diagnostics represent a huge, well-established and important analytical field, there is a great opportunity for introducing immunosensor devices. Moreover, the main reason to select immunochemical methods for clinical analysis is the high sensitivity and specificity of immuno-reactions. Furthermore, also the possibility to measure biological compounds in a fast continuous manner would make biosensors very useful in clinical practice. Therefore, biosensors could be developed in high throughput systems. Untill now, only enzyme-biosensors designed to measure glucose and lactate, have been developed for these systems.

In Chapter 4, a general description of biosensors as well as the recent developments of biosensors for FABP are given.

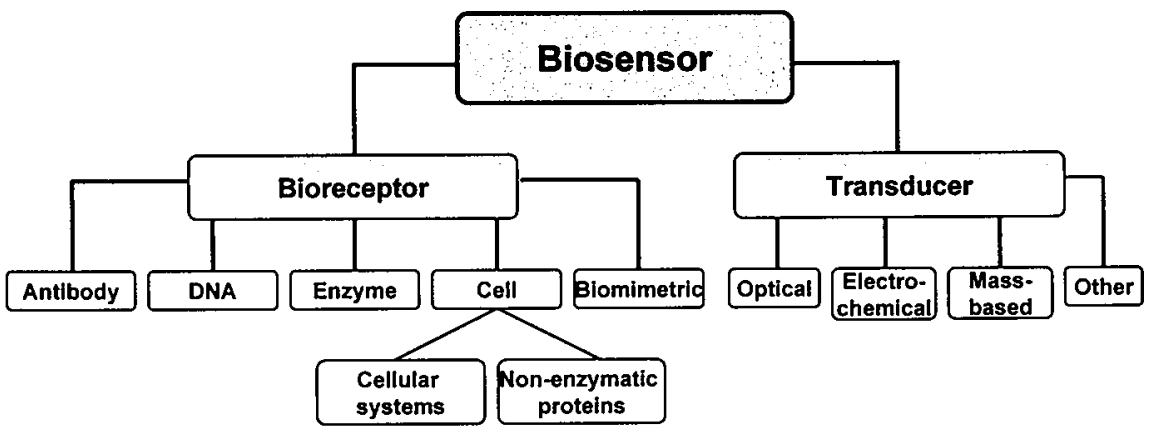

Figure 2.3 Schematic presentation of biosensor classification.

Biosensors can be classified by their type of bioreceptor or by their type of transducer. A bioreceptor is a biological molecular species (i.e., an antibody, an enzyme, a protein or a nucleic acid) or a living organism (e.g., cells, tissue, or whole organisms). The bioreceptors are responsible for binding the analyte of interest to the sensor for subsequent measurement. The transducer is the detector, monitoring the chemical or biochemical reaction initiated by the sample. (Figure adapted from reference 76 ) 


\subsection{On-line monitoring of circulating analytes}

For the development of a biosensor, which can be used for continuous (bio) chemical monitoring, direct contact with the matrix (i.e., the medium containing the analyte) is necessary, and two methodologically different invasive approaches can be applied. The first approach, direct in vivo measurement at a sampling site inside the body (as utilized in many (bio) sensors) has several technical limitations. Among these problems are in vivo calibration, stability and biocompatibility. In addition, the probes are often rather large, thus creating artefacts in the surrounding tissue. ${ }^{(77,78)}$ The second approach consists of continuous (on-line) sampling, preferably directly coupled to an ex-vivo analysis system. ${ }^{(79,80)}$ For continuous sampling in tissues two methods are widely used, namely microdialysis and ultrafiltration. A third method involves direct sampling from plasma.

\subsubsection{Microdialysis}

This first, universally working, continuous sampling technique was described by Delgado and Rubinstein in $1964 .^{(81)}$ They defined microdialysis as a dynamic sampling method based on analyte diffusion across a semi-permeable membrane due to a concentration gradient. ${ }^{(82)}$ Microdialysis can be used to monitor the chemistry of the extracellular space in living tissue. ${ }^{(83)}$ The microdialysis set-up consists of a microdialysis catheter, which contains a probe, and a high performance pump for the perfusion of the probe with a neutral solution. The microdialysis catheter is placed in the interstitial space of the tissue to be examined. ${ }^{(84,85)}$ When a physiological salt solution is slowly pumped through the microdialysis probe the solution equilibrates with the surrounding extracellular tissue fluid. After a while, this solution will contain a representative proportion of the tissue fluid's molecules. In this way, microdialysis can be used for monitoring changes in the concentration of a particular analyte, relative to some initial or basal level. ${ }^{(86)}$ However, for the determination of the actual concentration of that analyte in the tissue itself, microdialysis methods require additional manipulations and extrapolations in contrast with ultrafiltration. ${ }^{(87,88)}$

\subsubsection{Ultrafiltration}

Ultrafiltration (UF), first described by Janle-Swain in 1987, is a filtrate selection method with a wide range of biomedical and clinical applications. ${ }^{(89)}$ The UF probe consists of one or more hollow dialysis fibre loops connected to a microbore impermeable membrane. The loops are placed in the tissue of interest and a negative pressure gradient is used to create a flux across the porous membrane. The molecular cut-off value of this semipermeable filtration membrane determines the maximum size of particles that can pass through the membrane. ${ }^{(90)}$ The configuration and charge of a molecule also affect the membrane passing. Frequent subcutaneous sampling of ultrafiltrate depends on the rapid replacement of interstitial fluid by the blood vessels. In tissue with limited blood flow rate and low replenishment of interstitial fluid, only low sampling rates are possible. The forced transport across the membrane results in analyte recoveries of greater than $90 \%$ for small molecules. 


\subsubsection{Comparison of microdialysis and ultrafiltration}

$\mathrm{MD}$ and UF have several characteristics in common, but there are important differences (Table 2.2). Both the MD technique and the UF technique separate chemicals by moving them across a semipermeable membrane (Figure 2.4). In $\mathrm{MD}$, the separation is exclusively due to a concentration gradient and diffusion of the analytes, whereas in UF, analytes pass through the membrane by convection together with the body fluids in which they are dissolved. ${ }^{(91)}$ Both techniques measure the free concentration of the analyte.

For both MD and UF, off-line and on-line analysis techniques are available, and the fluid collection rate is similar, between 0.05 and $10 \mu \mathrm{l} / \mathrm{min}$. Whereas in the UF sample the analyte concentration directly reflects the tissue concentration, and the recovery is thus $100 \%$ (under $3000 \mathrm{kD}$, over this size the capillary walls will detain some of the solutes), the tissue concentration of the analyte from a MD sample needs to be calculated taking into account the diffusive characteristics of the membranes, the composition of the perfusion fluid, the flow rate of fluid through the membranes and the recovery of the analytes. ${ }^{(92-94)}$ Most of the calculation-methods are time-consuming, can be applied only at steady state situations, and there is risk of creating artefacts while performing the calculations.

The flow rate used in MD can be higher than the flow rate used in UF, but the higher the flow rate, the lower the recovered concentration of the analyte. Although there is a continuous transfer of fluid and small molecules between the blood and the extracellular space, ${ }^{(94)}$ analytes can be depleted from the tissue around the probe when the analytes diffuse into the dialysis fluid. ${ }^{(95,96)}$ UF has no such adverse effects on the sampling tissue. ${ }^{(94)}$

Table 2.2 Comparison of microdialysis and ultrafiltration characteristics

\begin{tabular}{|l|l|l|}
\hline \multicolumn{1}{|c|}{ Comparison } & \multicolumn{1}{|c|}{ Microdialysis } & \multicolumn{1}{c|}{ Ultrafiltration } \\
\hline Driving force & Pump & Negative pressure \\
\hline Method of analyte retrieval & Diffusion & Filtration \\
\hline Sampling in tissue & Sampling in tissues incl. brain & Sampling in tissues excl. brain \\
\hline Sample collection rate & $0.1-10 \mu$ l/min & $0.05-10 \mu /$ min \\
\hline Highest sampling frequency & Every minute & continuous \\
\hline Flow rate control & precise & Method dependent \\
\hline Calculation after retrieval & Calculation of recovery & $\begin{array}{l}\text { No calculation necessary for } \\
\text { small analytes }\end{array}$ \\
\hline Recovery & $5->95 \%$ & $>95 \%$ for small molecules \\
\hline Blood or fluid loss & None & None \\
\hline Drainage & Yes & No \\
\hline Limits in molecular weight & Limils in molecular weight & Limits in molecular weight \\
\hline Drug delivery & Yes & No \\
\hline Species & Various species and man & Various species and man \\
\hline Measurement of chemicals & Free concentration of analyte & Free concentration of analyte \\
\hline $\begin{array}{l}\text { Measurement } \\
\text { in vitro } / \text { in vivo }\end{array}$ & Both & Both \\
\hline
\end{tabular}

Adapted from reference 100 with permission 
A major advantage of $\mathrm{MD}$ is the possibility of local drug delivery via the inflowing perfusate, which is conveniently used in many neurotransmitter-studies. A near- $100 \%$ relative recovery can be created with $\mathrm{MD}$ when perfusing at very low flow rates, ${ }^{(97,98)}$ however, often large losses of perfusion fluid through the probe are seen when using ultra-slow MD.

In summary, UF gives recoveries of $100 \%$ for low molecular weight molecules because the recovery is essentially independent of the flow rate and there is no dilution factor. ${ }^{(91,99)}$ UF thus avoids the complicated and time-consuming recovery calculations of MD. However, UF does not allow the local application of drugs. But, in contrast to MD, UF is more practical at very low flow rates.

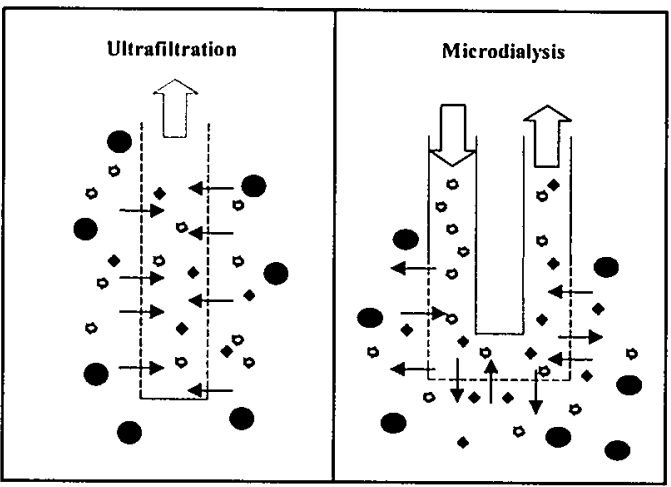

(Figure adapted from reference 100 with permission)
Figure 2.4 The principle of ultrafiltra-tion and microdialysis

Ultrafiltration uses negative pressure to collect a filtrate of body fluid; microdialysis is based on the use of a carrier solution, a concentration gradient and diffusion of analytes across the semi-permeable membrane. The cut-off value of the membrane determines the size of molecules that pass the membrane. In contrast to microdialysis, in which the recovery has to be calculated due to dilution of the analyte, the UF recovery is $100 \%$ as the ultrafiltrate directly reflects the tissue concentration.

\subsubsection{Continuous sampling in plasma}

In case of sampling for subsequent FABP immunoassay, concentration differences between interstitium and sample will occur for both MD and UF techniques. Moreover, there are delays in the subcutaneous and intra-muscular appearance of FABP. To detect small concentration differences of FABP it is preferred to measure this protein directly at the site of interest (the site of infarction). However, as mentioned above, there are several problems induced by direct in vivo measurement at a sampling site (i.e., tissue) inside the body. Therefore, another possible continuous sampling method could be the direct measurement of an analyte (FABP) in plasma. When an ultra slow flow is used, an intravenously placed needle, containing a membrane which prevents erythrocytes to enter the needle, can extract plasma from the circulation. This needle is attached to a tube through which the plasma is sucked, by use of a pump, towards a biosensor were the protein of interest can be quantified. The closer the needle to the site of interest, the earlier differences in protein concentration can be measured. A needle containing an UF device will preferably be used for continuous sampling in combination with the biosensor described in this thesis. 


\subsubsection{Displacement}

Apart from a continuous sampling technique, the analysis system of an on-line sensor has to employ a continuous detection method. For several metabolites specific enzymes are used to produce electrochemically active agents. As the enzymes continuously produce these agents, they can also be continuously monitored. For immunodetection, the antigen or antibody is labeled. So far, on-line continuous biosensors only have been described for the detection of metabolite molecules that can be specifically converted by enzymes. However, the most feasible immunochemical detection system allowing an on-line measurement of proteins is called displacement. The principle of displacement and the recent developments in application for continuous FABP measurements will be described in chapter 4.

\subsection{References}

1. Kragten JA. New myocardial proteins in acute myocardial infarction. Quantitative aspects. Assen, The Netherlands: Dekker\&van de Vegt en Van Gorcum;1998 (Thesis)

2. Mair J. Progress in myocardial damage detection: new biochemical markers for clinicians. Crit Rev Clin Lab Sci 1997;34:1-66.

3. Yeh ET. Life and death in the cardiovascular system. Circulation 1997;95:782-6.

4. Anversa P, Kajstura J. Myocyte cell death in the diseased heart. Circ Res 1998;82:1231-3.

5. Blom WM. Cell death in rat hepatocytes. Apoptosis-inducing and -protective mechanisms. Leiden, The Netherlands: Leiden University;2000 (Thesis)

6. Bär PR. Apoptosis, The cell's silent exit. Life Sciences 1996;59:369-78.

7. Baxter GF. Cellular mechanisms of ischemic myocardial damage. In: Kaski JD, Holt DW. Myocardial damage early detection by novel biochemical markers. Dordrecht, The Netherlands: Kluwer academic publishers;1998: chapter 1.

8. Alberts B, Bray D, Lewis J, Raff M, Roberts K, et al. Molecular biology of the cell. $3^{\text {rd }}$ edition. New York and London: Garland publishing; 1994.

9. van Nieuwenhoven FA. Heart fatty acid-binding proteins. Role in cardiac fatty acid up-take and marker for cellular damage. Maastricht, The Netherlands: Maastricht University;1996 (Thesis).

10. Wu AHB. Biochemical markers of cardiac damage: from traditional enzymes to cardiacspecific proteins. Scand J Clin Lab Invest 1999;59:74-82.

11. Alpert JS, Thygesen K, Rydén L, Garson A. Myocardial infarction redefined-a consensus document of The Joint European Society of Cardiology/American College of Cardiology committee for the redefinition of myocardial infarction. The Joint European Society of Cardiology/ American College of Cardiology Committee. J Am Coll Cardiol 2000;36:95969.

12. Report of the joint international society and federation of cardiology/ World health organisation (WHO) task force on standardization of clinical nomenclature. Nomenclature and criteria for diagnosis of ischemic heart disease. Circulation 1979;59:607-9.

13. van Domburg RT, Cobbaert C, Kimman GJ, Zerback R, Simoons ML. Long-term prognostic value of serial troponin $\mathrm{T}$ bedside tests in patients with acute coronary syndromes. Am J Cardiol 2000;86:623-7.

14. Kanna M, Nonogi H, Sumida H, Miyazaki S, Daikoku S, et al. Usefulness of serum troponin $\mathrm{T}$ levels on day three or four in predicting survival after acute myocardial infarction. Am J Cardiol 2001;87:294-7. 
15. Rao SV, Ohman EM, Granger CB, Armstrong PW, Gibler WB, et al. Prognostic value of isolated troponin elevation across the spectrum of chest pain syndromes. Am J Cardiol 2003;8:936-40.

16. Hamm CW, Ravkilde J, Gerhardt W, Ljungdahl L, Pettersson T, et al. The prognostic value of serum troponin T in unstable angina. N Engl J Med 1992;327:146-50.

17. van Lente F, McErlean ES, DeLuca SA, Peacock WF, Rao JS, et al. Ability of troponins to predict adverse outcomes in patients with renal insufficiency and suspected acute coronary syndromes: a case-matched study. J Am Coll Cardiol 1999;33:471-8.

18. Khan IA, Wattanasuwan N, Mehta NJ, Tun A, Singh N, et al. Prognostic value of serum cardiac troponin I in ambulatory patients with chronic renal failure undergoing long-term hemodialysis: a two-year outcome analysis. J Am Coll Cardiol 2001;38:991-8.

19. Apple FS, Henry TD, Berger CR, Landt YA. Early monitoring of serum cardiac troponin I for assessment of coronary reperfusion following thrombolytic therapy. Am J Clin Pathol 1996;105:6-10.

20. Wu AHB. Cardiac markers: cost-effective triage for MI admission and therapy. Med Lab Obs 2002;34:36-40.

21. Rude RE, Poole KW, Muller JE, Turi Z, Rutherford J, et al. Electrocardiographic and clinical criteria for recognition of acute myocardial infarction based on analysis of 3,697 patients. Am J Cardiol 1983;52;936-42.

22. Gibler WB, Young GP, Hedges JR, Lewis LM, Smith MS, et al. Acute myocardial infarction in chest pain patients with non-diagnostic ECG's: serial CK-MB sampling in the emergency department. Ann Emerg Med 1992;21:504-12.

23. Lindahl B, Venge $P$, Wallentin L. Early diagnosis and exclusion of acute myocardial infarction using biochemical monitoring. Coron Artery Disease 1995;6:321-8.

24. Karmen A, Wroblewski F, LaDue JS. Transaminase activity in human blood. J Clin Invest 1954;34:126-33.

25. Wevers RA, Delsing M, Klein-Gebbink JA, Soons JBJ. Postsynthetic changes in creatine kinase iso-enzymes. Clin Chim Acta 1978;86:323-7.

26. Dreyfus JC, Schapira G, Resnais J, Scebat L. La creatine-kinase serique dans le diagnositique de l'infarctus myocardique. Rev Fr Clin Biol 1960;5:386-7.

27. Rosalki SB. An improved procedure for serum creatine phosphokinase determination. J Lab Clin Med 1967;69:696-705.

28. Oliver IT. A spectrophotometric method for the determination of creatine phosphokinase and myokinase. Biochem J 1955;61:116-22.

29. Roe CR, Limbird LE, Wagner GS, Nerenberg ST. Combined isoenzyme analysis in the diagnosis of myocardial injury: application of electrophoretic methods for the detection and quantification of creatine kinase phosphokinase $\mathrm{MB}$ isoenzyme. $\mathrm{J}$ Lab Clin Med 1972;80:577-90.

30. Jockers-Wretoe E, Pfleiderer G. Quantification of creatine kinase isoenzymes in human tissues and sera by an immunological method. Clin Chim Acta 1975;58:223-32.

31. Malasky BR, Alpert JS. Diagnosis of myocardial injury by biochemical markers: problems and promises. Cardiol rev 2002;10:306-17.

32. Puelo PR, Meyer D, Wathen C, Tawa CB, Wheeler S, et al. Use of a rapid assay of subforms of creatine kinase MB to diagnose or rule out acute myocardial infarction. New Eng J Med 1994;331:561-6.

33. Gibler WB, Runyon JP, Levy RC, Sayre MR, Kacich R, et al. A rapid diagnostic and treatment center for patients with chest pain in the emergency department. Ann Emerg Med 1995;25:1-8. 
34. Gerhardt $\mathrm{W}$, Ljungdahl $\mathrm{L}$, Herbert $\mathrm{AK}$, Troponin $\mathrm{T}$ and $\mathrm{CK}-\mathrm{MB}$ (mass) in early diagnosis of ischemic myocardial injury. The Helsingborg Study (1992). Clin Biochem 1993;26:23140.

35. Wroblewski F, LaDeu JS. Lactic dehydrogenase activity in blood. Proc Soc Exper Biol Med 1955;90:210-3.

36. Bais R, Philcox M. Approved recommendation on IFCC methods for the measurement of catalytic concentration of enzymes. Part 8. IFCC method for lactate dehydrogenase (LLactate: NAD+ Oxidoreductase, EC 1.1.1.27). International Federation of Clinical Chemistry (IFCC). Eur J Clin Chem Clin Biochem 1994;32:639-55.

37. Wolf PL. LD isoenzymes in myocardial disease. Clinic Lab Med 1989;9:655-65.

38. Smit MJ, Duursma AM, Bouma JMW, Gruber M. Receptor-mediated endocytosis of lactate dehydrogenase $M$ by liver macrophages: a mechanism for elimination of enzymes from plasma. J Biol Chem 1987;262:13020-6.

39. Liu F, Belding R, Usategui-Gomex M, Reynoso G. Immunochemical determination of LDH-1. Am J Clin Pathol 1981;75:701-7.

40. Ali M, Braun EV, Laraia S, Fayemi AO, Nelebuff DJ, et al. Immunochemical LD1 assay for myocardial infarction. Am J Clin Pathol 1981;76:426-9.

41. Panteghini M, Bonara R, Pagani F. Evaluation of a new commercial kit for quantification of LD1 in serum. J Clin Chem Clin Biochem 1990;28:545-8.

42. Onigbinde TA, Wu AHB, Johnson M, Wu Y, Collinsworth WL, et al. Enzyme kinetics of LD isoenzymes and the mechanism of chemical inhibition for the BMC LD-1 assay. Clin Chem 1990;36:1819-22.

43. Von Eyben FE, Blaaberg O, Petersen PH, Horder M, Nielsen HV, et al. Serum lactate dehydrogenase isoenzyme 1 as a marker of testicular germ cell tumor. $J$ Urol 1988;140:986-90.

44. Kitsis RN, Scheuer J. Functional significance of alterations in cardiac contractile protein isoforms. Clin Cardiol 1996;19:9-18.

45. Farah CS, Reinach FC. The troponin complex and regulation of muscle contraction. Faseb J 1995;9:755-67.

46. Raggi A, Grand RJA, Moir AJC, Perry SV. Structure function relationships in carciac troponin T. Biochim Biophys Acta 1989;997:135-43.

47. Pharmacek MS, Leiden JM. Structure, function and regulation of troponin C. Circulation 1991;84:991-1003.

48. Katus HA, Remppis A, Looser S, Hallermeier K, Scheffold T, et al. Enzyme linked immunoassay of cardiac troponin $T$ for the detection of acute myocardial infarction in patients. J Mol Cell Cardiol 1989;21:1349-53.

49. Bodor GS, Porter S, Landt Y, Ladenson JH. Development of monoclonal antibodies for the assay of cardiac troponin I and preliminary results in suspected cases of myocardial infarction. Clin Chem 1992;38:2203-14.

50. Coudrey L. The troponins. Arch Intern Med 1998;158:1173-80.

51. Wu AHB, Feng YJ. Biochemical differences between cTnT and cTnI and their significance for diagnosis of acute coronary syndromes. Eur Heart J 1998;19:N25-N29.

52. Adams JE, Bodor GS, Davila-Roman VG, Delmez JA, Apple FS, et al. Cardiac troponin I: a marker with specificity for cardiac injury. Circulation 1993;88:101-6.

53. Ohman EM, Armstrong PW, Christenson RH, Granger CB, Katus HS, et al. Cardiac troponin $\mathrm{T}$ levels for risk stratification in acute myocardial ischemia. $\mathrm{N}$ Engl $\mathrm{J}$ Med $1996 ; 335: 1333-41$. 
54. Antman EM, Tanasijevic MJ, Thompson B, Schactman M, McCabe CH, et al. Cardiac specific troponin I levels to predict the risk of mortality in patients with acute coronary syndromes. N Engl J Med 1996;335:1342-9.

55. Stubbs P, Collinson P, Moseley D, Greenwood T, Nole M. Prognostic significance of admission troponin $\mathrm{T}$ concentrations in patients with myocardial infarction. Circulation 1996;94:1291-7.

56. Abe S, Arima S, Yamashita T, Nomoto K, Kawataki M, et al. Early assessment of reperfusion therapy using cardiac troponin T. J Am Coll Cardiol 1994;23:1382-9.

57. Apple FS. Acute myocardial infarction and coronary reperfusion. Serum cardiac markers for the 1990's. Am J Clin Pathol 1992;97:217-26.

58. Reimers B, Lachin M, Cacciavillani L, Secchiero S, Ramondo A, et al. Troponin $T$, creatine kinase $\mathrm{MB}$ mass, and creatine kinase $\mathrm{MB}$ isoform ratio in the detection of myocardial damage during non-surgical coronary revascularization. Int $\mathrm{J}$ Cardiol 1997;60:7-13.

59. Franz WM, Rempois A, Scheffold T, Kandolf R, Katus HA. Serum troponin T: a diagnostic marker for acute myocarditis? Circulation 1994;90:1-67.

60. Smith SC, Ladenson JH, Mason JW, Jaffe AS. Elevations of cardiac troponin I associated with myocarditis. Experimental and clinical correlates. Circulation 1997;95:163-8.

61. Adams JE, Davila-Roman VG, Bessey PQ, Blake DP, Ladenson JH, et al. Improved detection of cardiac contusion with cardiac troponin I. Am Heart J 1996;131:308-12.

62. Kiss $A$, Reinhard $W$. Über den nachweis des myoglobins im serum und im harn nach herzinfarkt. Wien Klein Wochenschr 1956;58:154-8.

63. Stone MJ, Willerson JT, Gomez-Sanchez CE, Waterman MR. Radioimmunoassay of myoglobin in human serum. Results in patients with acute myocardial infarction. $\mathrm{J}$ Clin Invest 1975;56:1334-9.

64. Wu AHB, Laios I, Green S, Gornet TG, Wong SS, et al. Immunoassays for serum and urine myoglobin: myoglobin clearance assessed as a risk factor for acute renal failure. Clin Chem 1994;40:796-802.

65. Braunlin EA, Wahler GM, Swayze CR, Lucas RV, Fox IJ. Myoglobin facilitated oxygen diffusion maintains mechanical function of mammalian cardiac muscle. Cardiovasc Res 1986;20:627-36.

66. Mair J. Myoglobin. In: Kaski JC, Holt DW. Myocardial damage early detection by novel biochemical markers. Dordrecht, The Netherlands: Kluwer academic publishers ;1998:chapter 5 .

67. YamashitaT, Abe S, Arima S, Nomoto K, Miyata M, et al. Myocardial infarct size can be estimated from serial plasma myoglobin measurements within 4 hours after reperfusion. Circulation 1993;87:1840-9.

68. Glatz JFC, van Bilsen M, Paulussen RJA, Veerkamp JH, van der Vusse GJ, et al. Release of fatty acid-binding protein from isolated rat heart subjected to ischemia and reperfusion or to the calcium paradox. Biochim Biophys Acta 1988;961:148-52.

69. Apple FS. Cardiac troponin: redefining the detection of myocardial infarction. Am Clin Lab 2002;21:32-4.

70. Bahayana V, Henderson AR. Biochemical markers of myocardial damage, review. Clin Biochem 1995;28:1-19.

71. de Winter RJ. Biochemical and inflammatory markers of acute myocardial damage. Amsterdam, The Netherlands: Amsterdam University; 1997 (Thesis).

72. van Dieijen-Visser MP, Kragten JA, Glatz JFC, Hermens WT. Clinical relevance of early markers for the diagnosis of acute myocardial infarction (AMI). Tijdschr Ned Ver Klin Chem 1993;3:140-4. 
73. Adams JE, Abendschein DR, Jaffe AS. Biochemical markers of myocardial injury is MB creatine kinase the choice for the 1990's? Circulation 1993;88:750-63.

74. Glatz JFC, van der Putten RFM, Hermens WT. Fatty acid binding protein as an early plasma marker of myocardial ischemia and risk stratification. In: Wu AHB. Cardiac Markers. Totowa, New Jersey: Humana Press; 2003. Chapter 20.

75. van der Voort D, McNeil CA, Renneberg R, Korf J, Hermens WT, et al. Biosensors for fatty acid-binding protein, an early plasma marker of myocardial injury. Sens Actuators. submitted.

76. Vo-Dinh T, Cullum B. Biosensors and biochips: advances in biological and medical diagnostics. Fresenius J Anal Chem 2000;366:540-51.

77. Fischer U, Alcock S, Turner APF. Assessment of devices for in vivo monitoring of chemical species. Biosens Bioelectron 1995;10:23-30.

78. Arner P, Bolinder J. Microdialysis of adipose tissue. J Intern Med 1991;230:381-6.

79. Ballerstadt R, Schultz JS. Sensor methods for use with microdialysis and ultrafiltration. Adv Drug Deliv Rev 1996;21:225-38.

80. Elmquist WF, SawchukRJ. Application of microdialysis in pharmacokinetic studies. Pharm Res 1997; 14:267-88.

81. Delgado JMR, Rubinstein L. Intracerebral release of neurohumors in unaesthetized monkeys. Arch Int Pharmacodyn Ther 1964;150:530-46.

82. Palmisano F, de Santis A, Tantillo G, Volpicella T, Zambonin PG. Microbial detection by a glucose biosensor coupled to a microdialysis fibre. Analyst 1997;122:1125-8.

83. Robinson J. Microdialysis: a novel tool for research in the reproductive system. Biol Reprod 1995:237-45.

84. Davies MI. A review of microdialysis sampling for pharmacokinetic applications. Anal Chim Acta 1999;379:227-49.

85. Torto N, Gorton L, Laurell T, Marko-Varga G. Technical issues of in vitro microdialysis sampling in bioprocess monitoring. Trends Anal Chem 1999;18:252-60.

86. Garrison KE, Pasas SA, Cooper JD, Davies MI. A review of membrane sampling from biological tissues with applications in pharmacokinetics, metabolism and pharmacodynamics. Eur J Pharm Sciences 2002;17:1-12.

87. Stenken JA. Methods and issues in microdialysis calibration. Anal Chim Acta 1999;379:337-58.

88. Song $Y$, Lunte CE. Comparison of calibration by delivery versus no net flux for quantitative in vivo microdialysis sampling. Anal Chim Acta 1999;379:251-62.

89. Janle-Swain E, van Vleet JF, Ash SR. Use of a capillary filtrate collector for monitoring glucose in diabetics. ASAIO Trans 1987;33:336-40.

90. Hsiao JK, Ball BA, Morrison PF, Mefford IN, Bungay PM. Effects of different semipermeable membranes on in vitro and in vivo performance of microdialysis probes. $\mathrm{J}$ Neurochem 1990;54:1449-52.

91. Janle EM, Kissinger PT. Microdialysis and ultrafiltration. Adv Food Nutr Res 1996;40:183-96.

92. Osborne PG, O'Connor WT, Ungerstedt U. Effect of varying the ionic concentration of a microdialysis perfusate on basal striatal dopamine levels in awake rats. $J$ Neurochem 1991;56:452-6.

93. Ungerstedt U. Microdialysis-principles and applications for studies in animals and man. J Intern Med 1991;230:365-73.

94. Linhares MC, Kissinger PT. Determination of endogenous ions in intercellular fluid using capillary ultrafiltration and microdialysis probes. J Pharm Biomed Anal 1993;11:1121-7. 
95. Kaptein WA. Development of sampling and bioselective techniques for on-line clinical biosensors. Wageningen, The Netherlands: Ponsen \& Looijen BV;1998 (Thesis).

96. Rosdahl H, Ungerstedt U, Jorfeldt L, Henriksson J. Interstitial glucose and lactate balance in human skeletal muscle and adipose tissue studied by microdialysis. J Physiol 1993;471:637-57.

97. Kaptein WA, Zwaagstra JJ, Venema K, Korf J. Continuous ultraslow microdialysis and ultrafiltration for subcutaneous sampling as demonstrated by glucose and lactate measurements in rats. Anal Chem 1998;70:4696-4700.

98. Rosdahl H, Ungerstedt U, Henriksson J. Microdialysis in human skeletal muscle and adipose tissue at low flow rates is possible if dextran-70 is added to prevent loss of perfusion fluid. Acta Physiol Scand 1997:159:261-2.

99. Linhares MC, Kissinger PT. Capillary ultrafiltration: in vivo sampling probes for small molecules. Anal Chem 1992;64:2831-5.

100. Leegsma-Vogt G, Janle E, Ash SR, Venema K, Korf J. Utilization of in vivo ultrafiltration in biomedical research and clinical applications. Life Sc 2003;73:2005-18. 


\section{Fatty acid-binding protein as the earliest available plasma marker of acute myocardial injury}

Part of this chapter is published:

Glatz JFC, van der Voort D, Hermens WT. Fatty acid-binding protein as the earliest available plasma marker of acute myocardial injury. J Clin Lig Assay 2002;25:167-177. 


\subsection{Abstract}

More rapid triaging of patients admitted to hospital with chest pain suggestive of acute myocardial infarction (AMI) is needed to facilitate early initiation of appropriate therapy in patients with AMI and to exclude low-risk patients who can safely be sent home. Biochemical markers of myocardial injury are now universally accepted as important determinants for the diagnosis of such patients, and at present attention is focused on defining those cardiac marker proteins (or combinations) that show a high sensitivity as well as specificity for AMI detection especially in the early hours after admission. Cytoplasmic fatty acid-binding protein (FABP), which functions as an intracellular fatty acid carrier, was suggested as a plasma marker of AMI in 1988 and is a small $(14.5 \mathrm{kDa})$ soluble protein that is not cardio-specific but is also expressed in relatively low amounts in skeletal muscle. The release and plasma kinetics of FABP closely resemble those of myoglobin, i.e., a rise is detectable as early as 1 to 3 hour after AMI onset, peak values are reached at 6 to 8 hours, and the plasma level returns to normal within 24 to 36 hours. Several (multi-center) clinical studies have unanimously revealed a significantly better performance of FABP over myoglobin for early AMI detection as well as early estimator of infarct size. This superior performance of FABP relates to its relatively low plasma reference concentration. Preliminary evidence suggests that FABP also detects minor myocardial injury and thus may serve as a prognostic marker for patients with unstable angina pectoris. It is concluded that FABP appears to be an excellent marker for early confirmation or exclusion of AMI. The results are discussed in relation to the recently formulated recommendations for use of marker proteins in the emergency room.

\subsection{Introduction}

Biochemical markers of myocardial injury have proven important tools for the diagnosis of patients with suspected acute myocardial infarction (AMI), especially in those cases in which electrocardiographic (ECG) changes are equivocal or absent, and recently have been included in the diagnosis of acute coronary syndromes. ${ }^{(1-3)}$ In the last decade, these so-called cardiac markers have received increasing attention for two reasons. First, the introduction of new therapeutic strategies has called for earlier and more appropriate diagnosis of patients admitted to the emergency room with chest pain to begin the proper therapy as early as possible. ${ }^{(4,5)}$ Second, several new plasma markers have been introduced, and some, for instance troponin $\mathrm{T}$, were found not only to allow for the assessment of myocardial infarction but also to be of prognostic value in patients with unstable angina. ${ }^{(6)}$

Fatty acid-binding protein (FABP) was first shown to be released from injured myocardium in 1988, after which several studies have investigated its application as a diagnostic plasma marker of acute coronary syndromes. ${ }^{(7)}$ In this review we summarize our current knowledge on the use of FABP as a marker of myocardial injury. Although the release and plasma kinetics of FABP closely resemble those of myoglobin, the relatively low plasma reference concentration of FABP makes it superior to myoglobin 
Fatty acid-binding protein as the.....

for the monitoring of myocardial ischemia, especially in the early hours after the onset of symptoms.

\subsection{FABP is abundantly expressed in cardiac myocytes}

Cytoplasmic FABP is a relatively small (14 to $15 \mathrm{kDa})$ protein that can reversibly and non-covalently bind long-chain fatty acids, and is abundantly expressed in tissues with an active fatty acid metabolism, such as heart muscle. ${ }^{(8,9)}$ To date, nine distinct types of FABP have been identified, and these belong to a multigene family of intracellular lipidbinding proteins that also includes the cellular retinoid-binding proteins. ${ }^{(8,10)}$ These proteins show a similar tertiary structure, which resembles that of a clam shell. The lipid ligand is bound in between the two halves of the clam by interaction with specific amino acid residues within the binding pocket, a so-called b-barrel, of the protein. ${ }^{(10,11)}$ The FABP types are named after the tissue in which they were first identified, and they each show a characteristic pattern of tissue distribution. Thus, $H$ (heart-type)-FABP is also found in skeletal muscle, in distal tubule cells of the kidney, and in some parts of the brain. ${ }^{(8,9)}$ Human H-FABP contains 132 amino acid residues $(14.5 \mathrm{kDa})$, and is an acidic protein $(\mathrm{p} I 5){ }^{(11,12)}$

The cardiac muscle content of H-FABP is approximately $0.57 \mathrm{mg} / \mathrm{g}$ wet weight of tissue, which is of comparable magnitude to the content of another small $(17.6 \mathrm{kDa})$ cytoplasmic protein, i.e., myoglobin $(2.7 \mathrm{mg} / \mathrm{g})$. Interestingly, the skeletal muscle content of FABP is only $0.04-0.14 \mathrm{mg} / \mathrm{g}$, while that of myoglobin is $2.2-6.7 \mathrm{mg} / \mathrm{g}^{(13-15)}$ This marked difference has been exploited for the discrimination of myocardial from skeletal muscle tissue injury (see below).

The FABPs appear to be stable proteins, exhibiting an intracellular turnover with a half-life of approximately 2 to 3 days. Their cellular expression is regulated primarily at the transcriptional level. In general, the FABP expression is responsive to changes in lipid metabolic activity as induced by various (patho) physiological and pharmacological stimuli. ${ }^{(8)}$ For instance, the (H-)FABP content of heart and skeletal muscles increases by endurance training, ${ }^{(16)}$ and is also higher in the diabetic state, ${ }^{(17)}$ but is slightly decreased in the hypertrophied heart. ${ }^{(13,18)}$

The primary biological function of the FABPs is their facilitation of the cytoplasmic translocation of long-chain fatty acids, which is normally hampered by the very low solubility of these compounds in aqueous solutions. ${ }^{(19)}$ Therefore, FABP can be regarded as an intracellular counterpart of plasma albumin. Definite proof of this function was obtained recently, when it was found that cardiac myocytes isolated from mice lacking the H-FABP gene showed a markedly lower (approximately -50\%) rate of fatty acid uptake and oxidation. ${ }^{(20)}$ Other functions for H-FABP and other types of FABP include participation in signal transduction pathways such as fatty acid regulation of gene expression. ${ }^{(21,22)}$ and the putative protection of myocytes against the adverse (detergentlike) effects of long-chain fatty acids, especially when these compounds accumulate in the heart during ischemia. ${ }^{(8,19)}$ 


\subsection{Immunochemical assay of FABP in plasma}

Because $\mathrm{FABP}$ is a non-enzymatic protein, its detection and quantification must be performed with an immunochemical assay. A large number of immunoassays for $\mathrm{H}$ FABP have been described, mostly enzyme-linked immunosorbent assays (ELISA) of the antigen capture type, but also a competitive immunoassay, and an immuno-fluorometric assay. ${ }^{(23,24-26)}$ In most cases monoclonal antibodies are used, and these show virtually no cross-reactivity with other FABP types. ${ }^{(12,27)}$ Recombinant H-FABP appears immunochemically equivalent to the tissue-derived protein and, therefore, is now commonly applied as a standard in the immunoassay. ${ }^{(12,23)}$

These assays have been used successfully for retrospective analyses of plasma FABP in patient samples. However, the implication of these tests for clinical decision making in the case of suspected AMI is hampered by the fact that the reported fastest immunoassay still takes 45 minutes to complete. ${ }^{(23)}$ Therefore, more rapid FABP immunoassays are being developed. To date, these include a microparticle-enhanced turbidimetric assay to be performed on a conventional clinical chemistry analyzer (performance time 10 minutes), ${ }^{(28)}$ an automated sandwich immunoassay (performance time 23 minutes), ${ }^{(29,30)}$ and an electrochemical immunosensor (performance time 20 minutes). ${ }^{(31-33)}$ The electrochemical immunosensor is based on screen printed graphite electrodes and uses an immunosandwich procedure and an amperometric detection system. ${ }^{(32)}$ Measurements of plasma samples from patients with AMI with this immunosensor and with an ELISA show an excellent correlation. ${ }^{(32,34)}$ More recently, a new principle for rapid immunoassay of proteins based on in situ precipitateenhanced ellipsometry was presented and applied to assay of FABP. ${ }^{(35)}$ This technique enables the development of a one-step ELISA with a performance time of less than 10 minutes. Finally, a whole blood panel test for FABP using a one-step immunochromatography technique has been developed. ${ }^{(36)}$ This panel test, which is completed in 15 minutes and is meant for point-of-care testing, identifies blood samples with an FABP concentration exceeding $6 \mu \mathrm{g} / \mathrm{L}$. With the exception of the ELISA assays, calibrated with recombinant $\mathrm{FABP}$, these new techniques still require further evaluation and standardization.

\subsection{FABP and myoglobin show similar plasma release curves upon muscle injury}

The release of H-FABP from injured muscle was first demonstrated in 1988 with isolated working rat hearts, ${ }^{(7)}$ and indicated the potential use of FABP as a plasma marker of myocardial injury in humans. Subsequently, several groups reported the release of FABP into plasma of patients with AMI. ${ }^{(25,37-39)}$ The characteristics of the release of FABP from injured myocardium closely resemble those of myoglobin. As an example, Fig. 1 shows mean plasma release curves of FABP, myoglobin, and, for comparison, troponin $T(\operatorname{TnT})$, for 15 AMI patients, treated with reperfusion therapy, from whom blood samples were obtained frequently during the first 24 hours of hospitalization. ${ }^{(40)}$ In patients treated with standard thrombolytic therapy after AMI, peak plasma concentrations of FABP and 
myoglobin are reached at about 4 hours after first symptoms (Fig. 1), whereas for creatine kinase (CK or CK-MB) this takes about 12 hours, and for lactate dehydrogenase (LDH) about 20 hours. ${ }^{(41,42)}$ Furthermore, plasma FABP and myoglobin return to their respective reference values already within 24 hours after AMI, indicating the usefulness of both markers particularly for the assessment of a recurrent infarction. However, for AMI patients not treated with thrombolytics, peak levels are reached approximately 8 hours after AMI, and elevated plasma FABP and myoglobin concentrations are found up to 24 to 36 hours after the onset of chest pain. ${ }^{(14)}$ The release of the myofibrillar proteins $\mathrm{TnT}$ and troponin I (TnI) from injured myocardium follows a different pattern with elevated plasma concentrations occurring from approximately 8 hours up to more than 1 week after infarction. ${ }^{(6.43)}$ Hence, the so-called diagnostic window of the various marker proteins differs considerably.

When the plasma release curves are expressed relative to the upper reference concentrations (discriminator value) of each of the marker proteins $(6,60$, and $0.1 \mu \mathrm{g} / \mathrm{L}$ for FABP, myoglobin and TnT, respectively), it appears that a few hours after the onset of AMI, FABP is elevated 18-fold, while myoglobin and TnT are elevated only 8- and 2fold, respectively (Fig. 3.1, middle panel). Furthermore, at peak values both FABP and TnT are elevated 30 - to 40 -fold above their respective discriminator values, while myoglobin is elevated only 15-fold (Fig. 3.1). This comparison already indicates that the sensitivity of FABP for detection of myocardial cell necrosis is greater than that of myoglobin and reaches that of TnT.
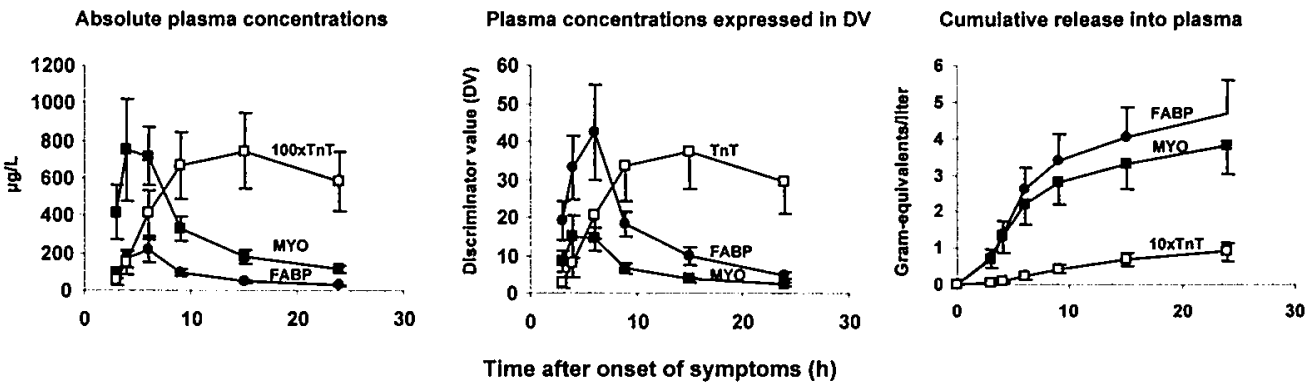

\section{Figure 3.1}

Mean plasma concentrations of FABP $(\bullet)$, myoglobin (MYO) $(\bullet)$, and troponin $T(T n T)(\square)$ as a function of time after acute myocardial infarction (AMI) for a subset of 15 patients who were treated successfully with reperfusion therapy and from whom serial blood samples were obtained up to $24 \mathrm{~h}$ after onset of symptoms. The data are presented as plasma concentrations in $\mathrm{mg} / \mathrm{L}$ (left panel or relative to the respective discriminator value (DV) for FABP (6 mg/L), MYO (60 $\mathrm{mg} / \mathrm{L}$ ), and $\operatorname{TnT}(0.1 \mathrm{mg} / \mathrm{L})$ (middle panel). The mean cumulative release expressed in gram equivalents ( $\mathrm{g}$-eq) of healthy myocardium per liter of plasma (infarct size) is also given (right panel). Data refer to mean \pm SEM.

Data obtained from reference 40 with permission.

The marked differences in the time course of plasma concentrations or activities among the cytoplasmic proteins (CK-MB, LDH, FABP, and myoglobin) are caused by: 1) a more rapid washout of the smaller proteins (FABP, myoglobin) from the interstitium to the vascular compartment; and 2) differences among the proteins in their rate of 
elimination from plasma. ${ }^{(44)}$ Studies of isolated cardiac myocytes subjected to simulated ischemia showed that protein release from the damaged myocytes is independent of molecular mass. ${ }^{(45)}$ This indicates that during the protein-release phase the sarcolemma does not act as a selective sieve through which small proteins are preferentially lost. The fact that smaller proteins can be detected in blood plasma earlier after muscle injury than can larger proteins therefore relates to a greater permeability of the endothelial barrier for smaller proteins. ${ }^{(44)}$ Structurally bound proteins such as TnT and TnI first must be dissociated from the myofibrillar structures before they can be released into the interstititial space. Moreover, these proteins are often released in complexes with each other or with $\mathrm{TnC} .^{(46,47)}$ This explains why $\mathrm{TnT}$, despite its relatively low molecular mass $(39 \mathrm{kDa}$ ), shows a delayed plasma release curve compared to FABP or myoglobin (Fig. $3.1)$.

The relatively rapid clearance of both FABP and myoglobin from plasma after AMI relates to the fact that these proteins, unlike the (larger) cardiac enzymes and the troponin complexes, are removed from the circulation predominantly by renal clearance. $^{(37-39,44)}$ This observation would further indicate that increased plasma concentrations of FABP and myoglobin are likely to be found in case of renal insufficiency. Indeed, it has been reported that patients with chronic renal failure and normal heart function show several-fold increased plasma concentrations of both FABP and myoglobin. ${ }^{(48,49)}$ In addition, Kleine and coworkers reported a patient with AMI and severe renal insufficiency in whom the plasma FABP concentration remained markedly elevated for at least 25 hours after infarction. ${ }^{(38)}$

\subsection{FABP shows a relatively low plasma reference concentration}

The role of the kidney in the clearance of FABP and myoglobin from plasma indicates the maintenance of relatively low plasma concentrations of these proteins in healthy subjects. The plasma concentrations in healthy individuals are determined mainly by the release of protein from skeletal muscle because its total mass far exceeds that of cardiac muscle. Because the skeletal muscle FABP content is relatively low compared with that of myoglobin (see above), the plasma reference concentration of FABP also is relatively low, amounting to approximately $1.8 \mu \mathrm{g} / \mathrm{L}$, whereas that of myoglobin is approximately $34 \mu \mathrm{g} / \mathrm{L} .^{(14,15,23,50-52)}$ This notion is also reflected in the ratio of the concentrations of myoglobin and FABP in plasma from healthy subjects (myoglobin:FABP ratio approximately 20), which resembles the ratio in which these proteins occur in skeletal muscle (myoglobin:FABP ratio 20 to 70 ). The plasma reference concentration of FABP increases gradually during aging, from approximately $0.9 \mu \mathrm{g} / \mathrm{L}$ in subjects of 21 to 30 years, to approximately $2.5 \mu \mathrm{g} / \mathrm{L}$ in subjects of 61 to 70 years. ${ }^{(52)}$ This increase with age is most likely explained by the decrease in renal function in elderly people.

\subsection{Discrimination of cardiac from skeletal muscle injury}

A potential drawback of the use of FABP as a plasma marker for monitoring myocardial injury is its presence in significant quantities not only in heart muscle but also in skeletal muscle cells. A proper diagnosis of AMI thus may be hampered in cases of extensive 
skeletal muscle injury such as multi-organ failure, post-operative states, or vigorous exercise. However, this problem can be overcome by the combined measurement of myoglobin and FABP concentrations in plasma and expressing the ratio of these, because this plasma ratio is a reflection of the ratio in which these proteins occur in the affected tissue cells and it differs between heart muscle (myoglobin:FABP ratio 4 to 5 ) and skeletal muscle (myoglobin:FABP ratio 20 to 70 , depending on type of muscle).$^{(6,14,15)}$

In accordance with this concept, it was found for patients after AMI that the plasma myoglobin:FABP ratio was approximately 5 during the entire period of elevated plasma concentrations, while for patients who underwent aortic surgery, which causes no-flow ischemia of the lower extremities, the plasma myoglobin:FABP ratio was approximately $45 .^{(14,15)}$ Importantly, it was reported that a patient who was defibrillated shortly after AMI, a treatment that most likely results in injury of intercostal pectoral muscles, displayed a plasma myoglobin:FABP ratio that increased from 8 to 60 during the first 24 hours after AMI. Thus, when AMI patients show a second increase of plasma concentrations of marker proteins, the ratio may be of help to delineate whether this second increase was caused either by a recurrent infarction or by the occurrence of additional skeletal muscle injury. In the former case, the ratio will remain unaltered. ${ }^{(14)}$

\subsection{Early diagnosis of AMI}

The application of FABP, especially for the early diagnosis of acute coronary syndromes, is already indicated because of its rapid release into plasma after myocardial injury and its relatively low plasma reference concentration. Several studies have now firmly established that FABP is an excellent plasma marker for the early differentiation of patients with and those without AMI, and that it even performs better than myoglobin.

Table 3.1 lists the results of the four major studies reported to date that compared the diagnostic performance of FABP with that of the early marker myoglobin in patients admitted to hospital with chest pain suggestive of AMI. In each study, the areas under the receiver operating characteristic (ROC) curves, constructed for the admission blood samples from all patients, were found significantly greater for FABP than for myoglobin (Table 3.1 and Fig. 3.2), indicating a superior performance of FABP for AMI detection in these plasma samples. In addition, analyses of subgroups of patients revealed that the difference in performance between FABP and myoglobin generally was greater for patients admitted earlier after the onset of symptoms. ${ }^{(30,53.55)}$ For instance, in the EUROCARDI multi-center study the subgroup of patients admitted 0-3 hours after onset of symptoms showed an area under the ROC curve of 0.845 for FABP and of 0.717 for myoglobin, while the subgroup of patients admitted 3 to 6 hours after onset of symptoms showed areas of 0.945 for FABP and 0.892 for myoglobin. ${ }^{(53)}$ These recent observations $^{2}$ are in line with previous reports on plasma samples from groups of patients with confirmed AMI, in which retrospective analyses of marker proteins had already indicated that FABP was an earlier marker than myoglobin. ${ }^{(6,51)}$ This better performance of FABP over myoglobin for the early diagnosis of AMI has also been reported in other smaller studies. $^{(29,56,57)}$ 
Table 3.1 Diagnostic performance of plasma FABP and myoglobin in detection of AMI in patients: a comparison of several studies.

\begin{tabular}{|c|c|c|c|c|c|c|c|c|}
\hline \multirow[t]{2}{*}{ First author } & \multirow{2}{*}{$\begin{array}{l}\text { Number } \\
\text { of centers }\end{array}$} & \multirow{2}{*}{$\begin{array}{c}\text { Number } \\
\text { of patients }\end{array}$} & \multirow{2}{*}{$\begin{array}{c}\text { Patients } \\
\text { with } \mathrm{AM} 1(\%)\end{array}$} & \multicolumn{2}{|c|}{ Admission time } & \multicolumn{3}{|c|}{ Area under ROC curve } \\
\hline & & & & Mean (h) & Range (h) & FABP & Myoglobin & $P^{*}$ \\
\hline Ishii et al., 1997(50) & 1 & 165 & 60 & 3.5 & $3-12$ & 0.898 & 0.782 & $<0.01$ \\
\hline Glatz et al., 1997 (53) & 4 & 312 & 54 & 3.3 & $1.5-8$ & 0.901 & 0.824 & $<0.001$ \\
\hline Okamoto et al., 2000 (55) & 1 & 189 & 74 & 4.0 & $0-12$ & 0.921 & 0.843 & $<0.05$ \\
\hline Ghani el al., $2000^{(30)}$ & 3 & 460 & 21 & $\sim 3^{* *}$ & $3-7^{* n}$ & 0.800 & 0.730 & Not given \\
\hline
\end{tabular}

The performance of the two early plasma markers is given for measurements made in admission blood samples taken from patients entering the hospital with chest pain suggestive of AMI.

$P^{\star}$ values comparing the areas under the ROC curve for FABP and myoglobin.

${ }^{\star \star}=0-4 \mathrm{~h}$ period with added hospital delay of approximately $3 \mathrm{~h}$ (see text).

Abbreviations: $\mathrm{AMI}=$ acute myocardial infarction, $\mathrm{ROC}$ curve $=$ receiver operating characteristics curve, $\mathrm{FABP}=$ fatty acid-binding protein

In the study by Okamoto and coworkers a comparison was also made with creatine kinase-MB activity, but the area under the ROC curve of this marker (0.654) was significantly less than that for either FABP or myoglobin (Table 3.1$){ }^{(55)}$ This indicates that for early AMI detection CK-MB is less well suited than either FABP or myoglobin. In contrast, in the multi-center study reported by Ghani and coworkers, the area under the ROC curve of CK-MB mass (0.79) was of similar magnitude, and that of cardiac TnI (0.91) even significantly larger than that of either FABP or myoglobin. ${ }^{(30)}$ This led the authors to conclude that in their study neither FABP nor myoglobin showed the sensitivity and specificity necessary to detect AMI significantly earlier than the existing markers. This conclusion seemingly contradicts the well-documented poor diagnostic performance of CK-MB mass and TnT or TnI in the very early hours after infarction. ${ }^{(43,46)}$ The discrepancy is explained by the fact that the zero time as reported in this study was the time of hospital admission rather than the time of onset of symptoms, ${ }^{(30)}$ so that the study results apply to a later period, whereas FABP and myoglobin are useful especially in the early hours after infarction.

In some of these above-mentioned studies, investigators evaluated whether the diagnostic performance of FABP as an early plasma marker of myocardial injury could further improve when the criterion of a plasma myoglobin:FABP ratio of less than 10 (or less than 14), i.e., the exclusion of skeletal muscle as source of FABP, is taken as an additional parameter. ${ }^{(30,50,53,57)}$ In each of these study populations, there were a few cases in which both myoglobin and FABP were elevated in the admission plasma sample, but in which the myoglobin:FABP ratio was greater than 10 (or 14). Without this latter result, these patients would be falsely diagnosed as having had myocardial injury. However, because the prevalence of skeletal muscle injury in these study populations was very low (less than $1 \%$ of cases), this additional parameter did not significantly alter the ROC curve for FABP (illustrated in Fig. 3.2). Therefore, the routine measurement of the myoglobin:FABP ratio in samples from patients suspected for AMI does not seem justified because it does not add value to the measurement of FABP alone. In addition, the myoglobin:FABP ratio cannot provide absolute cardiac specificity. ${ }^{(6)}$ 


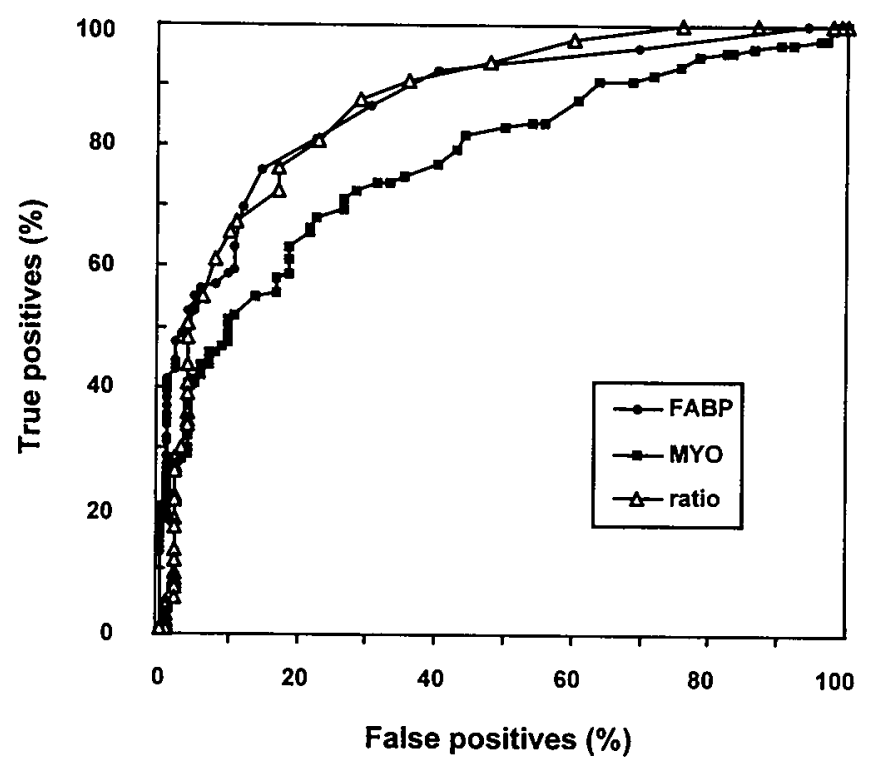

Figure 3.2

Receiver operating characteristic (ROC) curves for detection of acute myocardial infarction (AMI) in 238 patients with chest pain suggestive of AMI and admitted to hospital within 6 hours of the onset of symptoms, comparing the concentrations of fatty acid binding protein (FABP) (•) and myoglobin ( $(\mathbf{)}$, and the myoglobin:FABP ratio $(\Delta)$ in the admission blood sample. ROC curves were constructed by plotting the sensitivity (\% true positives) for the confirmed AMI group (135 patients) against 100 - specificity (\% false positives) for the non-AMI group (103 patients). The areas under the ROC curves are 0.874 for FABP, 0.780 for myoglobin, and 0.870 for the myoglobin:FABP ratio (FABP vs myoglobin, and FABP vs the ratio significantly different; $P$ < $0.001)$. Data obtained from the EUROCARDI multicenter trial. ${ }^{(53,54)}$

At first sight it may be surprising that FABP appears as an earlier marker for AMI detection than does myoglobin, even though the two proteins show similar plasma release curves. However, these findings can be explained when it is realized that the myocardial content of FABP $(0.57 \mathrm{mg} / \mathrm{g}$ wet weight) is four- to five-fold lower than that of myoglobin $(2.7 \mathrm{mg} / \mathrm{g}$ wet weight), yet the plasma reference concentration of FABP (1.8 $\mathrm{mg} / \mathrm{L})$ is 19 -fold lower than that of myoglobin $(34 \mathrm{mg} / \mathrm{L})$. This means that after injury the tissue to plasma gradient is almost five-fold steeper for FABP than for myoglobin, making plasma FABP rise above its upper reference concentration at an earlier point after AMI onset than does plasma myoglobin, thereby permitting an earlier diagnosis of AMI.

\subsection{FABP and the detection of minor myocardial injury}

It is now firmly documented that the subgroup of patients with unstable angina pectoris who show a significantly increased plasma concentration of TnT (greater than $0.2 \mu \mathrm{g} / \mathrm{L}$ ) have a prognosis as serious as do patients with definite AMI. ${ }^{(58,59)}$ This observation most likely relates to the occurrence in these patients of minor myocardial cell necrosis. In 
those patients in whom unstable angina pectoris is in fact acute minor MI, the advantage of FABP for early assessment of injury may be used. Recently, Katrukha and coworkers measured FABP and TnI in serial plasma samples from 31 patients with unstable angina and showed that in the admission sample TnI was elevated (cutoff value $0.2 \mu \mathrm{g} / \mathrm{L}$ ) in $13 \%$ and FABP (cutoff value $6 \mu \mathrm{g} / \mathrm{L}$ ) in $54 \%$ of patients, whereas at 6 hours after admission TnI was elevated in $58 \%$ and FABP in $52 \%$ of patients. Importantly, all patients who had an elevated FABP concentration at 6 hours showed an elevated TnI value at 12 hours after admission. ${ }^{(60)}$ These preliminary data suggest that FABP may identify acute minor MI with similar sensitivity as TnI but at an earlier point after admission of the patient.

The putative application of FABP as marker for the detection of minor myocardial injury is illustrated for four individual patients who were clinically diagnosed as having unstable angina, but whose plasma release curves of FABP showed a characteristic rise and fall and reached values above the discriminator value of $6 \mu \mathrm{g} / \mathrm{L}$ (Fig. 3.3). In each of these cases the plasma myoglobin concentration followed that of FABP but did not show a clear curve and/or did not reach the discriminator value of $60 \mu \mathrm{g} / \mathrm{L}$ (Fig. 3.3).
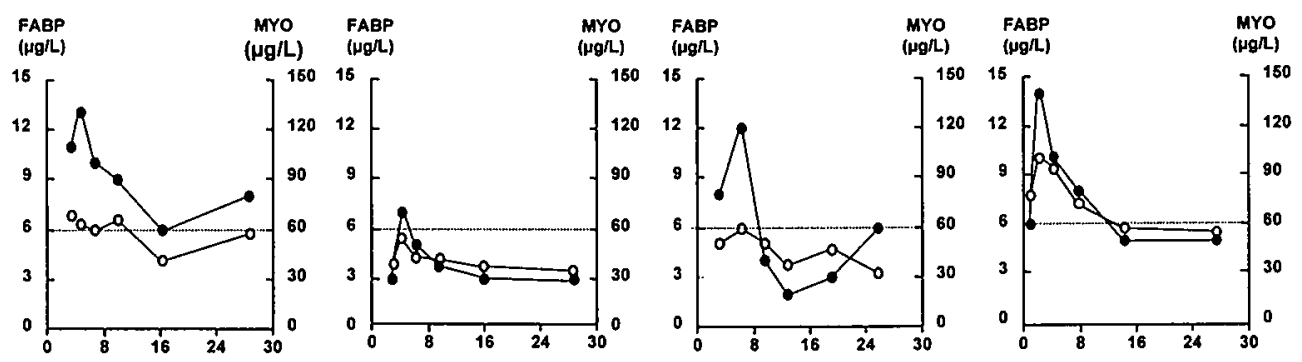

Time after onset of symptoms (h)

\section{Figure 3.3}

Examples of plasma release curves of FABP and myoglobin in four individual patients clinically diagnosed as having unstable angina pectoris (UAP). In these patients plasma FABP (•) and myoglobin (MYO) (0) were elevated above their respective discriminator values (dashed line; 6 $\mu \mathrm{g} / \mathrm{L}$ for $\mathrm{FABP}$ and $60 \mu \mathrm{g} / \mathrm{L}$ for myoglobin) and show a typical "rise and fall" pattern suggesting the occurrence of minor myocardial injury. Data obtained from the EUROCARDI multicenter trial. ${ }^{(53,54)}$

\subsection{Other established applications of the plasma marker FABP}

Investigations from several laboratories have firmly documented the usefulness of FABP also for the early and sensitive detection of postoperative myocardial tissue loss in patients undergoing cardiac surgery. ${ }^{(6,61-63)}$ In these patients, myocardial injury may be caused by global ischemia/reperfusion and, additionally, by postoperative MI. The data indicate that FABP would allow for an earlier exclusion of postoperative MI, thus permitting the earlier transfer of these patients from the intensive care unit to the ward.

Because FABP was found to be completely released from the heart after AMI and recovered quantitatively in plasma (Fig. 3.1), as has also been well documented for CK, $\mathrm{LDH}$, and myoglobin but does not apply for the structural proteins $\operatorname{TnT}$ and $\mathrm{TnI},{ }^{(43)}$ this 
marker can be used for estimation of myocardial infarct size. ${ }^{(41,42,64)}$ The latter is commonly calculated from the cumulative release of the marker protein over time (plasma curve area), taking into account its elimination rate from plasma. ${ }^{(41,65)}$ Because the release of FABP and myoglobin is completed much earlier than that of either CK/ CK-MB or LDH, an estimate of the mean extent of myocardial injury with FABP or myoglobin could be available already within 24 hours after the onset of AMI (instead of 48 to 72 hours when based on the enzymatic markers), i.e., while the patient is still in the acute care department. ${ }^{(66)}$ For individual patients, infarct size estimation using FABP or myoglobin is hampered by the fact that these proteins are cleared by the kidneys, and that the patients often suffer from renal insufficiency which would lead to overestimation of infarct size. However, De Groot and coworkers recently suggested the use of individually estimated clearance rates for FABP and myoglobin, based on glomerular filtration rates determined from plasma creatinine concentrations and corrected for age and gender, so that a reliable estimate of myocardial infarct size can become available for an individual patient within 24 hours, provided that frequent blood samples are taken and analyzed rapidly. ${ }^{(42)}$ Future studies will need to be performed to determine the clinical utility of obtaining this information.

The application of FABP as a plasma marker for the early detection of successful coronary reperfusion in patients with AMI has been investigated by three groups. ${ }^{(67-69)}$ Following successful reperfusion, both plasma FABP and myoglobin were found to rise sharply, whereas in patients with failed reperfusion these markers rise at a much slower rate. FABP and myoglobin perform equally well as non-invasive markers to discriminate between reperfused and non-reperfused patients, but generally relatively low sensitivities and specificities (approximately 70\%) were found. However, these could be improved (to approximately $80 \%$ ) by normalization to infarct size, indicating their suitability especially in retrospective studies where infarct size is known. ${ }^{(69)}$

Interestingly, preliminary data have been presented that suggest the use of plasma FABP for the detection and evaluation of latent and progressive myocardial injury in patients with chronic heart failure. ${ }^{(70,71)}$ Serum FABP concentrations were higher with more severe heart failure, and significantly correlated with serum $\operatorname{Tn} T{ }^{\left({ }^{(7)}\right.}$ In addition, the subgroup of patients with the highest serum FABP levels showed the highest incidence of subsequent cardiac events. ${ }^{(70,71)}$ These observations suggest that FABP, like TnT, may be a sensitive predictor of cardiac events in patients with chronic heart failure. ${ }^{(72)}$

Finally, antibodies directed against FABP have been shown to be useful for the immunohistochemical detection of very recent AMIs. ${ }^{(73-75)}$ Partial depletion of FABP was observed in cardiomyocytes with a post-infarction interval of less than 4 hours, indicating that FABP immunostaining can confirm the clinical diagnosis or suspicion of early $\mathrm{MI}$ in routine autopsy pathology. ${ }^{(73)}$

\subsection{New developments in the application of FABP as plasma marker}

A limitation of the use of markers of cell necrosis for assessment of tissue injury is the time lag between the onset of necrosis and the appearance of the marker proteins in plasma. This explains why up to 2 to 3 hours after the onset of AMI, the performance of such markers generally is insufficient for clinical decision making. Therefore, approaches 
have been presented to further increase the diagnostic performance of the plasma markers in these early hours after AMI.

To circumvent the problem of the upper reference concentration that is defined for populations and used for individual cases, it has been suggested to collect two or more serial blood samples during the first hours after admission and express the difference in marker concentration or activity in these samples. This so-called delta-serum marker approach generally shows a higher sensitivity and equal specificity for identification of AMI. ${ }^{(76)}$ Importantly, the method has been applied especially to identify low-risk patients who would show no ECG abnormalities as well as two negative results for protein markers (hence, no significant change in time), and for whom early discharge would be a safe option. ${ }^{(77,78)}$ In a second EUROCARDI Multicenter Trial, we studied whether in patients admitted for suspected AMI without ECG changes, AMI can be ruled out by assay of $\mathrm{FABP}$, myoglobin or $\mathrm{CK}-\mathrm{MB}$ mass in two serial blood samples, collected upon admission and 1 to 3 hours thereafter. For comparison, TnT was measured in a third sample taken 12 to 36 hours after admission. Preliminary results from this study revealed that two negative marker concentrations within 3 hours from admission ruled out AMI with very high negative predictive values (greater than $90 \%$ ) with the highest value found for FABP (negative predictive value 98\%), similar to that of TnT elevation (greater than or equal to $0.1 \mu \mathrm{g} / \mathrm{L}$ ) in the sample taken 12 to 36 hours after admission. ${ }^{(79)}$ A similar conclusion was also reached in a subsequent single-center study consisting of 130 patients admitted for suspected AMI with no significant ST-segment elevation. ${ }^{(80)}$ These data indicate the excellent utility of FABP for early triage and risk stratification of patients with chest pain.

Another approach to further increase the diagnostic performance of FABP in the early hours after onset of chest pain is its use in combination with markers of activated blood coagulation. ${ }^{(40)}$ Because intracoronary formation of blood clots on ruptured atherosclerotic plaques is considered the main cause of AMI, detection of activated blood coagulation potentially allows for the early diagnosis of AMI. ${ }^{(81)}$ Indeed, evidence has been presented that in the very early hours ( 0 to 3 hours) after AMI onset, coagulation markers show a higher sensitivity and specificity for AMI detection than necrosis markers. ${ }^{(82,83)}$ In a pilot study consisting of 25 patients with either AMI or unstable angina pectoris, we showed that combining a marker of muscle cell necrosis (FABP) and a marker of activated blood coagulation (thrombus precursor protein (TpP)) yielded a markedly higher sensitivity and specificity for AMI detection than either of the markers alone. ${ }^{(40)}$

Given the fact that FABP appears likely to be a sensitive plasma marker able to detect minor myocardial injury, similar to the sensitivity displayed by TnT or TnI (Fig. 3.3), frequent monitoring of its plasma concentration would more readily permit recognition of such events. Ideally, the plasma FABP concentration should be monitored continuously. New developments in sampling techniques and biosensor technology make such monitoring feasible. Sampling of blood constituents via a microdialysis probe or continuous ultrafiltration of venous blood (at a rate of $0.1-1 \mathrm{ml} / \mathrm{minute}$ ) have been described (Chapter 2), ${ }^{(84)}$ while the continuous measurement of analytes such as FABP would be possible with an on-line biosensor based on immuno-displacement (Chapter 4). ${ }^{(85)}$ 


\subsection{Conclusions}

The early diagnosis of acute coronary syndromes is important because it may improve patient treatment and reduce complications. Biochemical markers of myocardial cell damage continue to be important tools for differentiating patients with AMI from those without AMI, because specific ST-segment changes in the admission ECG remain absent in a great number of patients with AMI. ${ }^{(3,6)} \mathrm{FABP}$ is a novel biochemical marker that shows release characteristics from injured myocardium and elimination rates from plasma that are similar to those of myoglobin, which presently is regarded as the preferred early plasma marker of cardiac injury. ${ }^{(86-89)}$ Experimental studies indicate that this resemblance relates to the similar molecular masses of FABP $(14.5 \mathrm{kDa})$ and myoglobin $(17.6 \mathrm{kDa})$. All clinical studies with patients suspected of having AMI and studying both FABP and myoglobin have revealed a superior performance of FABP over myoglobin for the early detection of AMI. This finding most likely relates to marked differences in tissue contents of FABP and myoglobin in cardiac and skeletal muscles that result in a relatively low upper reference concentration in plasma for FABP compared with that for myoglobin. As a result, plasma FABP displays a sensitivity for detection of myocardial injury that is similar to that of TnT or TnI, as in patients with AMI they each are elevated up to 20 - to 40 -fold above their respective discriminator values, which is markedly higher than that of myoglobin (Fig. 3.1).

Limitations of the use of FABP as a diagnostic plasma marker in the clinical setting include 1) the fact that it is not strictly cardiospecific, 2) the relatively small diagnostic window, which extends to only 24 to 30 hours after the onset of chest pain, and 3) its elimination from plasma mainly by renal clearance, possibly causing falsely high values in case of kidney malfunction. These latter drawbacks can, however, be overcome by the simultaneous measurement in plasma of a late marker such as TnT or $\mathrm{TnI}$ and assay of plasma creatinine to identify patients with renal insufficiency and to calculate a corrected FABP concentration. It is important to note that these same limitations also apply to myoglobin, which is now recommended by both the National Academy of Clinical Biochemistry (NACB) Committee on Standards of Laboratory Practice and the International Federation of Clinical Chemistry (IFCC) Committee on Standardization of Markers of Cardiac Damage as the preferred early marker of MI, to be used in combination with cardiac TnT or cardiac TnI. ${ }^{(86,87)}$ Despite the recognition that, to date, relatively few centers have investigated the performance of FABP for early diagnosis of AMI, the uniformly observed superiority of FABP over myoglobin indicates that the optimal set of biochemical markers of muscle necrosis for assessment of acute coronary syndromes may be FABP together with cardiac TnT or cardiac TnI. ${ }^{(89)}$

\subsection{References}

1. Ryan TJ, Antman EM, Brooks NH, Califf RM, Hillis LD, et al. 1999 Update: ACC/AHA guidelines for the management of patients with acute myocardial infarction: Executive summary and recommendations. Circulation 1999;100:1016-30.

2. Alpert JS, Thygesen K, Rydén L, Garson A. Myocardial infarction redefined-a consensus document of The Joint European Society of Cardiology/ American College of Cardiology 
Committee for the redefinition of myocardial infarction. J Am Coll Cardiol 2000;36:95969.

3. Smith SC, Dove JT, Jacobs AK, Kennedy JW, Kereiakes D, et al. ACC/AHA guidelines for percutaneous coronary intervention-executive summary. J Am Coll Cardiol 2001;37: 2215-39.

4. Adams JE, Abendschein DR, Jaffe AS. Biochemical markers of myocardial injury. Is MB creatine kinase the choice for the 1990s? Circulation 1993;88:750-63.

5. Christenson RH, Azzazy HME. Biochemical markers of the acute coronary syndromes. Clin Chem 1998;44:1855-64.

6. Mair J. Progress in myocardial damage detection. New biochemical markers for clinicians. Crit Rev Clin Lab Sci 1997;34:1-66.

7. Glatz JFC, van Bilsen M, Paulussen RJA, Veerkamp JH, van der Vusse GJ, et al. Release of fatty acid-binding protein from isolated rat heart subjected to ischemia and reperfusion or to the calcium paradox. Biochim Biophys Acta 1988;961:148-52.

8. Glatz JFC, van der Vusse GJ. Cellular fatty acid-binding proteins. Their function and physiological significance. Prog Lipid Res 1996;35:243-82.

9. Storch J, Thumser EA. The fatty acid transport function of fatty acid-binding proteins. Biochim Biophys Acta 2000;1486:28-44.

10. Banaszak L, Winter N, Xu Z, Bernlohr DA, Cowan S, et al. Lipid binding proteins: a family of fatty acid and retinoid transport proteins. Adv Protein Chem 1994;45:89-151.

11. Young AC, Scapin G, Kromminga A, Patel SB, Veerkamp JH, et al. Structural studies on human muscle fatty acid binding protein at $1.4 \mathrm{~A}$ resolution: Binding interactions with three C18 fatty acids. Structure 1994;2:523-34.

12. Schreiber A, Specht B, Pelsers MMAL, Glatz JFC, Borchers T, et al. Recombinant human heart-type fatty acid-binding protein as standard in immunochemical assays. Clin Chem Lab Med 1998;36:283-8.

13. Kragten JA, van Nieuwenhoven FA, van Dieijen-Visser MP, Theunissen PHHM, Hermens WT, et al. Distribution of myoglobin and fatty acid-binding protein in human cardiac autopsies. Clin Chem 1996;42:337-8.

14. van Nieuwenhoven FA, Kleine $\mathrm{AH}$, Wodzig KWH, Hermens WT, Kragten JA, et al. Discrimination between myocardial and skeletal muscle injury by assessment of the plasma ratio of myoglobin over fatty acid-binding protein. Circulation 1995;92:2848-54.

15. Yoshimoto K, Tanaka T, Somiya K, Tsuji R, Okamoto F, et al. Human heart-type cytoplasmic fatty acid-binding protein as an indicator of acute myocardial infarction. Heart Vessels 1995;10:304-9.

16. van Breda E, Keizer HA, Vork MM, Surtel DA, de Jong YF, et al. Modulation of fatty acid-binding protein content of rat heart and skeletal muscle by endurance training and testosterone treatment. Eur J Physiol 1992;421:274-79.

17. Glatz JFC, van Breda E, Keizer HA, de Jong YF, Lakey JR, et al. Rat heart fatty acidbinding protein content is increased in experimental diabetes. Biochem Biophys Res Commun 1994;199:639-46.

18. Vork MM, Trigault N, Snoeckx LHEH, Glatz JFC, van der Vusse GJ. Heterogeneous distribution of fatty acid-binding protein in the hearts of Wistar Kyoto and Spontaneously Hypertensive rats. J Mol Cell Cardiol 1992;24:317-21.

19. Glatz JFC, Storch J. Unraveling the significance of cellular fatty acid-binding proteins. Curr Opinion Lipidol 2001;12:267-74.

20. Schaap FG, Binas B, Danneberg H, van der Vusse GJ, Glatz JFC. Impaired long-chain fatty acid utilization by cardiac myocytes isolated from mice lacking the heart-type fatty acid binding protein gene. Circ Res 1999;85:329-37. 
21. van der Lee KAJM, Vork MM, de Vries JE, Willemsen PH, Glatz JFC, et al. Long-chain fatty acid-induced changes in gene expression in neonatal cardiac myocytes. $\mathrm{J}$ Lipid Res 2000;41:41-7.

22. Wolfrum C, Borrmann CM, Börchers T, Spener F. Fatty acids and hypolipidemic drugs regulate peroxisome proliferator-activated receptors alpha- and gamma-mediated gene expression via liver fatty acid-binding protein. Proc Natl Acad Sci USA 2001;98:2323-8.

23. Wodzig KWH, Pelsers MMAL, van der Vusse GJ, Roos W, Glatz JFC. One-step enzymelinked immunosorbent assay (ELISA) for plasma fatty acid-binding protein. Ann Clin Biochem 1997;34:263-8.

24. Ohkaru Y, Asayama K, Ishii H, Nishimura S, Sunahara N. Development of a sandwich enzyme-linked immunosorbent assay for the determination of human heart type fatty acidbinding protein in plasma and urine by using two different monoclonal antibodies specific for human heart fatty acid-binding protein. J Immunol Meth 1995;178:99-111.

25. Knowlton AA, Burrier RE, Brecher P. Rabbit heart fatty acid-binding protein. Isolation, characterization, and application of a monoclonal antibody. Circ Res 1989;165:981-8.

26. Katrukha A, Bereznikova A, Filatov V, et al. Development of sandwich time-resolved immunofluorometric assay for the quantitative determination of fatty acid-binding protein (FABP). Clin Chem 1997;43:S106(abstract).

27. Roos W, Eymann E, Symannek M, Duppenthaler J, Wodzig KW, et al. Monoclonal antibodies to human heart fatty acid-binding protein. J Immunol Meth 1995;183:149-53.

28. Robers M, van der Hulst FF, Fischer MAJG, Roos W, Salud CE, et al. Development of a rapid microparticle-enhanced turbidimetric immunoassay for plasma fatty acid-binding protein, an early marker of acute myocardial infarction. Clin Chem 1998;44:1564-7.

29. Sanders GT, Schouten Y, de Winter RJ, et al. Evaluation of human heart type fatty acidbinding protein assay for early detection of myocardial infarction. Clin Chem 1998;44:A132(abstract).

30. Ghani F, Wu AHB, Graff L, Petry C, Armstrong G, et al. Role of heart-type fatty acidbinding protein in early detection of acute myocardial infarction. Clin Chem 2000;46:7189.

31. Siegmann-Thoss C, Renneberg R, Glatz JFC, Spener F. Enzyme immunosensor for diagnosis of myocardial infarction. Sensors Actuators 1996;30:71-6.

32. Schreiber A, Feldbrügge R, Key G, Glatz JFC, Spener F. An immunosensor based on disposable electrodes for rapid estimation of fatty acid-binding protein, an early marker of myocardial infarction. Biosens Bioelectr 1997;12:1131-7.

33. Renneberg R, Cheng S, Kaptein WA, McNeil CJ, Rishpon J, et al. Novel immunosensors for rapid diagnosis of acute myocardial infarction: a case report. Adv Biosens 1999;4:24172.

34. Key G, Schreiber A, Feldbrügge R, McNeil CJ, Jorgensen P, et al. Multicenter evaluation of an amperometric immunosensor for plasma fatty acid-binding protein: an early marker for acute myocardial infarction. Clin Biochem 1999;32:229-31.

35. Robers M, Rensink IJAM, Hack CE, Aarden LA, Reutelingsperger CP, et al. A new principle for rapid immunoassay of proteins based on in situ precipitate-enhanced ellipsometry. Biophys J 1999;76:2769-76.

36. Watanabe T, Ohkubo Y, Matsuoka H, Kimura H, Sakai Y, et al. Development of a simple whole blood panel test for detection of human heart-type fatty acid-binding protein. Clin Biochem 2001;34:257-63.

37. Tanaka T, Hirota Y, Sohmiya K, Nishimura S, Kawamura K. Serum and urinary human heart fatty acid-binding protein in acute myocardial infarction. Clin Biochem 1991;24:195201. 
38. Kleine $\mathrm{AH}$, Glatz JFC, van Nieuwenhoven FA, et al. Release of heart fatty acid-binding protein into plasma after acute myocardial infarction in man. Mol Cell Biochem 1992;116:155-62.

39. Tsuji R, Tanaka T, Sohmiya K, Hirota Y, Yoshimoto K, et al. Human heart-type cytoplasmic fatty acid-binding protein in serum and urine during hyperacute myocardial infarction. Int J Cardiol 1993;41:209-17.

40. Hermens WT, Pelsers MMAL, Mullers-Boumans ML, de Zwaan C, Glatz JFC. Combined use of markers of muscle necrosis and fibrinogen conversion in the early differentiation of myocardial infarction and unstable angina. Clin Chem 1998;44:890-2.

41. Wodzig KWH, Kragten JA, Hermens WT, Glatz JFC, van Dieijen-Visser MP. Estimation of myocardial infarct size from plasma myoglobin or fatty acid-binding protein. Influence of renal function. Eur J Clin Chem Clin Biochem 1997;35:191-8.

42. de Groot MJM, Wodzig KWH, Simoons ML, Glatz JFC, Hermens WT. Measurement of myocardial infarct size from plasma fatty acid-binding protein or myoglobin, using individually estimated clearance rates. Cardiovasc Res 1999;44:315-24.

43. Kragten JA, Hermens WT, van Dieijen-Visser MP. Cardiac troponin T release into plasma after acute myocardial infarction: Only fractional recovery compared with enzymes. Ann Clin Biochem 1996;33:314-23.

44. Hermens WT. Mechanisms of protein release from injured heart muscle. Dev Cardiovasc Med 1998;205:85-98.

45. van Nieuwenhoven FA, Musters RJP, Post JA, Verkleij AJ, van der Vusse GJ. Release of proteins from isolated neonatal rat cardiac myocytes subjected to simulated ischemia or metabolic inhibition is independent of molecular mass. J Mol Cell Cardiol 1996;28:142934.

46. Katrukha AG, Bereznikova AV, Esakova TV, Pettersson K, Lovgren T, et al. Troponin I is released in bloodstream of patients with acute myocardial infarction not in free form but as complex. Clin Chem 1997;43:1379-85.

47. McDonough JL, Arrell DK, van Eyk JE. Troponin I degradation and covalent complex formation accompanies myocardial ischemia/reperfusion injury. Circ Res 1999;84:9-20.

48. Górski J, Hermens WT, Borawski J, Mysliwiec M, Glatz JFC. Increased fatty acid-binding protein concentration in plasma of patients with chronic renal failure. Clin Chem 1997;43:193-5.

49. Nayashida N, Chihara S, Tayama E, Akasu K, Kai E, et al. Influence of renal function on serum and urinary heart fatty acid-binding protein levels. J Cardiovasc Surg 2001;42:73540.

50. Ishii J, Wang $\mathrm{JH}$, Naruse $\mathrm{H}$, Taga $\mathrm{S}$, Kinoshita $\mathbf{M}$, et al. Serum concentrations of myoglobin vs human heart-type cytoplasmic fatty acid-binding protein in early detection of acute myocardial infarction. Clin Chem 1997;43:1372-8.

51. Glatz JFC, van der Vusse GJ, Simoons M, Kragten JA, van Dieijen-Visser MP, et al. Fatty acid-binding protein and the early detection of acute myocardial infarction. Clin Chim Acta 1998;272:87-92.

52. Pelsers MMAL, Chapelle JP, Knapen M, Vermeer C, Muijtjens AM, et al. Influence of age and sex and day-to-day and within-day biological variation on plasma concentrations of fatty acid-binding protein and myoglobin in healthy subjects. Clin Chem 1999;45:441-3.

53. Glatz JFC, Haastrup B, Hermens WT, et al. Fatty acid-binding protein and the early detction of acute myocardial infarction: the EUROCARDI multicenter trial. Circulation 1997;96:I-215(abstract).

54. Kristensen SR, Haastrup B, Hørder M, et al. Fatty acid-binding protein: a new early marker of AMI. Scand J Clin Lab Invest 1996;56:36-37 (abstract). 
55. Okamoto F, Sohmiya K, Ohkaru Y, Kawamura K, Asayama K, et al. Human heart-type cytoplasmic fatty acid-binding protein (H-FABP) for the diagnosis of acute myocardial infarction. Clinical evaluation of $\mathrm{H}-\mathrm{FABP}$ in comparison with myoglobin and creatine kinase isoenzyme MB. Clin Chem Lab Med 2000;38:231-8.

56. Panteghini M, Bonora R, Pagani $\mathrm{F}$, et al. Heart fatty acid-binding protein in comparison with myoglobin for the early detection of acute myocardial infarction. Clin Chem 1997;43:S157(abstract).

57. Abe $S$, Saigo $M$, Yamashita $T$, et al. Heart fatty acid-binding protein is useful in early and myocardial-specific diagnosis of acute myocardial infarction. Circulation 1996;94:I323(abstract).

58. Hamm CW, Ravkilde J, Gerhardt W, Jorgensen P, Peheim E, et al. The prognostic value of serum troponin $\mathrm{T}$ in unstable angina. N Engl J Med 1992;327:146-50.

59. Ravkilde J, Hørder M, Gerhardt W, Ljungdahl L, Pettersson T, et al. Diagnostic performance and prognostic value of serum troponin $\mathrm{T}$ in suspected acute myocardial infarction. Scand J Clin Lab Invest 1993;53:677-83.

60. Katrukha A, Bereznekiva A, Filatov V, et al. Improved detection of minor ischemic cardiac injury in patients with unstable angina by measurement of cTnI and fatty acid binding protein (FABP). Clin Chem 1999;45:A139(abstract).

61. Fransen EJ, Maessen JG, Hermens WT, Glatz JFC. Demonstration of ischaemiareperfusion injury separate from postoperative infarction in CABG patients. Ann Thoracic Surg 1998;65:48-53.

62. Hayashida N, Chihara S, Akasu K, Oda T, Tayama E, et al. Plasma and urinary levels of heart fatty acid-binding protein in patients undergoing cardiac surgery. Jpn Circ J 2000;64:18-22.

63. Petzold T, Feindt P, Sunderdiek U, Boeken U, Fischer Y, et al. Heart-type fatty acid binding protein (hFABP) in the diagnosis of myocardial damage in coronary artery bypass grafting. Eur J Cardiothor Surg 2001;19:859-64.

64. Glatz JFC, Kleine AH, van Nieuwenhoven FA, Hermens WT, van Dieijen-Visser MP, et al. Fatty acid-binding protein as a plasma marker for the estimation of myocardial infarct size in humans. Br Heart J 1994;71:135-40.

65. Hermens WT, van der Veen FH, Willems GM, Mullers-Boumans ML, Schrijvers-vanSchendel A, et al. Complete recovery in plasma of enzymes lost from the heart after permanent coronary occlusion in the dog. Circulation 1990;81:649-59.

66. van der Laarse A. Rapid estimation of myocardial infarct size. Cardiovasc Res 1999;44:247-8.

67. Ishii J, Nagamura Y, Nomura M, Wang JH, Taga S, et al. Early detection of successful coronary reperfusion based on serum concentration of human heart-type cytoplasmic fatty acid-binding protein. Clin Chim Acta 1997;262:13-27.

68. de Lemos JA, Antman EM, Morrow D, Llevadot J, Giugliano RP, et al. Heart-type fatty acid binding protein as a marker of reperfusion after thrombolytic therapy. Clin Chim Acta 2000;298:85-97.

69. de Groot MJM, Muijtjens AMM, Simoons ML, Hermens WT, Glatz JFC. Assessment of coronary reperfusion in patients with myocardial infarction using fatty acid binding protein concentrations in plasma. Heart 2001;85:278-85.

70. Setsuta K, Arao M, Miyatake Y, Imai T. Elevated levels of heart type fatty acid binding protein in patients with chronic heart failure. Circulation 1999;100:I-649(abstract).

71. Komamura K, Ohkaru Y, Asayama K, et al. Heart-type fatty acid binding protein: An important predictor of cardiac events in heart failure. J Card Fail 1999;5:19(abstract). 
72. Missov E, Mair J. A novel biochemical approach to congestive heart failure: Cardiac troponin T. Am Heart J 1999;138:95-9.

73. Kleine AH, Glatz JFC, Havenith MG, et al. Immunohistochemical detection of very recent myocardial infarctions in man with antibodies against heart type fatty acid-binding protein. Cardiovasc Pathol 1993;2:63-9.

74. Watanabe K, Wakabayashi H, Veerkamp JH, Ono T, Suzuki T. Immunohistochemical distribution of heart-type fatty acid-binding protein immunoreactivity in normal human tissues and in acute myocardial infarct. J Pathol 1993;170:59-65.

75. Ortmann C, Pfeiffer H, Brinkmann B. A comparative study on the immunohistochemical detection of early myocardial damage. Int J Legal Med 2000;113:215-20.

76. Fesmire FM. Delta CK-MB outperforms delta troponin I at 2 hours during the ED rule out of acute myocardial infarction. Am J Emerg Med 2000;18:1-8.

77. de Winter RJ, Bholasingh R, Nieuwenhuijs AB, Koster RW, Peters RJ, et al. Ruling out acute myocardial infarction early with two serial creatine kinase-MB mass determinations. Eur Heart J 1999;20:967-72.

78. Noble MI. Can negative results for protein markers of myocardial damage justify discharge of acute chest pain patients after a few hours in hospital? Eur Heart J 1999;20:925-7.

79. Haastrup B. Application of biochemical markers for early diagnosis and treatment in acute myocardial ischemia. Odense: University of Southern Denmark; 2000. PhD thesis

80. Haastrup B, Gill S, Kristensen SR, Jorgensen PJ, Glatz JFC, et al. Biochemical markers of ischaemia for the early identification of acute myocardial infarction without ST segment elevation. Cardiology 2000;94:254-61.

81. Jesse RL, Kontos MC. Evaluation of chest pain in the emergency department. Curr Problems Cardiol 1997;22:149-236.

82. Merlini PA, Bauer KA, Oltrona L, Ardissino D, Cattaneo M. Persistent activation of coagulation mechanism in unstable angina and myocardial infarction. Circulation 1994;90:61-8.

83. Carville DGM, Dimitrijevic N, Walsh M, Digirolamo T, Brill EM, et al. Thrombus precursor protein (TpP): Marker of thrombosis early in the pathogenesis of myocardial infarction. Clin Chem 1996;42:1537-41.

84. Kaptein WA, Zwaagstra JJ, Venema K, Korf J. Continuous ultrasolw microdialysis and ultrafilrtration for subcutaneous sampling as demonstrated by glucose and lactate measurements in rats. Anal Chem 1998;70:4696-4700.

85. Kaptein WA, Korf J, Cheng S, Yang M, Glatz JFC, et al. On-line flow displacement immunoassay for fatty acid-binding protein. J Immunol Meth 1998;217:103-11.

86. Wu AHB, Apple FA, Gibler WB, Jesse RL, Warshaw MM, et al. National Academy of Clinical Biochemistry Standards on Laboratory Practice: Recommendations for the use of cardiac markers in coronary artery diseases. Clin Chem 1999;45:1 104-21.

87. Panteghini M, Apple FS, Christenson RH, Dati F, Mair J, et al. Use of biochemical markers in acute coronary syndromes. IFCC Scientific Division, Committee on Standardization of markers of Cardiac Damage. Clin Chem Lab Med 1999;37:687-93.

88. Storrow $\mathrm{AB}$, Gibler WB. The role of cardiac markers in the emergency department. Clin Chim Acta 1999;284:187-96.

89. Wu AH. Analytical and clinical evaluation of new diagnostic tests for myocardial damage. Clin Chim Acta 1998;272:11-21. 


\section{Biosensors for fatty acid-binding protein, an early plasma marker of myocardial injury.}

Part of this chapter will be published:

van der Voort D, McNeil CJ, Renneberg R, Korf J, Hermens WT, Glatz JFC. Biosensors for fatty acid-binding protein, an early plasma marker of myocardial injury. Sensors and Actuators, in press 


\subsection{Abstract}

Biosensors, especially immunosensors, are of great value for use in a clinical setting, since these are based on antigen-antibody reactions which are highly sensitive and specific. Furthermore, it becomes more and more important to measure specific compounds in biological matrices, such as blood or plasma, in a fast continuous manner. Biosensors are therefore suitable for application in high throughput systems. Untill now only enzyme-biosensors have been developed for such systems. Continuous measurement of proteins could be established by use of the principle of displacement. This mini-review also presents the current status of biosensors for fatty acid-binding protein (FABP), a protein which is released very rapidly into the bloodstream after myocardial injury, and proven applicable as a plasma marker for acute myocardial injury. The various types of immunosensors for FABP including their advantages and limitations are described.

\subsection{Introduction}

During the last decade there has been an explosive growth in biosensor reports and it was in 1999 when the International Union of Pure and Applied Chemistry (IUPAC) proposed a very stringent definition of a biosensor. ${ }^{(1-3)}$ They defined: "A biosensor is a selfcontained integrated device which is capable of providing specific quantitative or semiquantitative analytical information using a biological recognition element (biochemical receptor) which is in direct contact with a transducer element". Hence, they excluded bioanalytical systems which require additional processing steps, and bioprobes which are disposable after single use, or not suitable for continuous monitoring of the analyte. ${ }^{(4)}$ The ideal biosensor should have (i) the ability to detect selectively and to quantify the antigen, within the required concentration range and within a reasonable time, (ii) the capacity to generate a signal following the binding without externally added reagents, (iii) the capacity for repeated or continuous measurements with the same device, and (iv) the ability to detect the specific binding of the antigen in real samples. ${ }^{(5)}$ The first en third requirement are also applicable for immunoassays, however, the second and fourth are specific for biosensors. In practice, the definition for biosensors is not used very stringently, and therefore we restrict this review to the description of quantitative biosensors and bioassays for human fatty acid-binding protein (FABP) and will not further mention qualitative biosensors like dipsticks or immuno-spot methods.

Biosensors can be classified by bioreceptor-type or transducer-type. A bioreceptor is a biological molecular species (e.g., an antibody, an enzyme, a protein, or a nucleic acid) or a living biological system (e.g., cells, tissue, or whole organisms) that utilizes a biochemical mechanism for recognition. The bioreceptors are responsible for binding the analyte of interest to the sensor for subsequent measurement. Therefore, they are the key to specificity for biosensor technologies. The most common forms of bioreceptor recognition mechanisms can be classified in five major categories including (i) antibody/antigen interactions, (ii) nucleic acid/DNA interactions, (iii) enzymatic interactions, (iv) cellular structure/cell interactions (i.e., micro-organisms, proteins) and (v) interactions using bio-mimetic materials (i.e., synthetic bioreceptors) ${ }^{(6)}$ 
Classification of biosensors based on transducer-type includes (i) optical measurements (i.e., luminescence, light absorption, surface plasmon resonance, etc.), (ii) electrochemical measurements and (iii) mechanical measurements (i.e., surface acoustic wave, microbalance etc.). Biosensors that include transducers based on integrated circuit microchips are often referred to as biochips. In general, a biochip consists of an array of individual biosensors that can be individually monitored and generally are used for the analysis of multiple analytes. ${ }^{(6,7)}$

Immunosensors are biosensors that are aimed to detect the specific interaction of an antigen and an antibody thus changing the properties of either or both molecules or initiating an immunochemical reaction at the surface of an element known as the transducer. The focus of the present report is on some general aspects, and the classification and clinical potential of immunosensors, in particular those based on the displacement principle. As a clinical useful example of such an immunosensor, we describe the detection of a well-documented plasma biomarker of acute myocardial infarction (AMI).

AMI accounts for a major part of mortality from coronary heart disease (CHD), which is the world's number one cause of death. ${ }^{(8)}$ Recently, redefined criteria for AMI have established measurement of biomarkers of myocardial necrosis in the diagnosis of myocardial infarction. ${ }^{(9)}$ Although cardiac troponins are the only biomarkers for AMI with absolute cardiac specificity, they appear relatively late in the blood stream ( $6 \mathrm{~h}$ after onset of symptoms). For early diagnosis of AMI, repeated measurements of an early biomarker are preferable. ${ }^{(10,11)}$ Since the human heart-type fatty acid-binding protein (FABP) is proposed as an early plasma marker for AMI, several attempts have been made to develop a biosensor for detection of FABP in plasma. ${ }^{(12)}$ Chan et al. ${ }^{(13)}$ recently described some biosensors and the most important immunoassays for FABP. The present overview will be focused on the FABP biosensors, and on the recent developments in our lab concerning the development of an on-line continuous immunoassay device based on the principle of displacement for FABP measurements in plasma.

\subsection{Immunoassays}

The first widely used immunoassay method utilized radioactive labels and is called the radioimmunoassay (RIA). The RIA principle was first described by Berson et al. ${ }^{(14)}$ RIAs have been applied in agricultural sciences, clinical chemistry, environmental monitoring, forensic science, molecular epidemiology and pharmacology. However, its usefulness is limited by several shortcomings, including the cost of instrumentation, the limited shelf life of radioisotopes, and the potential deleterious biological effects inherent to radioactive materials. Due to these shortcomings, other techniques and instrumentation were developed. In the 1980's advances in spectrochemical instrumentation, laser miniaturization, biotechnology and fiber-optic research contributed in assay developments. Nowadays, the majority of routine immunoassays in laboratory settings consist of those that use enzyme labels. The common technique in this group is the enzyme-linked immunosorbent assay (ELISA). The most frequently used techniques in the clinical setting are based on chemi-luminescent methods, because these are more rapid and easier to perform. 
The advances in development as mentioned above for immunoassays, also lead to several immunosensor designs including amperometric (i.e., biotin ${ }^{(15)}$ and cocaine ${ }^{(16)}$ ), potentiometric (i.e., $\operatorname{IgG}^{(1)}$ and thyrotrophin ${ }^{(18)}$ ), piezoelectric (i.e., herpes ${ }^{(19)}$ and $\mathrm{HIV}^{(20)}$ ), surface plasmon resonance (i.e., morphine ${ }^{(21)}$ and $\mathrm{FABP}^{(22)}$ ), fluorescence (i.e., $\mathrm{LDH}^{(23)}$ and myoglobin $\left.{ }^{(24)}\right)$, optical ${ }^{(25)}$ and acoustic designs. ${ }^{(26,27)}$

\subsection{Biosensors based on antigen/antibody interactions.}

As already mentioned, immunosensors are biosensors that detect the binding of an antigen to its specific antibody by coupling the immunochemical reaction to the surface of a transducer. Essential of immunosensors is the specificity of the molecular recognition of antigens by antibodies to form a stable complex which is similar to the immunoassay methodology. ${ }^{(28)}$

For an immune response to be produced against a particular molecule, a certain molecular size and complexity are needed. ${ }^{(6)}$ In fact, in all immunosensor systems, as well as in immunoassays, the specificity for the measurement of analytes is dependent on the application of binding molecules.

Immunosensors can be categorized in direct and indirect devices, based on the immunoassay format they use. ${ }^{(5)}$ An indirect immunosensor uses a separate labeled species that is detected after binding of the analyte to the antibody by, e.g., fluorescence or luminescence (i.e., a heterogeneous immunoassay). A direct immunosensor detects the binding between antigen and antibody by a change in potential difference, current, resistance, mass, heat, or optical properties (i.e., a homogeneous immunoassay). Only direct immunosensors are capable of real-time monitoring of the antigen-antibody reaction. ${ }^{(29)}$

\subsection{Biosensors and their potential for clinical application}

There is a great opportunity for introducing immunosensor devices, since clinical diagnostics represent a huge, well-established and important analytical field. ${ }^{(30)}$ Moreover, the main reason to select immunochemical methods for clinical analysis is the high sensitivity and specificity of immuno-reactions.

Immunosensors are proposed to be used in the diagnosis of several illnesses such as hepatitis B, HIV, herpes, staphylococcus aureas, prostate, and leukemia by direct measurement of the biological compounds responsible for them. Also the assay of IgG, red blood cells, DNA, thyroid hormones, human T-lymphocytes, myoglobin and fatty acids is very important in clinical analysis. Besides the sensitivity and specificity also the possibility to measure biological compounds in a fast continuous manner would make biosensors very useful in clinical practice. Biosensors could therefore be developed in high throughput systems. Till now only enzyme-biosensors, like glucose and lactate, are developed for these systems. 


\subsection{Biochemical on-line monitoring}

For the development of a biosensor, which can be used for on-line measurements, technical as well as physiological aspects have to be considered. The technical aspects of an on-line biosensor can be divided into three parts, (i) contact with the body fluid, (ii) specific recognition of the analyte in the matrix (i.e., the medium containing the analyte), and (iii) the translation of the recognition into a quantitative signal. The most important physiological aspects are the choice of the analyte and the site in the body where this analyte has to be measured.

For continuous (bio)chemical monitoring, direct contact with the matrix is necessary and two methodologically different invasive approaches can be applied. The first approach, direct in vivo measurement at the sampling site inside the body (as utilized in many (bio)sensors) has several technical limitations. Among these problems are in vivo calibration, stability and biocompatibility. In addition, the probes are often rather large, thus creating artefacts in the surrounding tissue. ${ }^{(31,32)}$ The second approach consists in continuous (on-line) sampling, preferably directly coupled to an analysis system. ${ }^{(33,34)}$ For continuous sampling two methods are widely used, namely microdialysis and ultrafiltration. ${ }^{(35-38)}$ Both techniques are described in detail in Chapter 2.

The analysis system of the on-line sensor has to employ a continuous detection method. For several metabolites specific enzymes are used to produce electrochemically active agents. As the enzymes continuously produce these agents, they can also be continuously monitored. For immunodetection, the antigen or antibody is labeled. So far, on-line continuous biosensors have been only described for the detection of metabolite molecules that can be specifically converted by enzymes. However, the only immunochemical detection system allowing an on-line measurement of proteins is called displacement. The principle of displacement and the recent developments in application for continuous FABP measurements will be described in the following section.

\subsection{Displacement}

Displacement can be defined as the active breakage of the binding between antigen and antibody when free antigen is added. ${ }^{(39)}$ In a flow displacement assay, the displaced antigen or antibody will be taken downstream of the displacement unit where it subsequently can be measured, depending on the label which is attached to the displaced antigen or antibody (see Figure 4.1). Such a flow displacement assay generally is performed in a column, in which either antibodies or antigens are immobilized onto the packing material, such as beads or Sepharose. ${ }^{(40-42)}$ After saturation of the immobilized antibody or antigen with labeled counterparts (the interacting respective antigen or antibody), the actual displacement consists of the analyte perfusion stream over these antigen-antibody complexes and results in the release of the labeled molecules from the immobilized site, which is followed by their measurement downstream. 


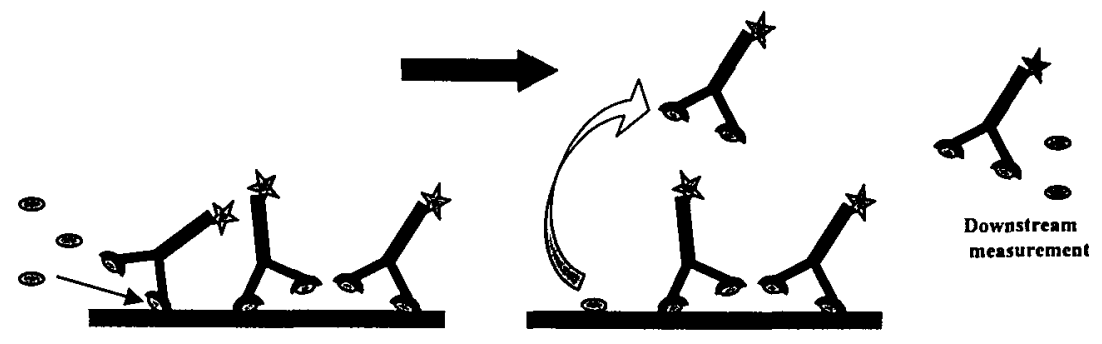

Figure 4.1

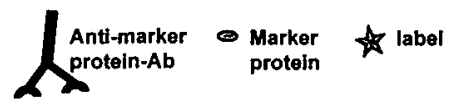

Schematic presentation of the principle of immunodisplacement for detection of marker proteins. Marker proteins will displace labeled antibodies from their binding to surface-bound antigen (left panel), after which the labeled antibodies are assayed downstream (right panel). The amount of labeled antibody thus displaced is proportional to the concentration of marker protein in the effluent sample.

Flow displacement immunoassays can be divided into two categories. In the most frequently used set-up, labeled antigens (or antigen analogues), associated to immobilized antibodies, are placed in a flow-system. When antigens in the sample run through this flow-system, some of them will displace labeled analogues from the antibodies, thereby raising the concentration of the label downstream. This label can be analyzed, directly or indirectly, by colorimetric ${ }^{(43)}$, fluorometric ${ }^{(44)}$ or electrochemical ${ }^{(45,46)}$ detection. In the other displacement set-up, the analyte is immobilized to the matrix, and when a labeled antibody is bound, it can be displaced by the analyte in the sample. Freytag published a patent describing such a displacement system. ${ }^{(47)}$ Warden et al. described a displacement assay for T-2 toxin while Kaptein et al. described, for the first time, the displacement principle for FABP in buffer. ${ }^{(47-49)}$

In our group we are interested in the fastest appearing and most sensitive biomarker in the blood stream after onset of AMI symptoms, namely FABP, and we therefore used the displacement principle in the development of an on-line continuous measuring device which is described in Chapters 5 and 6.

\section{Fatty acid-binding protein}

As already outlined in Chapter 3, cytoplasmic fatty acid-binding protein (FABP), which functions as intracellular fatty acid carrier, was suggested as plasma marker of AMI in $1988 .{ }^{(12)}$ It is a small $(14.5 \mathrm{kD})$ soluble protein that is not cardio-specific but is expressed in relatively small amounts in skeletal muscles. The release and plasma kinetics of FABP closely resemble those of myoglobin, however, several clinical studies have revealed a significantly better performance of FABP over myoglobin for early AMI detection as well as early estimation of infarct size (see Chapter 3). ${ }^{(50-53)}$ Preliminary evidence suggests that FABP also detects minor myocardial injury, and thus may serve as 
prognostic marker for patients with unstable angina pectoris and for those with heart failure.

For the measurement of FABP several immunoassays and immunosensors have been developed. An overview of the immunosensors is given in Table 4.1. The different biosensors are displayed in chronological order and the main features are given. Each FABP-immunosensor will briefly be described below.

Table 4.1 Overview of biosensors for fatty acid-binding protein and their main characteristics.

\begin{tabular}{|c|c|c|c|c|c|}
\hline $\begin{array}{l}\text { First } \\
\text { Author }\end{array}$ & Sensor type & $\begin{array}{c}\text { Measurement } \\
\text { solution }\end{array}$ & $\begin{array}{c}\text { Detection } \\
\text { limit for } \\
\text { FABP (ng/ml) }\end{array}$ & $\begin{array}{l}\text { Assay } \\
\text { time } \\
\text { (min) }\end{array}$ & Remarks \\
\hline $\begin{array}{l}\text { Siegmann- } \\
\text { Thoss et al., } \\
1996^{(54)}\end{array}$ & $\begin{array}{l}\text { Amperometric enzyme } \\
\text { immunosensor }\end{array}$ & PBS buffer & 5 & 27 & $\begin{array}{l}\text {-First FABP sensor } \\
\text {-Capable of } 10 \text { repeated } \\
\text { measurements }\end{array}$ \\
\hline $\begin{array}{l}\text { Kunz et al., } \\
1996^{(22)}\end{array}$ & $\begin{array}{l}\text { Optical immuno-sensor } \\
\text { (planar device versus } \\
\text { a fiber optic device) }\end{array}$ & PBS buffer & 200 & 25 & $\begin{array}{l}20 \text { repeated } \\
\text { measurements }\end{array}$ \\
\hline $\begin{array}{l}\text { Schreiber et } \\
\text { al., } 1997^{(55)}\end{array}$ & $\begin{array}{l}\text { Amperometric } \\
\text { immunosensor }\end{array}$ & Human plasma & 10 & 20 & $\begin{array}{l}\text { Only FABP sensor used } \\
\text { in clinical setting }\end{array}$ \\
\hline $\begin{array}{l}\text { Orban et al., } \\
1998^{(59)}\end{array}$ & Grating coupler sensor & PBS buffer & - & - & No data reported \\
\hline 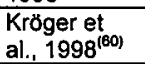 & $\begin{array}{l}\text { Direct optical } \\
\text { immunosensor }\end{array}$ & PBS buffer & 330 & 7 & $\begin{array}{l}10 \text { repeated } \\
\text { measurements }\end{array}$ \\
\hline $\begin{array}{l}\text { Kaptein et } \\
\text { al., } 1998^{(49)}\end{array}$ & Displacement sensor & PBS buffer & 2 & $20-60$ & $\begin{array}{l}\text { Continuous sensor for } \\
\text { FABP measurements in } \\
\text { PBS buffer }\end{array}$ \\
\hline $\begin{array}{l}\text { O'Regan et } \\
\text { al., } 2002^{(44)}\end{array}$ & $\begin{array}{l}\text { Amperometric } \\
\text { immunosensor }\end{array}$ & $\begin{array}{l}\text { PBS buffer and } \\
\text { whole blood }\end{array}$ & 4 & 50 & $\begin{array}{l}\text { Only sensor available for } \\
\text { measurements in whole } \\
\text { blood }\end{array}$ \\
\hline $\begin{array}{l}\text { Van der } \\
\text { Voort et al.. } \\
2003^{(85)}\end{array}$ & $\begin{array}{l}\text { Displacement } \\
\text { immunosensor }\end{array}$ & $\begin{array}{l}\text { PBS buffer and } \\
\text { human plasma }\end{array}$ & 25 & 30 & $\begin{array}{l}\text { Continuous sensor for } \\
\text { FABP measurements in } \\
\text { plasma }\end{array}$ \\
\hline
\end{tabular}

Abbreviations: PBS = phosphate buffered saline, FABP = Fatty acid-binding protein

\subsection{Biosensors for the quantification of fatty acid-binding protein}

\subsubsection{The first FABP biosensor}

The first FABP biosensor was developed by Siegmann-Thoss et al. ${ }^{(54)}$ This amperometric enzyme immunosensor was based on anti-FABP antibodies immobilized on nitrocellulose or activated nylon membranes covering a modified Clark-type oxygen electrode. The electrode reaction is based on the reduction of oxygen, consumed in the reaction of glucose-oxidase, at a platinum cathode. The resulting current was proportional to the oxygen concentration, which in turn was proportional to the activity of the marker enzyme. Using bovine heart-type FABP as a model, both a competition as well as a sandwich principle were tested. The competition principle includes the competition of defined amounts of glucose-oxidase-labeled FABP with free FABP for binding to immobilized capture antibodies. The sandwich principle covers the binding of free FABP to an immobilized capture antibody and to a secondary glucose-oxidase-labeled antibody, forming a sandwich. In both approaches, after addition of glucose, the activity of the enzyme label is determined with the amperometric electrode within minutes. The sandwich principle with monoclonal anti-bovine-FABP antibodies as capture and 
glucose-oxidase-labeled goat-anti-human-FABP antibodies as secondary antibodies appeared to be better for the detection of FABP and was therefore chosen in further studies.

Although this was the first FABP biosensor reported, there were several shortcomings. Firstly, due to contamination risk (open system), the sensor could not be used in a clinical setting. Secondly, the samples were diluted before they could be measured and were rather large $(2 \mathrm{ml})$. Thirdly, experiments were performed in buffer instead of plasma. Due to the marked amounts of protein present in plasma, these can interfere with the reaction on the electrode, and provide under- or overestimated FABP values. Finally, the immunosensor could only be used for ten subsequent measurements, due to increased denaturation of the capture antibodies as a result of the regeneration step with glycine/ $\mathrm{HCl}$. In conclusion, the above-mentioned FABP biosensor is not suitable for clinical use.

\subsubsection{A direct optical immunosensor for FABP}

Kunz et al. developed a direct optical immunosensor for the detection of FABP based on surface plasmon resonance spectroscopy (SPRS). ${ }^{(2)}$ This method allows a visualization of macromolecular interactions in real time without labeling of proteins. These investigators constructed two different SPRS devices, one according to the widely used planar configuration, and the other as a new fiber-optical transducer. Both sensors were coated in the same manner with a specific recognition layer in order to compare their sensitivity and behavior. A competitive immunoassay was used instead of direct detection of the antigen with immobilized antibodies. Advantages from this assay, when compared to the direct detection, are a ten times lower detection limit, a shorter analysis time and a lower amount of antibodies to be used. From testing each condition in both devices it was concluded that the fiber-optical SPRS device is more convenient, and applicable for miniaturization for remote sensing.

The direct optical immunosensor has several limitations. The sensor is temperature dependent and the required sample volume is high $(1 \mathrm{ml})$, which each are drawbacks for use in a clinical setting. Furthermore, the sensor can be used for not more than 20 subsequent measurements due to the glycine/ $\mathrm{HCl}$ in the regeneration step, which affects the recognition layer. Kunz et al. also showed that the signal of the sensor is influenced by lipids and proteins in a real plasma sample, and that these, therefore, have to be eliminated before use. ${ }^{(22)}$ However, washing steps are not desirable for biosensors as stated in the definition for biosensors in $1999 .{ }^{(3)}$ Moreover, the biosensor set-up seems very complicated and not suitable for "simple" use in a clinical setting. Finally, the detection limit of $200 \mathrm{ng} / \mathrm{ml} \mathrm{FABP}$ is not suitable for the detection of small myocardial infarctions.

\subsubsection{The first FABP biosensor applicable in plasma}

There is only one FABP biosensor that has been used in a clinical setting. Schreiber et al. ${ }^{(55)}$ developed the first amperometric immunosensor for rapid estimation of FABP in human plasma samples. Screen-printed graphite working and $\mathrm{Ag} / \mathrm{AgCl}$ reference 
electrodes combined with an immunosandwich procedure for FABP quantification were used (Fig. 4.2, panel A). So-called capture antibodies bound to the electrode surface by adsorption, will trap FABP from the plasma sample. The sandwich is completed by a second monoclonal antibody conjugated with alkaline phosphatase. This enzyme induces a specific reaction, which can be amperometrically measured. In this way, it was possible to measure a plasma sample within $20 \mathrm{~min}$. and FABP could be quantificated in the range of $10-350 \mathrm{ng} / \mathrm{ml}$ (Fig. 4.2, panel B). Validation of the sensor was performed by 8 repeated measurements of normal human plasma spiked with 8 different concentrations of FABP. Each sample revealed recovery rates between 80 and $100 \%$. Intra-assay and inter-assay coefficients of variation (CV) were $10-15 \%$ and $9-16 \%$, respectively.
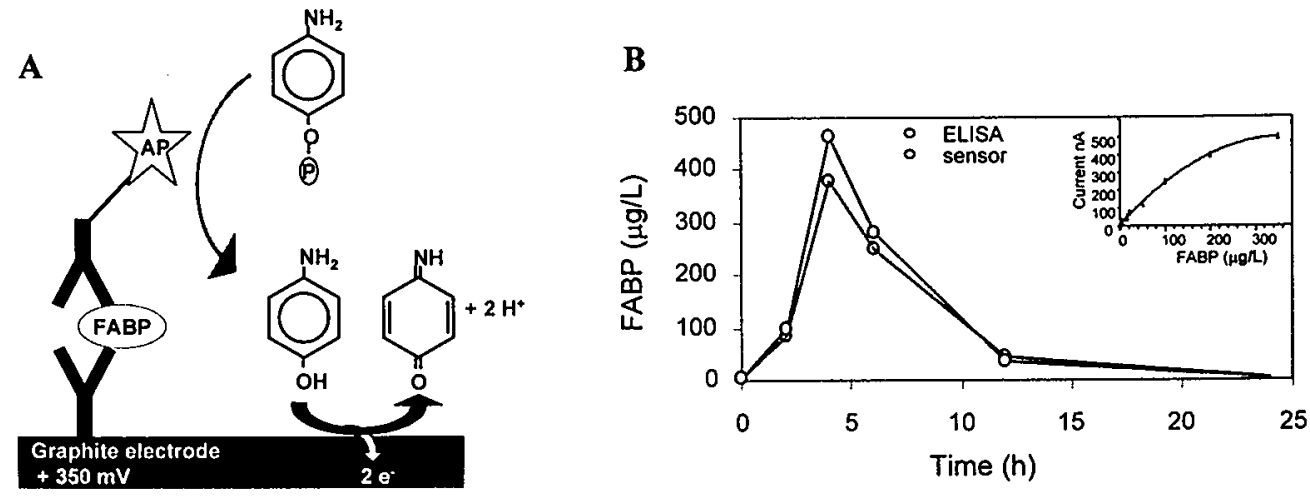

\section{Figure 4.2.}

Panel A. Schematic presentation of the sandwich configuration and substrate conversion path of the amperometric immunosensor of Schreiber et al. ${ }^{(55)}$

Panel B. FABP concentration in plasma from an AMI patient during first $24 \mathrm{~h}$ after onset of AMI symptoms. The plot shows the comparison of the FABP values of this patient measured with their immunosensor (o), and with the reference ELISA $(\bullet)$. The inset represents the calibration-curve for FABP in plasma measured with the immunosensor. Data are means of duplicate determinations within $12 \%$ error. $^{(55)}$

The above-mentioned technique of screen-printing can easily be automated for cost-effective mass production. Because the graphite electrode is stable for at least 3 months, when stored in a refrigerator, large batches can be made in advance. Other advantages of this sensor are the relatively short assay-time of $20 \mathrm{~min}$ and the ability of the sensor to measure undiluted plasma samples with FABP concentrations ranging from $10-350 \mathrm{ng} / \mathrm{ml}$. However, the electrodes could only be used once, which causes this sensor not to be suitable for continuous on-line monitoring.

Despite these limitations, Key et al. reported the first multicenter-trial with this amperometric immunosensor. ${ }^{(56)}$ Four different European hospitals contributed to this study and plasma samples of 20 patients per hospital were measured. The results were compared with those obtained using a reference ELISA as described by Wodzig et al. and with the reference amperometric sensor used in Münster (Germany). ${ }^{(57)}$ The agreement between ELISA and sensor was excellent for FABP concentrations below $400 \mu \mathrm{g} / \mathrm{L}$. Key et al. concluded that the biosensor could be helpful for clinical decision making, as it was 
fast and able to run on-site. Due to overestimation of the FABP concentration in the lower concentration range $(5-15 \mu \mathrm{g} / \mathrm{L})$, it was stated that the detection limit of the sensors should be set at $15 \mu \mathrm{g} / \mathrm{L}$. Nowadays, the detection limit of myocardial injury suggesting acute myocardial infarction is about $6 \mu \mathrm{g} / \mathrm{L} \mathrm{FABP}{ }^{(58)}$ As a result, the sensor would not be able to detect minor infarctions, or distinguish these minor AMI's from unstable angina.

\subsubsection{Grating coupler sensors for the detection of FABP}

In 1998, Orban et al. and Kröger et al. performed surface studies for the development of a direct optical immunosensor for FABP. ${ }^{(59.60)}$ They used the BIOS-1 system based on the input grating coupler principle. ${ }^{(61-63)}$ Generally, this method detects changes in the effective refractive index of a thin planar waveguide due to the adsorption or desorption of proteins onto the waveguide surface. In these particular immunosensors, FABP is coupled to an activated sensor surface. Then, the sample containing anti-FABP antibodies is brought into contact with this surface. Due to the formation of the immuno-complex, the thickness of the protein layer increases, which leads to an increase in effective refractive index of the waveguide. This then is detected by the different incoupling angles of the grating coupler.

Orban et al. revealed technical characteristics of their sensor, including calculation of surface coverage (less than $53 \%$ ) as well as the apparent rate and equilibrium constants determined by applying linearization and the non-linear least square methods. ${ }^{(59)}$ Besides these technical aspects, no detection limit or assay time were determined and the possible use of this sensor for detection of myocardial infarction was not concluded. It is beyond the scope of this review to discuss their results in detail. Further information can be found in their paper.

Kröger et al. tested a direct assay, a sandwich-assay and a competitive assay type for the detection of FABP. ${ }^{(60)}$ The latter gave the best results regarding sensitivity and individual preparation time, and further experiments were performed in this sensor setup. The final response time, when using a flow of $180 \mu \mathrm{l} / \mathrm{min}$, was $7 \mathrm{~min}$., and a detection limit of $330 \mathrm{ng} / \mathrm{ml} \mathrm{FABP}$ was achieved. Although a very rapid assay time was established here, the detection limit was relatively high. However, more important is the fact that the experiments were performed in buffer and not in plasma. Proteins in plasma will nonspecifically bind to the sensor surface and in that way be detected by the direct optical sensor. Therefore, this sensor is not suitable for use in a clinical setting and till now, no data are known concerning the optimisation of this sensor for plasma measurements.

\subsubsection{The first FABP biosensor for quantification in whole blood}

The group of O'Regan reported the first biosensor for the detection of FABP in whole blood. ${ }^{(64)}$ As in Schreiber's sensor, they also used screen-printed carbon electrodes combined with an immunosandwich procedure for FABP quantification. ${ }^{(55)}$ The authors stated that their sensor could measure FABP concentrations in whole blood ranging from 4-250 ng/ml within 50 minutes. ${ }^{(64)}$ Whole blood was spiked with four different FABP concentrations while the samples were also tested with an ELISA method. ${ }^{(57)}$ Importantly, undiluted blood could be used in this sensor. Furthermore, no cross 
reactivity between myoglobin and FABP was found and bilirubin, human serum albumin and the anticoagulant citrate phosphate dextrose (CPD) did not affect the quantification of FABP.

This sensor seems to be very sensitive and applicable for measurements in whole blood. However, the analysis time is too long $(50 \mathrm{~min})$ to take full advantage of FABP as an early marker. Therefore, this sensor can not be used in the emergency room. In addition, the disposable electrodes do not allow continuous measurement, which is another disadvantage.

In conclusion, till now, no FABP biosensor is able to measure the FABP concentrations in plasma or whole blood of patients suspected for an acute myocardial infarction on-line and continuously. As stated above, the ability to continuously monitor a patient in the coronary care unit is of great importance. Therefore, we will briefly describe the method for FABP quantification based on the displacement principle, which allows continuous monitoring.

\subsubsection{On-line continuous displacement assays for FABP}

Kaptein et al. developed an on-line displacement flow immunoassay for FABP in buffer. $^{(49)}$ Displacement columns based on chemically bound FABP and based on antibody bound FABP were compared. Only the column with FABP chemically bound to a sepharose matrix enabled the detection of physiological FABP concentrations of 2-20 $\mu \mathrm{g} / \mathrm{L}$. However, these semi-quantitative results showed a non-linear FABP concentration dependent displacement over the interval from $0-2000 \mu \mathrm{g} / \mathrm{L}$ FABP. Furthermore, the reproducibility of the sensor was not studied and no plasma samples were tested.

Our recent study (Chapter 5) on the principle of displacement for FABP revealed that the semi-continuous method enables the measurement of FABP concentrations in human plasma. ${ }^{(65)}$ The method used was different from the one described by Kaptein et al. ${ }^{(49)}$

To complete the overview of biosensors for FABP (Table 4.1), several characteristics of this displacement assay are also included. The development and characteristics of the sensor are outlined in Chapters 5 and 6.

\subsection{Future outlook}

An on-line continuous monitoring device for the quantification of FABP in plasma is of great value for patients suspected from having an acute myocardial infarction (AMI), and seems feasible especially for post-operative care of patients undergoing cardiac surgery, as they have increased risk of developing an AMI. Although many attempts have been made, no such device yet exists.

The ultimate FABP biosensor is easy to use, allows rapid and sufficiently sensitive monitoring, i.e., allows to distinguish minor infarctions from unstable angina, and is usable for at least several hours of continuous monitoring. Till now, only the principle of displacement is applicable for continuous monitoring devices. Furthermore, in view of the importance of monitoring the physiological status of patients in real-time, the displacement principle is not only useful in a biosensor setup for the detection of 
FABP, but also for the detection of hormones, drugs, other cardiac markers, plasma proteins etc. Further development of such displacement sensors may include several optimization procedures (see Chapter 8).

For bedside monitoring, a slow continuous flow, generated by use of microdialysis or ultrafiltration, is preferable. A sensor that can be placed on the skin or subcutanuously, and is miniaturized to a small device will be advantageous and with modern nanoscale technology such developments are feasible. For instance, a likely future generation of biosensors could include biosensors which use the principle of displacement for continuous measurement miniaturized on a biochip. ${ }^{(66,67)}$ A futuristic example for an on-line biosensor setup for use in a clinical setting is presented in Chapter 8, Fig. 8.4.

\subsection{References}

1. Dong S, Chen X. Some new aspects in biosensors. Rev Molec Biotechnol 2002;82:303-23.

2. Sharma SK, Sehgal N, Kumar A. Biomolecules for development of biosensors and their applications. Curr Applied Physics 2003;3:307-16.

3. Thévenot DR, Toth K, Durst RA, Wilson GS. Electrochemical biosensors: recommended definitions and classification. Biosens Bioelectron 2001;16:121-31.

4. Scheller FW, Wollenberger U, Warsinke A, Lisdat F. Research and development in biosensors. Curr Opin Biotechnol 2001;12:35-40.

5. Gizeli E, Lowe CR. Immunosensors. Curr Opin Biotechnol 1996;7:66-71.

6. Vo-Dinh V, Cullum B. Biosensors and biochips: advances in biological and medial diagnostics. Fresenius J Anal Chem 2000;366:540-51.

7. Stefan RI, van Staden JF, Aboul-Enein HY. Immunosensors in clinical analysis Fresenius J Anal Chem 2000;366:659-68.

8. World Health Organization, World Health Report. Geneva, Switzerland:World Health Organization;2000.

9. Alpert JS, Thygesen K, Rydén L, Garson A. Myocardial infarction redefined-a consensus document of The Joint European Society of Cardiology/American College of Cardiology committee for the redefinition of myocardial infarction. The Joint European Society of Cardiology/ American College of Cardiology Committee. J Am coll Cardiol 2000;36:95969.

10. Fesmire FM. Improved identification of acute coronary syndromes with delta cardiac serum marker measurements during the emergency department evaluation of chest pain patients. Cardiovasc Toxicol 2001;1:117-23.

11. Winter RJ de, Lijmer JG, Koster RW, Hoek FJ, Sanders GT. Diagnostic accuracy of myoglobin concentration for the early diagnosis of acute myocardial infarction. Ann Emerg Med 2000;35:113-20.

12. Glatz JFC, van Bilsen M, Paulussen RJA, Veerkamp JH, van der Vusse GJ, et al. Release of fatty acid-binding protein from isolated rat heart subjected to ischemia and reperfusion or to the calcium paradox. Biochim Biophys Acta 1988;961:148-52.

13. Chan CPY, Cheng WS, Glatz JFC, van der Voort D, Hempel A, et al. Early diagnosis of acute myocardial infarction using immunosensors and immunotests. Anal Lett 2003;36:1987-2004.

14. Berson SA, Yalow RS. Assay of plasma insulin in human subjects by immunological methods. Nature 1959;184:1648-9. 
15. Lu B, Iwuoha EI, Smyth MR, O'Kennedey R. Development of an "electrically wired" amperometric immunosensor for the determination of biotin based on a non-diffusional redox osmium polymer film containing an antibody to the enzyme label horseradish peroxidase. Anal Chim Acta 1997;345:59-66.

16. Suleiman $\mathrm{AA}, \mathrm{Xu} \mathrm{Y}$. An Amperometric Immunosensor for Cocaine. Electroanalysis 1998;10:240-3.

17. Brown DV, Meyerhoff ME. Potentiometric enzyme channelling immunosensor for proteins. Biosens Bioelectron 1991;6:615-22.

18. Lin Z, Shen, Miao Q, Yu R. A thyroid-stimulating hormone immuno-electrode. Anal Chim Acta 1996;325:87-92.

19. Koenig B, Graetzel M. A novel immunosensor for herpes viruses. Anal Chem 1994;66:341-4.

20. Kößlinger C, Drost S, Aberl F, Wolf $\mathrm{H}$. Quartz crystal microbalance for immunosensing. Fresenius J Anal Chem 1994;349:349-54.

21. Sakai G, Ogata K, Uda T, Miura N, Yamazoe N. A surface plasmon resonance-based immunosensor for highly sensitive detection of morphine. Sens Actuators 1998;49:5-12.

22. Kunz U, Katerkamp A, Renneberg R, Spener F, Cammann K. Sensing fatty acid binding protein with planar and fiber-optical surface plasmon resonance spectroscopy devices. Sens Actuators 1996;32:149-55.

23. McCormack T, O'Kennedy R, O'Keefe G, MacCraith BD. Optical immuno-sensing of lactate dehydrogenase. Sens Actuators B Chem 1997;41:89-96.

24. Hanbury CM, Miller WG, Harris RB. Fiber-optic immunosensor for measurement of myoglobin. Clin Chem 1997;43:2128-36.

25. Papkovsky DB, O'Riordan TC, Guilbault GG. An immunosensor based on the glucose oxidase label and optical oxygen detection. Anal Chem 1999;71:1568-73.

26. Bender F, Dahint R, Meimeth F, Grunze M, Josse F. Mechanisms of interaction in acoustic plate mode immunosensors. Sens Actuators B Chem 1997;40:105-10.

27. Dahint R, Grunze M, Josse F, Renken J. Acoustic Plate Mode Sensor for Immunochemical Reactions. Anal Chem 1994;66:2888-92.

28. Luppa PB, Sokoll LJ, Chan DW. Immunosensors-principles and applications to clinical chemistry. Clin Chim Acta 2001;314:1-26.

29. Morgan MCL, Newman DJ, Price CP. Immunosensors: technology and opportunities in laboratory medicine. Clin Chem 1996;42:193-209.

30. Malhotra BD, Chaubey A. Biosensors for clinical diagnostics industry. Sens Actuators 2003;91:117-27.

31. Fischer U, Alcock S, Turner APF. Assessment of devices for in vivo monitoring of chemical species. Biosens Bioelectron 1995;10:xxiii-xxx.

32. Arner P, Bolinder J. Microdialysis of adipose tissue. J Intern Med. 1991;230:381-6.

33. Ballerstadt R, Schultz JS. Sensor methods for use with microdialysis and ultrafiltration. Adv Drug Deliv Rev 1996;21:225-38.

34. Elmquist WF, SawchukRJ. Application of microdialysis in pharmacokinetic studies. Pharm Res 1997;14:267-88.

35. Delgado JMR,Rubinstein L. Intracerebral release of neurohumors in unaesthetized monkeys. Arch Int Pharmacodyn Ther 1964;150:530-46.

36. Janle-Swain E, van Vleet JF, Ash SR. Use of a capillary filtrate collector for monitoring glucose in diabetics. ASAIO Trans 1987;33:336-40.

37. Janle EM, Kissinger PT. Microdialysis and ultrafiltration. Adv Food Nutr Res 1996;40:183-96. 
38. Leegsma-Vogt G, Janle E, Ash SR, Venema K, Korf J. Utilization of in vivo ultrafiltration in biomedical research and clinical applications. Life Sc 2003;73:2005-18

39. Kusterbeck AW, Wemhoff GA, Charles PT, Yeager DA, Bredehorst R, et al. A continuous flow immunoassay for rapid and sensitive detection of small molecules. J Immunol Methods 1990;135:191-7.

40. Wemhoff GA, Rabbany SY, Kusterbeck AW, Ogert RA, Bredehorst R, et al. Kinetics of antibody binding at solid-liquid interfaces in flow. J Immunol Methods 1992;156:223-30.

41. Rucklidge GJ, Milne, Chaudhry SM, Robins SP. Preparation of biotinylated, affinitypurified antibodies for enzyme-linked immunoassays using blotting membrane as an antigen support. Anal Biochem 1996;243:158-64.

42. Kaptein WA, Zwaagstra JJ, Venema K, Korf J. Continuous ultrasolw microdialysis and ultrafiltration for subcutaneous sampling as demonstrated by glucose and lactate measurements in rats. Anal Chem 1998;70:4696-4700.

43. Warden BA, Allam K, Sentissi A, Cecchini DJ, Giese RW. Repetitive hit- and-run fluoroimmunoassay for T-2 toxin. Anal Biochem 1987;162:363-9.

44. Yu H, Kusterbeck AW, Hale MJ, Ligler FS, Whelan JP. Use of the USDT flow immunosensor for quantification of benzoylecgonine in urine. Biosens Bioelectron 1996;11:725-34.

45. Tiefenauer LX, Kossek S, Padeste C, Thiébaud P. Towards amperometric immunosensor devices. Biosens Bioelectron 1997;12:213-23.

46. McNeil CJ, Athey D, Renneberg R. Immunosensors for clinical diagnostics. EXS 1997;81:17-25.

47. Freytag JW. Immunoassay wherein labeled antibody is displaced from immobilized analyte-analogue. E.I. Du Pont de Nemours \& Co (US patent 4,434,236) (1984).

48. Warden BA, Sentissi A, Ehrat M, Cecchini DJ, Allam K, et al. Chromatographic enzyme immunoassay for T-2 toxin. J Immunol Methods 1990;131:77-82.

49. Kaptein WA, Korf J, Cheng S, Yang M, Glatz JFC, et al. On-line flow displacement immunoassay for fatty acid-binding protein. J Immunol Meth 1998;217:103-11.

50. Ishii $\mathrm{J}$, Wang $\mathrm{JH}$, Naruse $\mathrm{H}$, Taga $\mathrm{S}$, Kinoshita $M$, et al. Senum concentrations of myoglobin vs human heart-type cytoplasmic fatty acid-binding protein in early detection of acute myocardial infarction. Clin Chem 1997;43:1372-8.

51. Mair J. Progress in myocardial damage detection. New biochemical markers for clinicians. Crit Rev Clin Lab Sci 1997;34:1-66.

52. Panteghini M, Bonora $\mathrm{R}$, Pagani $\mathrm{F}$, et al. Heart fatty acid-binding protein in comparison with myoglobin for the early detection of acute myocardial infarction. Clin Chem 1997;43:S157(abstract).

53. Abe S, Saigo M, Yamashita $\mathrm{T}$, et al. Heart fatty acid-binding protein is useful in early and myocardial-specific diagnosis of acute myocardial infarction. Circulation 1996;94:I323(abstract).

54. Siegmann-Thoss C, Renneberg R, Glatz JFC, Spener F. Enzyme immunosensor for diagnosis of myocardial infarction. Sensors Actuators 1996;30:71-6.

55. Schreiber A, Feldbrügge R, Key G, Glatz JFC, Spener F. An immunosensor based on disposable electrodes for rapid estimation of fatty acid-binding protein, an early marker of myocardial infarction. Biosens Bioelectr 1997;12:1131-7.

56. Key G, Schreiber A, Feldbrügge R, McNeil CJ, Jorgensen P. Multicenter evaluation of an amperometric immunosensor for plasma fatty acid-binding protein: an early marker for acute myocardial infarction. Clin Biochem 1999;32:229-31. 
57. Wodzig KWH, Pelsers MMAL, van der Vusse GJ, Roos W, Glatz JFC. One-step enzymelinked immunosorbent assay (ELISA) for plasma fatty acid-binding protein. Ann Clin Biochem 1997;34:263-8.

58. Glatz JFC, van der Voort D, Hermens WT. Fatty acid-binding protein as the earliest available plasma marker of acute myocardial injury. J Lig Assay 2002;25:167-77.

59. Orban M, Katerkamp A, Renneberg R, Spener F, Cammann K. Kinetic analysis of immunointeractions with covalently immobilized fatty acid-binding protein using a grating coupler sensor. J Immunol Methods 1998;215:17-26.

60. Kröger D, Katerkamp A, Renneberg R, Cammann K. Surface investigations on the development of a direct optical immunosensor. Biosens Bioelectron 1998;13:1141-47.

61. Lukosz W, Tiefenthaler K. Sensitivity of integrated optical grating and prism couplers as (bio)chemical sensors. Sens Actuators 1988;15:273-84.

62. Nellen PM, Tiefenthaler K, Lukosz W. Integrated optical input grating couplers as biochemical sensors, Sens Actuators B Chem 1988;15:285-95.

63. Tiefenthaler $\mathrm{K}$. Integrated optical couplers as chemical waveguide sensors, A.P.F. Turner, Adv. Biosens., JAI Press, London, 1992.

64. O'Regan TM, Pravda M, O'Sullivan CK, Guilbault GG. Development of a disposable immunosensor for the detection of human heart fatty acid-binding protein in whole blood using screen-printed carbon electrodes. Talanta 2002;57:501-10.

65. van der Voort D, Pelsers MMAL, Korf J, Hermens WT, Glatz JFC. Development of a displacement immunoassay for human heart-type fatty acid-binding protein in plasma: the basic conditions. Biosens Bioelectron 2003;19:465-71.

66. Bergveld P. The future of biosensors. Sens Actuators A 1996;56:65-73.

67. Bergveld $P$. Thirty years of ISFETOLOGY, what happened in the past 30 years and what may happen in the next 30 years. Sens Actuators B Chem 2003;88:1-20. 
Chapter 4 


\section{Development of a displacement immunoassay for human heart-type fatty acid-binding protein in plasma: the basic conditions}

Part of this chapter is published van der Voort D, Pelsers MMAL, Korf J, Hermens WT, Glatz JFC. Development of a displacement immunoassay for human heart-type fatty acid-binding protein in plasma: the basic conditions. Biosens Bioelectron 2003;19:465-71 


\subsection{Abstract}

To risk-stratify patients with chest pain who are admitted to emergency rooms and for whom initial evaluation is not conclusive, the use of cardiac markers has become a standard procedure. A recently introduced early plasma marker for acute myocardial infarction (AMI) is the $14.5-\mathrm{kDa}$ cytoplasmic heart-type fatty acid-binding protein (FABP). To fully exploit its early release from injured myocardium, a rapid method for repeated measurements or continuous monitoring of FABP in plasma is desirable. Such an on-line method could be an immunosensor based on displacement. The aim of the present study was to further investigate the principles underlying the displacement assay of FABP, both in buffer and in plasma. Batches of sepharose-bound FABP were loaded with an antibody-horseradish peroxidase (HRP) conjugate (anti-FABP). Continuous measurement of FABP was mimicked by repeated addition of FABP containing solutions followed by several washing steps. In the presence of free FABP the antibody-HRP complex dissociated and was subsequently quantified. Significant displacement in the presence of free FABP was observed in both buffer and human plasma. Anti-FABP could be intermittently displaced in the same batch, for at least $9 \mathrm{~h}$, and the displacement was concentration-dependent. These results show the feasibility of a sensor based on the displacement principle to be used for the diagnosis of AMI in emergency medicine.

\subsection{Introduction}

Ischaemic heart disease is the most common health problem in the industrialized world. Acute myocardial infarction (AMI) is the major single cause of cardiovascular morbidity and mortality. Because only early treatment, such as administration of thrombolytic therapy, improves survival of cardiac muscle, rapid differentiation of patients with and those without AMI is important. However, in only a minority of patients with chest pain who are admitted to emergency rooms, initial evaluation (medical history, physical examination and electrocardiogram), is conclusive. ${ }^{(1,2)}$ In order to risk-stratify nonconclusive patients, the use of cardiac markers has become a standard procedure. ${ }^{(3-5)}$

Commonly used cardiac markers are creatine kinase-MB (CK-MB), cardiac troponins I or T (cTnI and cTnT, respectively), and myoglobin. ${ }^{(5-10)}$ Recently, $14.5 \mathrm{kDa}$ cytoplasmic heart-type fatty acid-binding protein (FABP) was introduced as an early marker for myocardial injury. ${ }^{(11-16)}$ Due to its abundant occurrence in heart muscle combined with its relatively low plasma reference concentration, ${ }^{(17,18)}$ FABP plasma concentrations are significantly increased above the upper reference level (URL) within 2-3 $\mathrm{h}$ after cardiac injury. In addition, FABP appears to be more specific and more sensitive than myoglobin. ${ }^{(16,19)}$

It has recently been demonstrated that using measurements of marker concentrations in plasma from two successive samples, taken at short time intervals, may considerably improve diagnostic performance. ${ }^{(20,21)}$ Therefore, in order to fully exploit the early release of FABP from injured myocardium, rapid methods should be available for repeated measurements in plasma. In fact, continuous monitoring of FABP in plasma would be desirable. 
Various methods for immunochemical assessment of FABP in plasma have been described, including a sandwich-type enzyme-linked immunosorbent assay (ELISA $\left.{ }^{(22,23)}\right)$, a micro-particle-enhanced turbidimetric immunoassay, ${ }^{(24)}$ an enzyme-linked immunosensor, ${ }^{(25)}$ an immunosensor based on disposable electrodes, ${ }^{(26)}$ and a whole blood panel test. ${ }^{(27,28)}$ However, none of these tests are suitable for on-line monitoring. We and others have speculated previously that an immunosensor based on displacement could be a suitable on-line method for quantifying FABP. ${ }^{(29-31)}$ Although several displacement immunoassays have been described none of these were developed for molecules with a molecular mass exceeding $1 \mathrm{kDa} .^{(32-35)}$

Preliminary data showed that an immunosensor for FABP based on displacement could in principle be used for continuous monitoring of purified FABP in buffer solutions. ${ }^{(30)}$ In the present study the principle of displacement is further investigated, and extended to measurements in plasma.

\subsection{Materials and methods}

\subsubsection{The assay principle}

The displacement principle is explained in chapter 4 (Fig. 4.1). FABP is coupled to a matrix and thereafter loaded with antibody labeled with horseradish peroxidase (HRP) (Ab-HRP). Following the addition of a sample containing FABP, competition occurs with the immobilized FABP to occupy the antigen-binding site of the antibody, thereby preventing the reassociation of the antibody to the immobilized FABP and resulting in the release of a soluble displacement complex (FABP-Ab-HRP) which subsequently can be assayed.

In this study, the displacement mechanisms were studied by a discontinuous approach. In a reaction vial, a sepharose matrix was loaded with FABP and its labeled antibody. The continuous flow of FABP through this matrix was simulated by repeated washing- and displacement steps.

\subsubsection{Preparation of immobilized FABP}

Recombinant human heart-type FABP (14.5 kDa), a gift from Dr. T. Börchers, ICB, Münster, Germany, and produced as described previously ${ }^{(26)}$ was covalently bound to $\mathrm{N}$ hydroxysuccinimide (NHS)-activated Sepharose 4 fast flow (Pharmacia, Biotech, Uppsala, Sweden). A reaction vial (Eppendorf, Netheler-Hinz-Gmbh, Hamburg, Germany) containing $300 \mu \mathrm{l}$ NHS-activated Sepharose, was washed three times with phosphate buffered saline (PBS) $\left(10 \mathrm{mM} \mathrm{H}_{2} \mathrm{PO}_{4}, 150 \mathrm{mM} \mathrm{NaCl}, \mathrm{pH}\right.$ 7.4). Thereafter, 9 nmol $(138 \mu \mathrm{g})$ of FABP in $500 \mu \mathrm{l}$ coupling buffer $\left(0.5 \mathrm{M} \mathrm{NaCl}, 0.2 \mathrm{M} \mathrm{Na} \mathrm{CO}_{3}, 0.2 \mathrm{M}\right.$ $\mathrm{NaHCO}_{3}, \mathrm{pH} 8.3$ ) was added to the reaction vial, and incubated with gentle rotation for 2 h. After centrifugation $\left(2 \mathrm{~min}\right.$ at $1000 \times \mathrm{g}$ ), the supernatant was stored at $-20^{\circ} \mathrm{C}$. The remaining pellet was used for further experiments. In a second step, free NHS spacer arms of the Sepharose were blocked by incubation with PBS supplemented with $5 \%$ bovine serum albumin (BSA) (A-4503 Sigma, St. Louis, MO, USA) for 50 min. Again, the vial was centrifuged and the supernatant, containing residual FABP, was stored at 
$-20^{\circ} \mathrm{C}$ for determination of the amount of FABP bound to the Sepharose matrix. Finally, the matrix with immobilized FABP was washed three times with PBS supplemented with $0.1 \% \mathrm{BSA}$ and stored overnight at $4^{\circ} \mathrm{C}$.

\subsubsection{Coupling of labeled antibody to sepharose-bound FABP}

FABP Horseradish peroxidase-labeled monoclonal antibody (mAb, 66E2-HRP) against human heart-type $\mathrm{FABP}^{(36)}$ was provided by HyCult biotechnology (Uden, The Netherlands). An amount of $30 \mu \mathrm{g}$ of Ab-HRP $(0.16 \mathrm{nmol})$ was added to the reaction vial with immobilized FABP and rotated at room temperature for $2 \mathrm{~h}$. Thereafter, the Sepharose-FABP-mAb-HRP complex was washed eleven times with PBS containing $0.1 \%$ BSA. The supernatant obtained after each step was collected and stored at $4^{\circ} \mathrm{C}$ to determine the amount of bound Ab-HRP. The remaining Sepharose matrix was immediately used for further experimentation.

\subsubsection{Displacement experiments}

Each experiment consisted of six so-called displacement steps, each followed by seven washing steps. For displacement, $240 \mu \mathrm{l}$ of a specified solution, containing the displacing agent, was added to the vial, followed by gentle rotation of the reaction vial at room temperature for $25 \mathrm{~min}$. Then the vial was centrifuged $(2 \mathrm{~min}$ at $1000 \mathrm{x} \mathrm{g}$ ) and the supernatant stored until further analysis. Each washing step consisted of addition of 300 $\mu \mathrm{l}$ washing buffer (PBS containing $0.1 \% \mathrm{BSA}$ ) to the reaction vial. Thereafter, the reaction vial was vortexed for several seconds, followed by centrifugation ( $2 \mathrm{~min}$ at 1000 $\mathrm{x} \mathrm{g}$ ). The supernatant was collected and stored at $4^{\circ} \mathrm{C}$ until further analysis. Pooled plasma was obtained from ten healthy individuals and contained $2 \mu \mathrm{g} / \mathrm{L}$ FABP.

\subsubsection{FABP assay}

FABP concentrations were measured at room temperature, using a sandwich-type ELISA kit obtained from HyCult biotechnology (Uden). This assay has been described previously. ${ }^{(23)}$ Detection limit of this assay was $0.3 \mu \mathrm{g} / \mathrm{L}$, and inter-assay imprecision was $11 \%$.

\subsubsection{Ab-HRP assay}

The concentration of HRP-labeled anti-FABP (Ab-HRP) was measured at room temperature in 96-well NUNC maxisorb microtitre plates (Invitrogen, Merkelbeke, Belgium). The plates were washed three times with PBT buffer (PBS buffer, pH 7.2, supplemented with $0.1 \%(\mathrm{w} / \mathrm{v})$ BSA and $0.05 \%(\mathrm{v} / \mathrm{v})$ Tween 20$)$. Each sample was diluted for at least five times with PBT, and $50 \mu \mathrm{l}$ was added to the well. Then, $100 \mu \mathrm{l}$ tetra-methyl benzidine (Lucron Bioproducts, Gennep, The Netherlands) was added and after $2 \mathrm{~min}$, the colour development was stopped with $2 \mathrm{M} \mathrm{H}_{2} \mathrm{SO}_{4}$. The optical density (OD) of each sample was measured at $450 \mathrm{~nm}$ by use of a Titertek Multiscan II spectro-photometer (Labsystems, Helsinki, Finland) and compared with a standard curve 
(range $0-12 \mu \mathrm{g} / \mathrm{L}$ ) of Ab-HRP. The detection limit of this assay was $0.12 \mu \mathrm{g} / \mathrm{L}$ and interassay imprecision was $<10 \%$.

\subsubsection{Statistics}

Data are presented as mean \pm S.D. for the indicated number of experiments. Student's $t$ test for unpaired values was used to calculate differences between the Ab-HRP concentrations measured in the different supernatants. $P<0.05$ was considered statistically significant.

\subsection{Results}

\subsubsection{Binding of FABP to the sepharose matrix}

Coupling of $138 \mu \mathrm{g}$ of FABP to $300 \mu \mathrm{l}$ of the NHS Sepharose matrix, resulted in $94 \pm 3 \%$ binding, which is in accordance to its high binding capacity as indicated by the manufacturer. During the blocking step with 5\% BSA, some FABP was found to be displaced from the matrix resulting in a final preparation containing approximately 126 $\mu \mathrm{g}$ of bound FABP per $300 \mu \mathrm{l}$ Sepharose matrix.

\subsubsection{Binding of Ab-HRP to matrix-bound FABP}

HRP-labeled antibody was added to the Sepharose-bound FABP. After a $2 \mathrm{~h}$ incubation period, it appeared that $50 \%$ of the Ab-HRP was bound to the matrix. During the subsequent eleven washing steps, even more Ab-HRP was released. Fig. 5.1 shows the Ab-HRP concentration measured in the supernatants of these washing steps. However, after the final washing step, about $15 \%$ of the initially added amount of Ab-HRP remained attached to the immobilized FABP and a relatively stable baseline was obtained. The displacement experiments were commenced with this material.

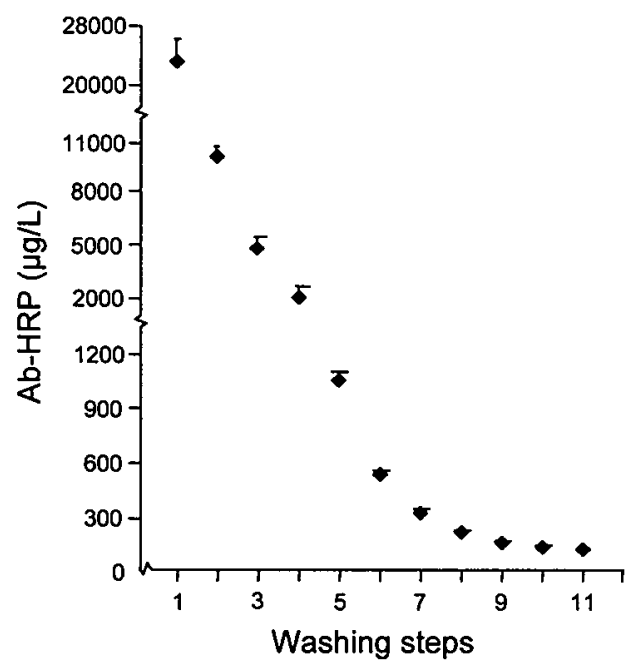

Figure 5.1 Ab-HRP release during the first eleven washing steps.

The Ab-HRP concentration measured in the supernatant after centrifugation is given as function of the number of washing steps. Data are presented as mean \pm S.D. $(n=7)$. Units of the ordinate are comparable to the units shown in Figs. 3-5 


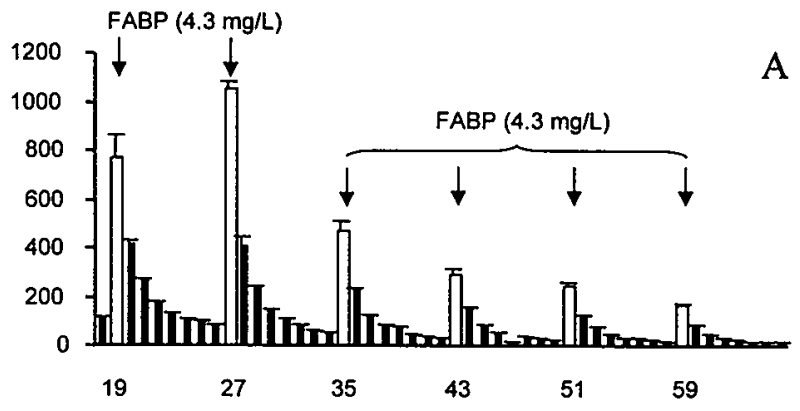

A Panel A: Effect of repeated FABP additions.

Solution added during the displacement steps contains 4.3 $\mathrm{mg} / \mathrm{L}$ FABP buffer.

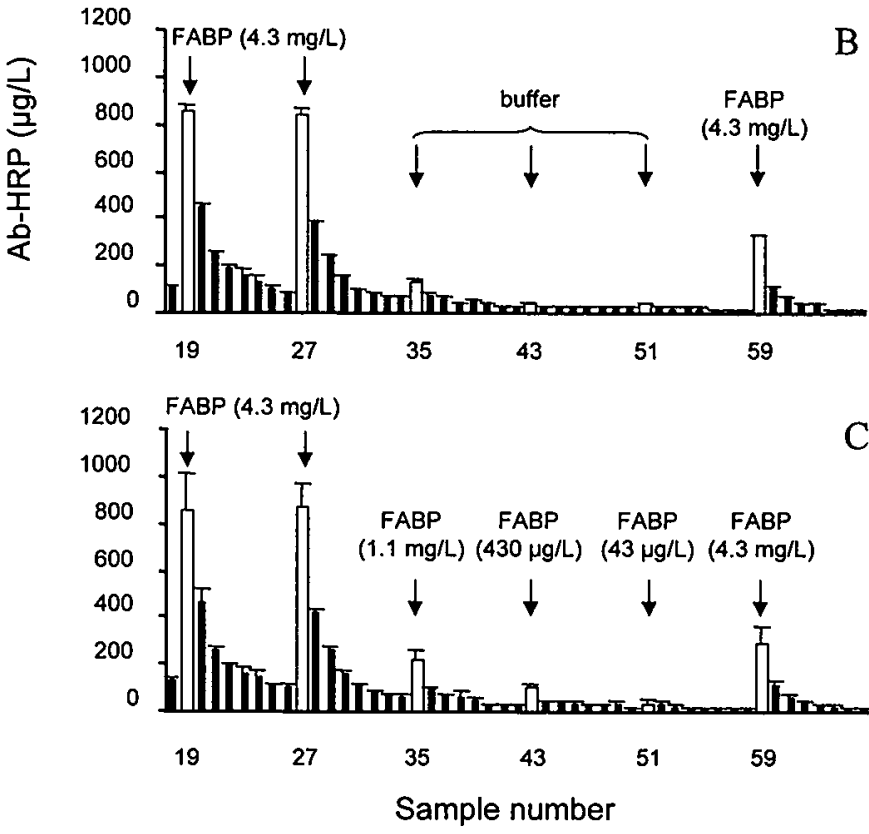

Panel B: Effect of time delay.

During the displacement steps FABP (4.3 $\mathrm{mg} / \mathrm{L}$ buffer) or buffer is added.

C Panel C: Sensitivity of the displacement response.

FABP concentrations be-tween 0.043 and $4.3 \mathrm{mg} / \mathrm{L}$ buffer are added during the displacement steps.

Figure 5.2 Displacement of anti-FABP-HRP in buffer.

Panel A-C present the release of Ab-HRP during displace-ment steps (indicated by arrows; open bars) and washing steps (black bars). Data are presented as mean \pm S.D. for $n=2$ (panel $A$ and B) and $n=3$ (panel $C$ ).

\subsubsection{Displacement of Ab-HRP by FABP in buffer}

Fig. 5.2, panel A, presents the effects of repeated addition of $4.3 \mathrm{mg} / \mathrm{L}$ FABP on displaced Ab-HRP measured in the supernatant, during a total observation period of $9 \mathrm{~h}$ (including preparation of the Sepharose matrix). During all displacement steps, a significant amount of Ab-HRP was released from the matrix.

Displacement was not in a single washing step, because a considerable additional amount of Ab-HRP was released during the subsequent washing steps. In addition, after the second displacement step, the same amount of FABP displaced progressively less Ab- 
HRP. However, each of the Ab-HRP amounts released during the displacement steps displayed in Fig. 5.2 (panels A-C) were significantly higher than the amounts released during the preceding washing steps $(\mathrm{P}<0.01)$.

Fig. 5.2, panel B, presents Ab-HRP concentrations after displacement due to addition of buffer with or without FABP. Lower Ab-HRP levels were measured after addition of buffer without FABP compared with buffer supplemented with FABP. It demonstrates that the same amount of FABP displaces progressively less Ab-HRP. If the third displacement step is postponed to the end of the experiments, the Ab-HRP response is larger than in the $6^{\text {th }}$ displacement step of panel A, but not as pronounced as in the third displacement step of that panel. This indicates that the diminished release response is partly due to exhaustion of displaceable Ab-HRP, and partly to the duration of the experiment.

The dose-response of Ab-HRP displacement for FABP concentrations when varied from 43 to $4300 \mu \mathrm{g} / \mathrm{L}$ is shown in Fig. 5.2, panel C. It should be noted that during all displacement steps, the resulting Ab-HRP level was significantly higher than in the preceding washing step.

\subsubsection{Displacement of Ab-HRP by FABP in plasma}

When plasma spiked with FABP $(0.8 \mathrm{mg} / \mathrm{L})$ was added repeatedly, the first two displacement steps showed the release of similar amounts of Ab-HRP (Fig. 5.3, panel A). The following four displacement steps showed a markedly lower release of Ab-HRP, but the amounts released were not statistically different. When plasma was also used as washing-solution (panel B) instead of buffer (panel A), and the same amount of FABP $(0.8 \mathrm{mg} / \mathrm{L})$ in plasma was added during the displacement steps, a significantly higher release of Ab-HRP was measured in each displacement step.

To explore the sensitivity of the system, lower amounts of FABP ( 0.1 and 0.02 $\mathrm{mg} / \mathrm{L}$ ) in plasma were added during the displacement-steps and plasma was used as washing solution (Fig. 5.4). Compared with Fig. 5.3, panel B, this lower amount of FABP spiked in plasma induced a less but still significant displacement of Ab-HRP. The amount of Ab-HRP released during the displacement-steps in Fig. 5.4, panel A and B are $33 \pm 5$ and $20 \pm 5 \%$, respectively, of the corresponding Ab-HRP levels of Fig. 5.3, panel B (from the $3^{\text {rd }}$ displacement-step onwards). 

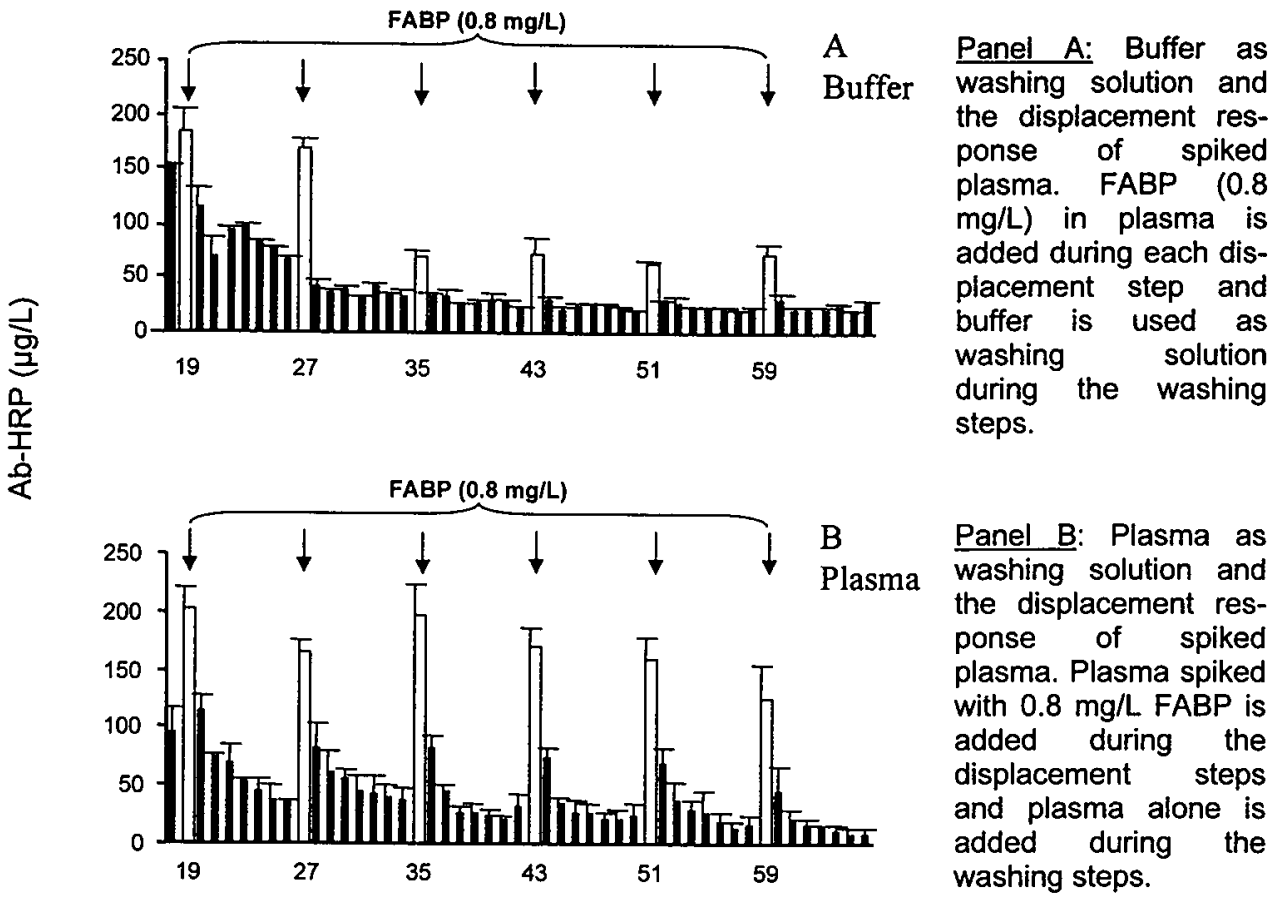

Sample number

Figure 5.3 Displacement of anti-FABP-HRP in buffer vs. plasma.

Panel $A$ and $B$ present the release of Ab-HRP during displacement steps (indicated by arrows; open bars) and washing steps (black bars). Data are presented as mean \pm S.D. for $n=2$ (panel A) and $n=4$ (panel $B$ ).

\subsection{Discussion}

In this study a displacement immunosensor for continuous measurement of FABP was mimicked by repeated addition of FABP containing solutions to Ab-HRP loaded Sepharose-FABP, followed by several washing steps. It was shown that addition of FABP repeatedly resulted in a significant displacement of Ab-HRP, both in buffer as well as in plasma, for a duration of at least $9 \mathrm{~h}$.

During the preparation of the immobilized Ab-HRP complex, it appeared that after incubation only $50 \%$ of the initially added labeled antibody was bound. After the first washing step, a marked release of the Ab-HRP complex occurred, which can be explained by the rather high dissociation constant $\left(\mathrm{K}_{\mathrm{off}}\right)$ of the Ab-HRP complex. ${ }^{(37)}$ Additional non-specific interactions between Ab-HRP and the matrix probably explain the quantity of $\mathrm{Ab}-\mathrm{HRP}$ that remained bound to the matrix.

With the displacement studies, the measured Ab-HRP levels in the supernatants are not only the result of the displacement phenomenon but are also influenced by the 
spontaneous release of the Ab-HRP complex (=bleeding) that will occur throughout the experiment, although this release will finally be reduced to a small stable baseline. At the start of the experiment this influence will be greater than at the end when the bleeding is more stable. The Ab-HRP level measured during the displacement steps is also influenced by the mechanical treatment of the reaction vial during $25 \mathrm{~min}$. This disturbs the equilibrium between antigen and antibody, and a small part of the antibody will be released (see Fig. 5.2, panel B).

Although successive additions of $F A B P$ resulted in progressively lower responses, the small standard deviations (see Fig. 5.2, panel A) show that this is quite a reproducible phenomenon. The fact that the second addition of $1000 \mathrm{ng}$ FABP did not cause a lower response than the first is most likely explained by the phenomenon that when Ab-HRP is added to the Sepharose-bound FABP, one of the two Fab fragments of this antibody will remain free to bind FABP from solution. This binding would diminish the displacement capacity of the first addition.

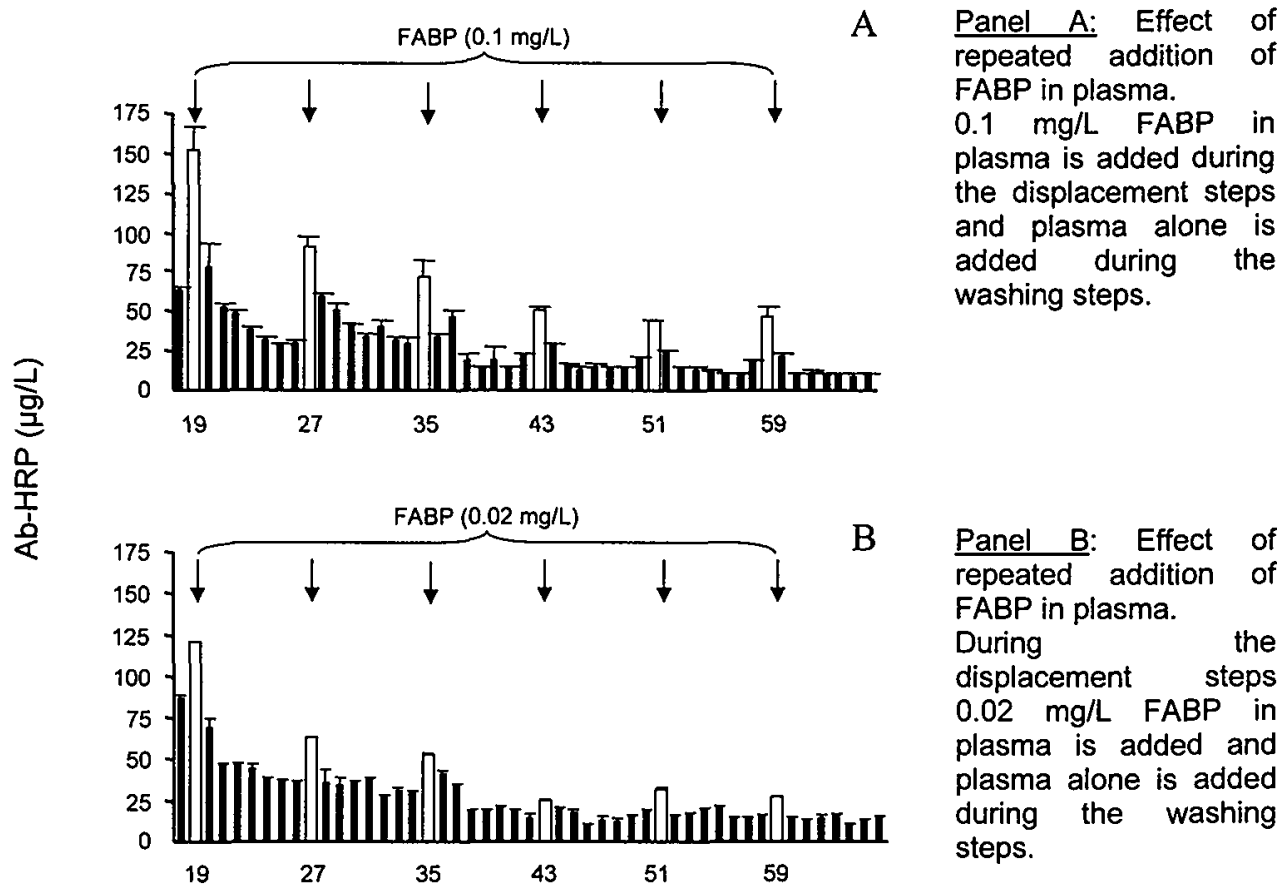

Sample number

Figure 5.4 Displacement of anti-FABP-HRP in plasma.

Panel $A$ and $B$ present the release of Ab-HRP during displacement steps (indicated by arrows; open bars) and washing steps (black bars). Data are presented as mean \pm S.D. for $n=2$ (panel $A$ and $\mathrm{B}$ ). 
The release of labeled antibody is reproducible, but progressively less as a function of time. When equal concentrations of FABP were added, lower Ab-HRP values were found at the end of the experiment compared with the first hours of the experiment. This effect could partly be explained by progressive loss of antibody (mass action effect). For example in the experiment shown in panel A of Fig. 5.2, the total loss of antibody in samples $27-34$ is $5.5 \%$ of the total amount of antibody still present on the column. An additional explanation for the diminishing Ab-HRP release could be that its binding affinity will increase with time due to a growing number of non-specific interactions with the Sepharose matrix. Furthermore, it was found that inactivation of HRP at room temperature over a period of $9 \mathrm{~h}$ was negligible (data not shown).

A factor that might influence the Ab-HRP release in the experiments employing plasma is the large amount of protein. The higher concentration of bulk protein in plasma competes with the antibodies for the non-specific interactions that interfere with the release of the Ab-HRP, and thus cause higher released amounts of Ab-HRP when compared with experiments performed in buffer.

Patho-physiological FABP concentrations in plasma due to an AMI generally range from 10 to $1000 \mu \mathrm{g} / \mathrm{L}$. From our sensitivity studies, we can conclude that even small AMIs above $40 \mu \mathrm{g} / \mathrm{L}$ FABP (when buffer is used as washing solution) and even above $20 \mu \mathrm{g} / \mathrm{L}$ FABP (when plasma is used as washing solution) could be measured using the present system. Depending on the type of FABP and its specificity for an organ, this would enable the estimation of the extent of tissue damage. In addition to different types of FABP, changing the antibody would also permit the assay of other proteins by this displacement principle.

The present study is a step in the development of a FABP immunosensor for continuous measurement of FABP concentrations in plasma. Such continuous measurement would not only be useful for patients entering the emergency room with chest pain, but may also be applied for non-invasive detection of coronary reperfusion. ${ }^{(38)}$

\subsection{References}

1. Katz IA, Irwig L, Vinen JD, March L, Wyndham LE, et al. Biochemical markers of acute myocardial infarction: strategies for improving their clinical usefulness. Ann Clin Biochem 1998;35:393-9.

2. Newby LK, Storrow AB, Gibler WB, Garvey J, Tucker JF, et al. Bedside multimarker testing for risk stratification in chest pain units: The chest pain evaluation by creatine kinaseMB, myoglobin, and troponin I (CHECKMATE) study. Circulation 2001;103:1832-7.

3. Hamm CW. New serum markers for acute myocardial infarction. New Engl J Med 1994;331:607-8.

4. Hamm CW, Katus HA. New biochemical markers for myocardial cell injury. Curr Opin Cardiol 1995; 10:355-60.

5. Haider KH, Stimson WH. Cardiac myofibrillar proteins: biochemical markers to estimate myocardial injury. Mol Cell Biochem 1999;194:31-9.

6. McComb JM, McMaster EA, Jadgey AA. Myoglobin in the very early phase of acute myocardial infarction. Ann Clin Biochem 1985;22:152-5. 
7. Mair J, Morandell,D, Genser N, Lechleitner P, Dienstl F, et al. Equivalent early sensitivities of myoglobin, creatine kinase MB mass, creatine kinase isoform ratios, and cardiac troponins I and T for acute myocardial infarction. Clin Chem 1995;41:1266-72.

8. Mair J. Progress in myocardial damage detection: new biochemical markers for clinicians. Crit Rev Clin Lab Sci 1997;34:1-66.

9. Johnson PA, Goldman L, Sacks DB, Garcia T, Albano M, et al. Cardiac troponin T as a marker for myocardial ischemia in patients seen at the emergency department for acute chest pain. Am Heart J 1999;137:1137-44.

10. Plebani M, Zaninotto M. Cardiac markers: present and future. Int J Clin Lab Res 1999;29:5663.

11. Kleine AH, Glatz JFC, van Nieuwenhoven FA, van der Vusse GJ. Release of heart fatty acidbinding protein into plasma after acute myocardial infarction in man. Mol Cell Biochem 1992;116:155-62.

12. Ishii J, Wang JH, Naruse H, Taga S, Kinoshita M, et al. Serum concentrations of myoglobin vs. human heart-type cytoplasmic fatty acid-binding protein in early detection of acute myocardial infarction. Clin Chem 1997;43:1372-8.

13. Hermens WT, Pelsers MM, Mullers-Boumans ML, de Zwaan C, Glatz JFC. Combined use of markers of muscle necrosis and fibrinogen conversion in the early differentiation of myocardial infarction and unstable angina. Clin Chem 1998;44:890-2.

14. van der Laarse A. Rapid estimation of myocardial infarct size. Cardiovasc Res 1999;44:2478 .

15. Hayashida N, Chihara S, Akasu K, Oda T, Tayama E, et al. Plasma and urinary levels of heart Fatty acid-binding protein in patients undergoing cardiac surgery. Jpn Circ J 2000;64:18-22.

16. Glatz JFC, van der Voort D, Hermens WT. Fatty acid-binding protein as the earliest available plasma marker of acute myocardial injury. J Clin Ligand Assay 2002;25:167-77.

17. Kragten JA, van Nieuwenhoven FA, van Dieijen-Visser MP, Theunissen PH, Hermens WT, et al. Distribution of myoglobin and fatty acid-binding protein in human cardiac autopsies. Clin Chem 1996;42:337-8.

18. Pelsers MM, Chapelle JP, Knapen M, Vermeer C, Muijtjens AM, et al. Influence of age and sex and day-to-day and within-day biological variation on plasma concentrations of fatty acid-binding protein and myoglobin in healthy subjects. Clin Chem 1999;45:441-3.

19. van Nieuwenhoven FA, Kleine AH, Wodzig WH, Hermens WT, Kragten HA, et al. Discrimination between myocardial and skeletal muscle injury by assessment of the plasma ratio of myoglobin over fatty acid-binding protein. Circulation 1995:92:2848-54.

20. de Winter RJ, Bholasingh R, Nieuwenhuijs AB, Koster RW, Peters RJ, et al. Ruling out acute myocardial infarction early with two serial creatine kinase-MB mass determinations. Eur Heart J 1999;20:967-72.

21. Haastrup B, Gill S, Kristensen SR, Jorgensen PJ, Glatz JFC, et al. Biochemical markers of ischaemia for the early identification of acute myocardial infarction without St segment elevation. Cardiology 2000;94:254-61.

22. Ohkaru Y, Asayama K, Ishii H, Nishimura,S, Sunahara N, et al. Development of a sandwich enzyme-linked immunosorbent assay for the determination of human heart type fatty acidbinding protein in plasma and urine by using two different monoclonal antibodies specific for human heart fatty acid-binding protein. J Immunol Methods 1995;178:99-111.

23. Wodzig KWH, Pelsers MMAL, van der Vusse GJ, Roos W, Glatz JFC. One-step enzymelinked immunosorbent assay (ELISA) for plasma fatty acid-binding protein. Ann Clin Biochem 1997;34:263-8. 
24. Robers M, van der Hulst FF, Fischer MA, Roos W, Salud CE, et al. Development of a rapid microparticle-enhanced turbidimetric immunoassay for plasma fatty acid-binding protein, an early marker of acute myocardial infarction. Clin Chem 1998;44:1564-7.

25. Siegmann-Thoss C, Renneberg R, Glatz JFC, Spener F. Enzyme immunosensor for diagnosis of myocardial infarction. Sens Actuators 1996;30:71-6.

26. Schreiber A, Feldbrugge R, Key G, Glatz JFC, Spener F. An immunosensor based on disposable electrodes for rapid estimation of fatty acid-binding protein, an early marker of myocardial infarction. Biosens Bioelectron 1997;12:1131-7.

27. Watanabe T, Ohkubo Y, Matsuoka H, Kimura H, Sakai Y, et al. Development of a simple whole blood panel test for detection of human heart-type fatty acid-binding protein. Clin Biochem 2001;34:257-63.

28. O'Regan TM, Pravda M, O'Sullivan CK, Guibault GG. Development of a disposable immunosensor for the detection of human heart fatty-acid binding protein in human whole blood using screen-printed carbon electrodes. Talanta 2002;57:501-10.

29. Glatz JFC, Kleine AH, van Nieuwenhoven FA, Hermens WT, van Dieijen-Visser MP, van der Vusse GJ. Fatty acid-binding protein as a plasma marker for the estimation of myocardial infarct size in humans. Br Heart $\mathrm{J}$ 1994;71:135-140.

30. Kaptein WA, Korf J, Cheng S, Yang M, Glatz JFC, et al. On-line flow displacement immunoassay for fatty acid-binding protein. J Immunol Methods 1998;217:103-11.

31. Rabbany SY, Marganski WA, Kusterbeck AW, Ligler FS. A membrane-based displacement flow immunoassay. Biosens Bioelectron 1998;13:939-44.

32. Freytag JW, Dickinson,JC, Tseng SY. A highly sensitive affinity-column-mediated immunometric assay, as exemplified by digoxin. Clin Chem 1984;30:417-20.

33. Warden BA, Sentissi A, Ehrat M, Cecchini DJ, Alam K, et al. Chromatographic enzyme immunoassay for T-2 toxin. J Immunol Methods 1990;131:77-82.

34. Aizawa M. Immunosensors for clinical analysis. Adv Clin Chem 1994;3:247-275.

35. Kronkvist K, Lovgren U, Svenson J, Edholm LE, Johansson G. Competitive flow injection enzyme immunoassay for steroids using a post-column reaction technique. J Immunol Methods 1997;200:145-53.

36. Roos W, Eymann E, Symannek M, Duppenthaler J, Wodzig $K W$, et al. Monoclonal antibodies to human heart fatty acid-binding protein. J Immunol Methods 1995;183:149-53.

37. de Groot MJM, Kragten HJA, Hermens, WT, Glatz JFC. Assessment of coronary reperfusion by cardiac marker proteins in patients with myocardial infarction: a review Cardiovasc Rev Rep 2003;24:144-9. 


\section{A displacement immunoassay for human heart-type fatty acid- binding protein in plasma.}

Part of this chapter is submitted:

Van der Voort D, Pelsers MMAL, Korf J, Hermens WT, Glatz JFC. A displacement immunoassay for human heart-type fatty acid-binding protein in plasma. $\mathrm{J}$ Immunol Meth submitted 


\subsection{Abstract}

Human heart-type fatty acid-binding protein (FABP) is suggested as an early plasma marker of acute myocardial infarction (AMI) and several subsequent studies have proved that for early diagnosis of AMI, FABP performs better than myoglobin, a more often used early marker protein. Because serial measurement of biochemical markers in plasma now is universally accepted as an important determinant in AMI diagnosis, a rapid and continuous measuring method for FABP would be desirable. The aim of the present study was to develop an immunoassay based on the principle of displacement and using a column for rapid and continuous measurement of FABP in plasma. Glass columns filled with Sepharose-bound FABP were loaded with a horseradish peroxidase (HRP) labeled antibody $(\mathrm{Ab})$ and equilibrated with human plasma. After reaching a stable baseline, human plasma spiked with FABP or plasma from AMI patients was added. The Ab-HRP complex dissociated due to the presence of FABP in plasma and was subsequently quantified. For plasma from AMI patients $(n=5)$ the Ab-HRP level thus measured correlated with the corresponding plasma FABP concentration $(\mathrm{R}=0.96)$. The results of this study show the feasibility of a sensor for continuous monitoring of FABP in plasma.

\subsection{Introduction}

The definition of acute myocardial infarction (AMI) states that acute, evolving, or recent MI requires the typical rise and fall of biomarkers (creatine-kinase (CK) mass, CK subforms, myoglobin, troponin I, troponin $\mathrm{T}) .{ }^{(1)}$ As a result, studies on biomarker characteristics and their quantification methods have increased rapidly. ${ }^{(2-8)}$ However, an optimal cardiac marker cannot be defined. The required biomarker properties may vary according to its performance as a marker in early versus late diagnosis, monitoring of reinfarction, prognosis, infarct size, detection of reperfusion etcetera, generally depending on different and sometimes mutually exclusive properties. ${ }^{(9-13)}$ It is generally accepted that the optimal marker for infarct timing and diagnosis would be the combination of an early released cytosolic marker (e.g., myoglobin) with a cardiacspecific troponin. ${ }^{(14-18)}$ Early diagnosis of AMI is still problematic in patients with nonconclusive electrocardiograms (ECG). However, prompt diagnosis and treatment limit mortality and the rapid exclusion of myocardial infarction can help to reduce unnecessary stays in intensive care units. ${ }^{(19-21)}$ Therefore, a rapid assay for early diagnosis of AMI is important. Furthermore, continuous measurement of cardiac proteins is advantageous because changes in cardiac protein levels during the first hours after onset of AMI symptoms, is often more telling than the value itself. ${ }^{(12,22)}$

Heart-type fatty acid-binding protein (FABP) is a sensitive plasma marker of $\mathrm{AMI},{ }^{(23-26)}$ and shows a significantly better performance than myoglobin. ${ }^{(27-29)}$ For early confirmation or exclusion of myocardial injury, a rapid assay would be desired, but, till now, a method suitable for fast and continuous monitoring or quantification of FABP is not available. Existing methods are based on immunoassay techniques, and take 30-45 minutes for a sample to be quantified. ${ }^{(29-33)}$ Recently, Kaptein et al. ${ }^{(34)}$ developed an online displacement immunoassay for FABP. However, the intra-assay variation of this assay is large and results were performed in buffer spiked with FABP, not in plasma. 
The aim of the present study was to develop an immunoassay based on the principle of displacement and using a column for rapid and continuous measurement of FABP in plasma. The present method combines features of affinity column chromatography and immunodisplacement. Concentration and diffusion effects on columns will greatly affect the results as further discussed below.

Glass columns filled with a specific matrix (i.e., the Sepharose-preparation used) were used. The addition of a sample containing FABP, resulted in the release of a soluble displacement complex which subsequently could be assayed downstream. The results of this study show the feasibility of a sensor based on the displacement principle to be used for emergency medicine.

\subsection{Materials and methods}

\subsubsection{Human plasma}

\section{From healthy donors}

EDTA plasma from healthy subjects was obtained from donors visiting at the local blood bank. Subjects were not taking medication. Plasma was obtained between 9 and 12 am and collected in plastic containers. After routine checking of plasma for the absence of viral diseases, plasma was stored at $-20^{\circ} \mathrm{C}$ until use.

\section{From AMI patients}

Plasma was obtained from patients with confirmed AMI. Inclusion criteria were (i) patient's hospital delay (i.e., timespan between onset of AMI symptoms and entrance at the emergency department) of less than $6 \mathrm{~h}$, (ii) absence of treatment with heparine before or during transportation to the hospital and (iii) absence of earlier thrombolytic treatment. AMI was confirmed by ST-segment elevation typical of AMI, and increased troponin $T$ values within $24 \mathrm{~h}$. Samples of $10 \mathrm{ml}$ blood of these patients were collected in EDTA plasma-tubes, centrifuged $(1500 \mathrm{~g}, 10 \mathrm{~min})$ and stored at $-20^{\circ} \mathrm{C}$ till further use. All patients signed informed consent and the study was approved by the local Medical Ethical Committee.

\subsubsection{Preparation of immobilized FABP}

Recombinant human heart-type FABP (14.5 kDa) (a kind gift of Dr. T. Börchers, ICB, Münster, Germany) was produced as described previously ${ }^{(31)}$ and was covalently bound to N-hydroxysuccinimide (NHS)-activated Sepharose 4 fast flow (Pharmacia, Biotech, Uppsala, Sweden). Conditions for binding of FABP to sepharose were determined in separate pilot studies and resulted in the following protocol. A reaction vial containing 50 or $200 \mu \mathrm{l}$ NHS-activated Sepharose $(0.8$ or $3.2 \mu \mathrm{mol})$ was washed three times with phosphate buffered saline (PBS) $\left(10 \mathrm{mM} \mathrm{H}_{2} \mathrm{PO}_{4}, 150 \mathrm{mM} \mathrm{NaCl}\right.$, pH 7.4). Thereafter, 7.4 nmol $(111 \mu \mathrm{g})$ of FABP in $200 \mu \mathrm{l}$ coupling buffer $\left(0.5 \mathrm{M} \mathrm{NaCl}, 0.2 \mathrm{M} \mathrm{Na}_{2} \mathrm{CO}_{3}, 0.2 \mathrm{M}\right.$ $\mathrm{NaHCO}_{3}, \mathrm{pH}$ 8.3) was added, and incubated with gentle rotation for $2 \mathrm{~h}$. After centrifugation $(2 \mathrm{~min}$ at $1000 \mathrm{~g})$, the supernatant was stored at $-20^{\circ} \mathrm{C}$. The remaining pellet, i.e., Sepharose-bound FABP, was used for further experiments. In a second step, free NHS spacer arms of the Sepharose were blocked by incubation with 50 or $200 \mu \mathrm{l}$ 
PBS, corresponding to the volume of Sepharose (packed gel), supplemented with $5 \%$ bovine serum albumin (BSA) (A-4503 Sigma, St. Louis, MO, USA) for $50 \mathrm{~min}$. Again, the vial was centrifuged and the supernatant, containing residual $F A B P$, was stored at -20 ${ }^{\circ} \mathrm{C}$ for determination of binding efficiency. Finally, the Sepharose-bound FABP was washed three times with PBS supplemented with $0.1 \% \mathrm{BSA}$ and stored overnight at $4^{\circ} \mathrm{C}$.

\subsubsection{Coupling of labeled antibody to Sepharose-bound FABP}

Horseradish peroxidase-labeled monoclonal antibody (mAb, 66E2-HRP) against human heart-type $\mathrm{FABP}^{(35)}$ was provided by HyCult biotechnology (Uden, The Netherlands). An amount of $15 \mu \mathrm{g}$ of Ab-HRP $(0.08 \mathrm{nmol})$ was added to the reaction vial containing Sepharose-bound FABP and rotated at room temperature for $2 \mathrm{~h}$. Thereafter, a glass column was filled with this Sepharose-FABP-Ab-HRP complex. The same column was used in the displacement experiments.

\subsubsection{Assay principle}

A glass column was filled with Sepharose-bound FABP and loaded with antibody labeled with horseradish peroxidase (HRP) (Ab-HRP). Following the addition of a (plasma) sample containing FABP, competition occurs with the immobilized FABP to occupy the antigen-binding site of the antibody, resulting in the release of a soluble displacement complex (FABP-Ab-HRP) from the column matrix. The amount of downstream displacement-complex was then measured semi-continuously.

\subsubsection{Displacement experiments}

For each experiment new columns were prepared. For this, $10 \mathrm{~cm}$ of the tip of a long Pasteur capillary (Wu, Mainz, USA) was cut off and the end was filled with glass wool. The column was attached to skalar tube (orange/red $0.03 \mathrm{ml} / \mathrm{min}$ ), (Skalar, Breda, The Netherlands) inserted in an Ismatec IPC pump (high-precision multichannel dispenser, ISM 937, Ismatec Labortechnik, Glattbrugg, Switzerland). Each column was filled with the matrix mentioned above (Sepharose-FABP-Ab-HRP) and after $30 \mathrm{~min}$, pumping was started and the column was equilibrated and eluted with healthy human plasma at a velocity (v) of 15 or $30 \mu \mathrm{l} / \mathrm{min}$.

During the experiments, aliquots of plasma (obtained from a healthy donor), plasma spiked with FABP, or plasma from an AMI patient, were added to the column. The pump-velocity determined the time intervals $(2-6 \mathrm{~min})$ at which $75 \mu \mathrm{l}$ fractions of eluate could be collected. The fractions were stored at $4^{\circ} \mathrm{C}$ until assay of $\mathrm{Ab}-\mathrm{HRP}$ content.

\subsubsection{Ab-HRP assay}

The concentration of HRP-labeled anti-FABP (Ab-HRP) was measured at room temperature in 96-well NUNC maxisorb microtitre plates (Invitrogen, Merkelbeke, Belgium) as described previously. ${ }^{(36)}$ Each sample was diluted for at least 5 times with 
PBS supplemented with $0.05 \%(\mathrm{w} / \mathrm{v})$ Tween-20 (PBT), and $50 \mu \mathrm{l}$ was added to each well. Then, $100 \mu$ tetra-methyl benzidine (Lucron Bioproducts, Gennep, The Netherlands) was added, and after 2 min colour development was stopped with $2 \mathrm{M} \mathrm{H}_{2} \mathrm{SO}_{4}$. The optical density (OD) of each sample was measured at $450 \mathrm{~nm}$ by use of a Titertek Multiscan II spectrophotometer (Labsystems, Helsinki, Finland) and compared to a standard curve (range 0 to $12 \mu \mathrm{g} / \mathrm{L}$ ) of Ab-HRP. The detection limit of this assay was $0.12 \mu \mathrm{g} / \mathrm{L}$ and inter-assay imprecision was $<10 \%$.

\subsubsection{FABP assay}

FABP concentrations were measured in plasma, using a sandwich-type ELISA kit obtained from HyCult biotechnology (Uden, the Netherlands). This assay has been described in detail previously. ${ }^{(33)}$ The detection limit of this assay is $0.3 \mu \mathrm{g} / \mathrm{L}$, and interassay imprecision $11 \%$.

\subsubsection{Statistics}

Data are presented as mean \pm SD for the indicated number of experiments. Student's ttest for unpaired values was used to calculate differences between the Ab-HRP concentrations measured in the different fractions. $\mathrm{P}<0.05$ was considered statistically significant. In Figure 6.3, the Pearson's correlation coefficient is indicated.

\subsection{Results}

\subsubsection{Preparation of displacement columns}

Coupling of $111 \mu \mathrm{g}$ of FABP to $50 \mu \mathrm{L}$ of the NHS Sepharose matrix resulted in $84 \pm 4 \%$ binding (mean $\pm S D, n=11$ ), which is in accordance to the high binding capacity of this matrix as indicated by the manufacturer $(16-23 \mu \mathrm{mol} / \mathrm{ml})$. During the blocking step with $5 \% \mathrm{BSA}$, some FABP was found to be displaced from the matrix resulting in a final preparation containing approximately $93 \mu \mathrm{g}$ of bound FABP per $50 \mu \mathrm{l}$ Sepharose matrix.

\subsubsection{Binding of Ab-HRP to matrix-bound FABP}

HRP-labeled antibody was added to the Sepharose-bound FABP. After a 2 hours incubation period, about $50 \%$ of the Ab-HRP was bound to the matrix.

\subsubsection{Displacement of Ab-HRP from matrix-bound FABP}

Fig. 6.1, panel A, presents the spontaneous release of Ab-HRP from a displacement column containing $50 \mu \mathrm{l}$ Sepharose-bound-FABP after addition of plasma from a healthy donor during a total observation period of approximately 6 hours (including preparation of the Sepharose matrix). Flow velocity was $15 \mu \mathrm{l} / \mathrm{min}$ and $75 \mu$ fractions were collected every 2-3 min. A considerable fraction of the bound Ab-HRP was released, but 
eventually a relatively stable baseline was obtained with about $15 \%(\sim 0.01 \mathrm{nmol})$ of the initially added amount of Ab-HRP still attached to the immobilized FABP $(\sim 0.06 \mathrm{nmol})$.

When a single sample of plasma spiked with FABP $(1.3 \mathrm{mg} / \mathrm{L})$, was added to the displacement column followed by addition of donor plasma, a significantly increased $\mathrm{Ab}$ HRP level was measured in the subsequent 4-6 fractions before its return to baseline levels (Fig. 6.1, panel B) $(p<0.01)$. When, subsequently, another sample of plasma spiked with FABP was added, Ab-HRP levels increased less than after the first addition of FABP. Although successive additions of FABP thus resulted in progressively lower responses, the small standard deviations show that this was a quite reproducible phenomenon (Fig. 6.1, panel B).

To optimize the sensitivity of the displacement column, various parameters were tested such as the velocity of the flow through the matrix, the amounts of Sepharose and of FABP used for binding to this Sepharose, the amount of coupling buffer, the amount of labeled antibody, and the column height. Only two parameters appeared significant, i.e., flow velocity and amount of Sepharose (illustrated in Fig. 6.2). At a flow of 15 $\mu \mathrm{l} / \mathrm{min}$, the Ab-HRP levels after addition of plasma spiked with FABP $(1.3 \mathrm{mg} / \mathrm{L})$ were significantly higher than at a flow velocity of $30 \mu \mathrm{l} / \mathrm{min}$ (Fig. 6.2, panel A). Fig. 6.2, panel B presents the influence of the amount of Sepharose to which FABP was initially bound. Equal amounts of FABP were used to bind to 50 or $200 \mu \mathrm{l}$ Sepharose. To induce displacement, samples of $1000 \mathrm{ng}$ FABP in $200 \mu \mathrm{l}$ plasma $(5 \mathrm{mg} / \mathrm{L})$ were added four times to the two types of columns ( 50 versus $200 \mu \mathrm{l}$ Sepharose). This addition of FABP resulted in a significantly higher release of Ab-HRP from the $50 \mu$ Sepharose column, than from the $200 \mu \mathrm{l}$ Sepharose column. Thus, the higher FABP/Sepharose ratio resulted in a higher Ab-HRP release, allowing a more sensitive detection.

The amount of FABP immobilized to the Sepharose matrix was also varied, but increasing the amount of FABP for binding to the matrix did not result in increased levels of Sepharose-bound-FABP (data not shown). Similarly, variations of the amount of AbHRP used for coupling to Sepharose-bound FABP were tested. When lowering the amount of Ab-HRP from 15 to $3 \mu \mathrm{g}$, the column contained no measurable HRP anymore at the end of the experiment, while increasing the amount to $30 \mu \mathrm{g} \mathrm{Ab-HRP,} \mathrm{a} \mathrm{stable}$ plasma baseline could not be reached within $4 \mathrm{~h}$ (data not shown). 


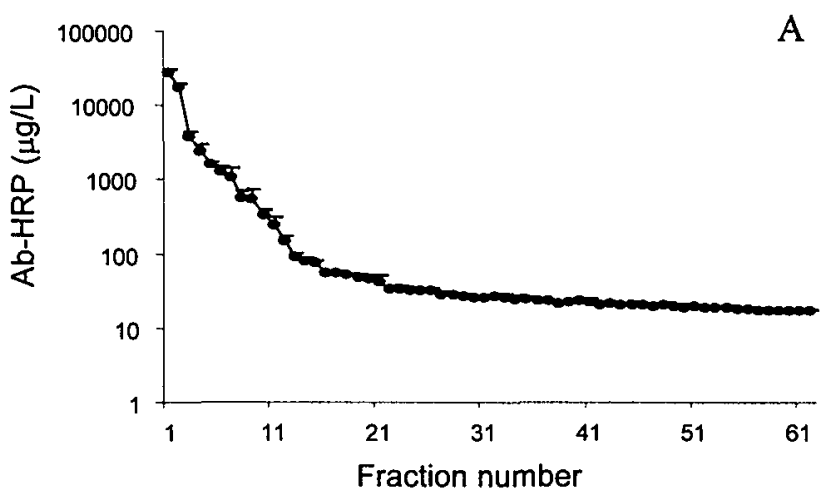

Panel A: spontaneous release of Ab-HRP from a displacement column during elution with human plasma, obtained from a healthy donor, for $4 \mathrm{~h}$.

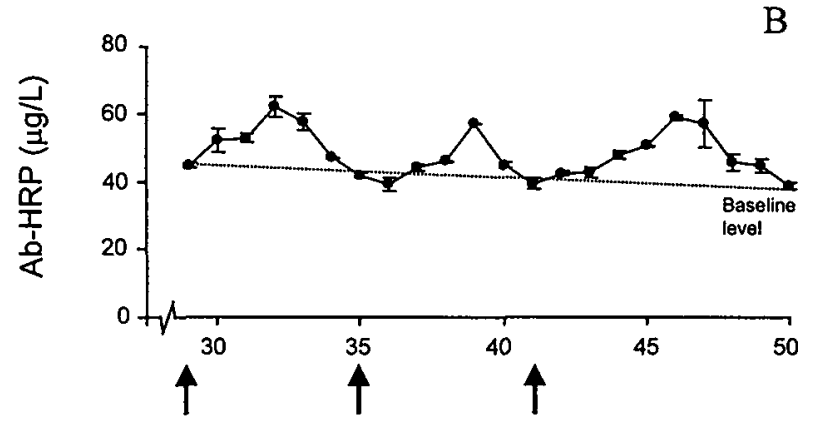

B Panel B: Ab-HRP levels after addition of donor plasma or donor plasma spiked with $1.3 \mathrm{mg} / \mathrm{L}$ FABP to a displacement column. Arrows indicate the time points at which addition of donor plasma is alternated by addition of $75 \mu \mathrm{l}$ of $1.3 \mathrm{mg} / \mathrm{L}$ FABP in plasma. The dotted line indicates the baseline level recorded when using donor plasma only.

Fraction number

Figure 6.1. Release of anti-FABP-HRP from a displacement column.

The displacement columns contain $50 \mu$ of Sepharose-bound FABP. Flow velocity was $15 \mu 1 / \mathrm{min}$ and $75 \mu$ column fractions were assayed for Ab-HRP. Data are presented as mean $\pm S D$ for $n=3$ on a $\log$ scale in panel $A$ and a linear scale in panel $B$. 


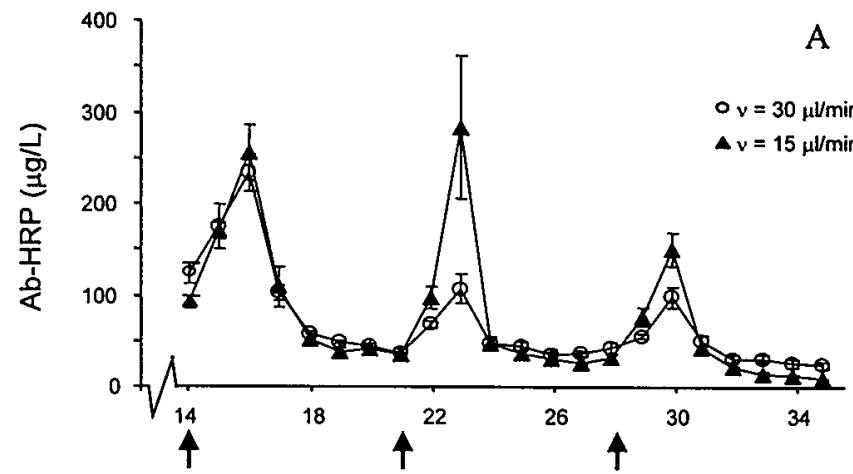

Fraction number

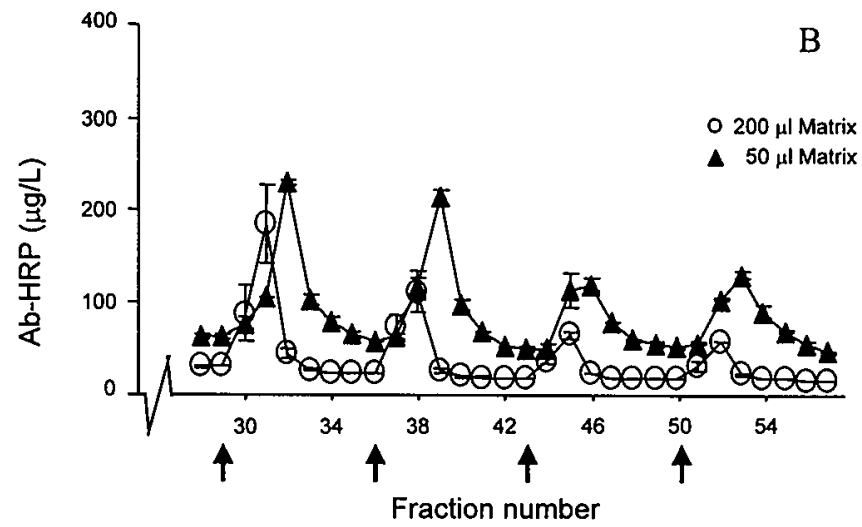

A Panel A: effect of flow velocity on displacement of Ab-HRP from a column containing 200 $\mu \mathrm{l}$ Sepharose-bound FABP. The flow velocity through the column was $30 \mu \mathrm{l} / \mathrm{min}$ (open circles) or $15 \mu \mathrm{l} / \mathrm{min}$ (black triangles). In both column types, addition of $200 \mu \mathrm{l}$ donor plasma, was alternated by additions of $200 \mu /$ of $5 \mathrm{mg} / \mathrm{L}$ FABP in donor plasma (arrows). Column fractions of $200 \mu l$ were assayed for AbHRP.

Panel B: release of Ab-HRP from columns containing $50 \mu \mathrm{l}$ or $200 \mu \mathrm{l}$ Sepharose-bound FABP (black triangles and open circles, respectively). In both column types, addition of $200 \mu$ donor plasma was alternated by addition of $200 \mu \mathrm{l}$ donor plasma spiked with 1000 ng (5 mg/L) FABP (arrows). Flow velocity through the column was $30 \mu \mathrm{l} / \mathrm{min}$ and column fractions of $200 \mu \mathrm{l}$ were assayed for Ab-HRP.

For both panels, data are presented as mean $\pm S D$ for $n=3$.

\section{Figure 6.2. Effect of flow velocity and Sepharose volume on displacement of Ab-HRP.}

\subsubsection{Studies with plasma from patients}

Displacement experiments with plasma from seven AMI patients are presented in Fig. 6.3. After preparation of a column containing $50 \mu \mathrm{l}$ Sepharose-bound-FABP, donor plasma was added to the displacement column so as to obtain a stable baseline. At a velocity of $15 \mu \mathrm{l} / \mathrm{min}$, a total amount of $375 \mu \mathrm{l}$ human AMI plasma was added. Then, again donor plasma was added to elute the column, and fractions of $75 \mu l$ eluate were collected and the concentration of Ab-HRP measured. Results obtained from three AMI patients, containing FABP concentrations between 300-1000 $\mu \mathrm{g} / \mathrm{L}$, are illustrated in panel A.

To calculate the total amount of Ab-HRP release induced by human AMI plasma, the area under the release curve was used. The slight decrease of spontaneous release of Ab-HRP during this time-interval was corrected for. Fig. 6.3, panel B, presents the overview of total Ab-HRP displaced after addition of plasma of AMI patients. In the range between $250-800 \mu \mathrm{g} / \mathrm{L} \mathrm{FABP}$, the level of displaced Ab-HRP was found to 
correlate to the plasma FABP concentrations measured by standard ELISA $(R=0.96$, $\mathrm{n}=5$ ).

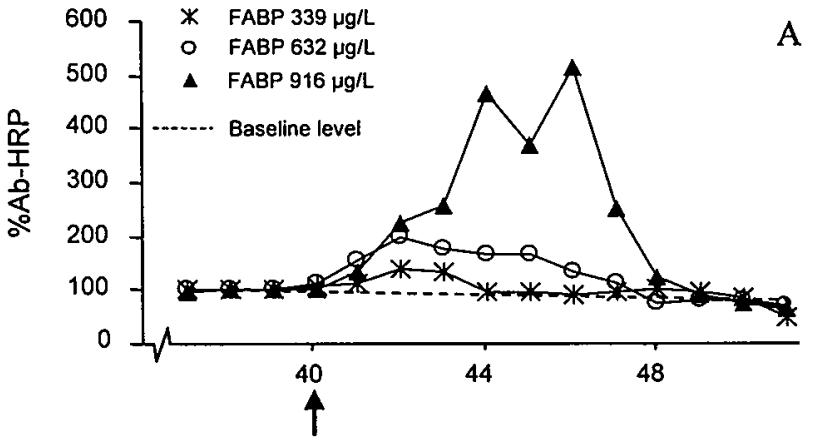

Fraction number

Panel A: procentual elevation in the eluate of Ab-HRP from a displace-ment column as a function of time, after addition of human plasma, obtained from a healthy donor, and of plasma samples from AMI patients, containing various concentrations of FABP (measured by ELISA). Arrow indicates the time point at which addition of healthy plasma was alternated by addition of $375 \mu \mathrm{l}$ plasma from AMl patients. Separate columns, each containing $50 \mu \mathrm{l}$ Sepharose- bound FABP, were used for each AMI patient and flow velocity was $15 \mu \mathrm{l} / \mathrm{min}$. $75 \mu \mathrm{l}$ column fractions were assayed for Ab-HRP. To allow proper comparison of the amount of Ab-HRP release between the different columns, the baseline plasma level was set at $100 \%$ for each column. The results for three representative patient samples are shown.

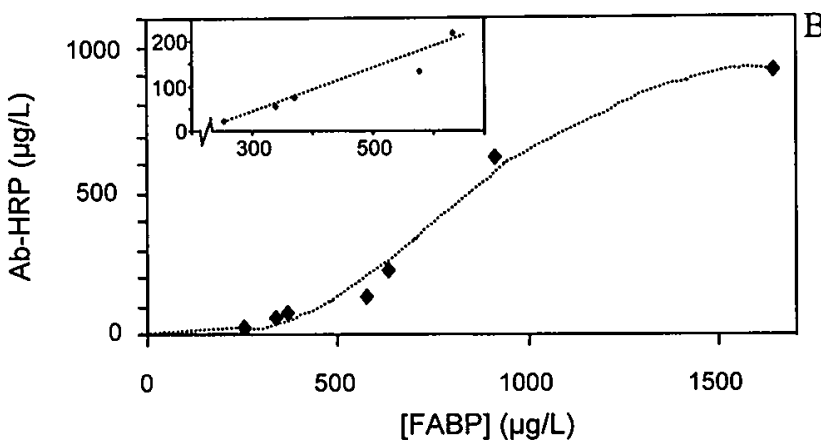

Panel B: total amount of Ab-HRP released from a displacement column, calculated as area under the- release- curve (fractions $40-48$ in panel $A$ ), as a function of the FABP concentration measured by ELISA, in plasma samples from $7 \mathrm{AMl}$ patients. The inset shows that in the range of $250-650 \mu \mathrm{g} / \mathrm{L}$ FABP there is a good correlation between these parameters $(R=0.96, n=5)$. Columns contained $50 \mu \mathrm{l}$ Sepharose-bound FABP and the flow velocity was $15 \mu \mathrm{l} / \mathrm{min}$.

Figure 6.3. Estimation of FABP in plasma from AMI patients using displacement columns

\subsection{Discussion}

This study presents the development of a displacement immunoassay for measurement of FABP in plasma. The assay consists of a glass column filled with Sepharose-bound FABP to which an anti-FABP-HRP complex (Ab-HRP) is bound. It was shown that 
addition of plasma containing FABP, repeatedly resulted in a significant displacement of $\mathrm{Ab}-\mathrm{HRP}$ and that such columns could be used for at least $6 \mathrm{~h}$. Importantly, a good correlation was found between the amount of FABP present in plasma and the resulting released displacement-complex. In addition, the results of the various experiments showed a high reproducibility. The present set up was semi-continuous, because the amount of displaced Ab-HRP in the fractions was measured separately downstream, but the column could well be used in a continuous measuring device.

\subsubsection{Characteristics of the immunoassay}

During the preparation of the immobilized Ab-HRP complex, it appeared that, after incubation, only $50 \%$ of this complex was bound to the Sepharose-bound-FABP matrix. Following the subsequent addition of healthy human plasma, a marked release of the $\mathrm{Ab}$ HRP complex from the matrix occurred. This can be explained by the rather high dissociation constant ( $k_{\text {off }}$ ) of the Ab-HRP complex. ${ }^{(35)}$ The amount of Ab-HRP that remained bound to the matrix is probably determined by additional non-specific interactions between Ab-HRP and the matrix.

Throughout the experiment spontaneous release of the Ab-HRP complex occurred. Although this release ultimately was reduced to a stable baseline (Fig. 6.1), the influence on the displacement signal (i.e., on the assay of samples) will be somewhat higher at the start of the experiment than at the end. Therefore, the Ab-HRP levels measured after addition of the FABP-containing samples, will be the result of displacement of Ab-HRP augmented with some spontaneous release of Ab-HRP.

When repeated measurements were made, the release of Ab-HRP was progressively less as a function of time, but the decline was quite reproducible. Because $10 \%$ of the labeled antibody is still available for displacement at the end of the experiment, the non-linearity observed is not due to a lack of antibody. This reduced displacement can neither be caused by inactivation of HRP, because HRP activity in plasma, incubated at room temperature, remained stable over a period of $8 \mathrm{~h}$ (data not shown). A likely explanation for the diminishing Ab-HRP release could be that its binding affinity would increase with time due to a growing number of non-specific interactions with the Sepharose matrix.

Both reduction of the flow through the column, and increasing the $\mathrm{FABP} /$ Sepharose ratio were found to increase the sensitivity of the system. The lower the flow (Fig. 6.2, panel A) the more time is available for displacement to occur, and then displacement-inducing FABP is more evenly distributed over the Sepharose-matrix.

Based on these results, a flow of $15 \mu \mathrm{l} / \mathrm{min}$ through a column containing $1 \mu \mathrm{g}$ FABP bound to $50 \mu \mathrm{l}$ Sepharose matrix was chosen. It remains to be determined whether a further increase in the FABP/Sepharose ratio would further increase the sensitivity of the assay.

\subsubsection{Clinical application}

Patho-physiological FABP concentrations in plasma due to an acute myocardial infarction (AMI) generally range from $10-1000 \mu \mathrm{g} / \mathrm{L}$. From our studies (Fig. 6.3), we can 
conclude that AMI's with plasma FABP levels above $250 \mu \mathrm{g} / \mathrm{L}$ could be measured using the present system. To enable the measurement of lower plasma FABP concentrations, the sensitivity of the assay has to be increased. As discussed above, lowering the flow could be a realistic option, however, this will increase the time needed for a sample to be assayed. Therefore, an optimum between flow and assay-time has to be determined in further experiments. Other options to increase the sensitivity are optimizing antibody affinity, the amount of Ab-HRP bound to the Sepharose-FABP or replacement of the HRP label by a label that can be amplified in the system.

The present study is a critical step in the development of a FABP immunosensor that can be used for on-line continuous measurement of FABP concentrations in plasma. When the sensitivity of the sensor described above can be improved, this measuring technique would decrease the time in which a biochemical marker in patient plasma can be quantified. Furthermore, changes of the release pattern of the marker in the patient plasma can be measured and the sensor would therefore not only be useful for patients entering the emergency room with chest pain, but may also be applied for non-invasive detection of coronary reperfusion. . $^{(37)}$

Finally, it should be noted that the assay principle outlined here is of generic nature. Changing the antibody would permit the continuous and repeated assay of other proteins by this displacement principle. This would especially apply to other types of FABP, like liver-type FABP and intestinal-type FABP which recently have been established as early markers of liver and intestinal injury. ${ }^{(38,39)}$

\subsection{References}

1. Alpert JS, Thygesen K, Rydén L, Garson A. Myocardial infarction redefined-a consensus document of The Joint European Society of Cardiology/American College of Cardiology committee for the redefinition of myocardial infarction. The Joint European Society of Cardiology/ American College of Cardiology Committee. J Am Coll Cardiol 2000;36:959-69.

2. Aartsen WM, Pelsers MMAL, Hermens WT, Glatz JFC, Daemen MJAP, et al. Heart fatty acid binding protein and cardiac troponin $\mathrm{T}$ plasma concentrations as markers for myocardial infarction after coronary artery ligation in mice. Pflugers Arch Eur J Physiol 2000;439:41622.

3. de Winter RJ, Lijmer JG, Koster RW, Hoek FJ, Sanders GT. Diagnostic accuracy of myoglobin concentration for the early diagnosis of acute myocardial infarction. Ann Emerg Med 2000;35:113-20.

4. Ghani F, Wu AH, Graff L, Petry C, Armstrong G, et al. Role of heart-type fatty acid-binding protein in early detection of acute myocardial infarction. Clin Chem 2000;46:718-9.

5. Nakata $T$, Hashimoto A, Hase M, Tsuchihashi K, Shimamoto K. Human heart-type Fatty Acid-binding protein as an early diagnostic and prognostic marker in acute coronary syndrome. Cardiology 2003;99:96-104.

6. Okamoto F, Sohmiya K, Ohkaru Y, Kawamura K, Asayama K, et al. Human heart-type cytoplasmic fatty acid-binding protein (H-FABP) for the diagnosis of acute myocardial infarction. Clinical evaluation of H-FABP in comparison with myoglobin and creatine kinase isoenzyme MB. Clin Chem Lab Med 2000;38:231-8.

7. Jesse RL, Kukreja R. Rationale for the early clinical application of markers of ischemia in patients with suspected acute coronary syndromes. Cardiovasc Toxicol 2001;1:125-33. 
8. Apple FS. Cardiac troponin: redefining the detection of myocardial infarction. Am Clin Lab 2002;21:32-4.

9. Apple FS. Acute myocardial infarction and coronary reperfusion. Serum cardiac markers for the 1990's. Am J Clin Pathol 1992;97:217-26.

10. Bakker AJ, Koelemay MJW, Gorgels JPMC, van Vlies B, Smits R, et al. Troponin T and myoglobin at admission: value of early diagnosis of acute myocardial infarction. Eur Heart $\mathrm{J}$ 1994;15:45-53.

11. Bahayana V, Henderson AR. Biochemical markers of myocardial damage, review. Clin Biochem 1995;28:1-19.

12. de Winter RJ, Koster RW, van Straalen JP, Gorgels JP, Hoek FJ, et al. Critical difference between serial measurements of CK-MB mass to detect myocardial damage. Clin Chem 1997;43:338-43.

13. van Dieijen-Visser MP, Kragten JA, Glatz JFC, Hermens WT. Clinical relevance of early markers for the diagnosis of acute myocardial infarction (AMI). Tijdschr Ned Ver Klin Chem 1993;3:140-4.

14. Chu WW, Dieter RS, Stone CK. A review of clinically relevant cardiac biochemical markers. WMJ 2002;101:40-8.

15. Chu WW, Dieter RS, Stone CK. Evolving clinical applications of cardiac markers: a review of the literature. WMJ. 2002;101:49-55.

16. Malasky BR, Alpert JS. Diagnosis of myocardial injury by biochemical markers: problems and promises. Cardiol Rev 2002;10:306-17.

17. Panteghini M. The measurement of cardiac markers: where should we focus? Am J Clin Pathol 2002;118:354-61.

18. Wu AH. Analytical and clinical evaluation of new diagnostic tests for myocardial damage. Clin Chim Acta 1998;272:11-21.

19. Pope JH, Selker HP. Diagnosis of acute cardiac ischemia. Emerg Med Clin North Am 2003;21:27-59.

20. Ryan TJ, Melduni RM. Highlights of latest American college of cardiology and American heart association guidelines for management of patients with acute myocardial infarction. Cardiol Rev 2002;10:35-43.

21. Wu AH. Cardiac markers: cost-effective triage for MI admission and therapy. Med Lab Obs 2002;34:36-40.

22. Fesmire FM. Improved identification of acute coronary syndromes with delta cardiac serum marker measurements during the emergency department evaluation of chest pain patients. Cardiov Toxicol 2001;01:117-123.

23. Glatz JFC, van Bilsen M, Paulussen RJA, Veerkamp JH, van der Vusse GJ, et al. Release of fatty acid-binding protein from isolated rat heart subjected to ischemia and reperfusion or to the calcium paradox. Biochim Biophys Acta 1988;961:148-52.

24. Tanaka T, Hirota $Y$, Sohmiya K, Nishimura S, Kawamura K. Serum and urinary human heart fatty acid-binding protein in acute myocardial infarction. Clin Biochem 1991;24:195-201.

25. Kleine AH, Glatz JFC, van Nieuwenhoven FA, van der Vusse GJ. Release of heart fatty acidbinding protein into plasma after acute myocardial infarction in man. Mol Cell Biochem 1992;116:155-62.

26. Tsuji R, Tanaka T, Sohmiya K, Hirota Y, Yoshimoto K, et al. Human heart-type cytoplasmic fatty acid-binding protein in serum and urine during hyperacute myocardial infarction. Int $J$ Cardiol 1993;41:209-17.

27. Glatz JFC, van der Voort D, Hermens WT. Fatty acid-binding protein as the earliest available plasma marker of acute myocardial injury. J Clin Lig Assay 2003;25:167-77. 
28. Mair J. Progress in myocardial damage detection: new biochemical markers for clinicians. Crit Rev Clin Lab Sci 1997;34:1-66.

29. van Nieuwenhoven FA, Kleine AH, Wodzig KWH, Hermens WT, Kragten HA, et al. Discrimination between myocardial and skeletal muscle injury by assessment of the plasma ratio of myoglobin over fatty acid-binding protein. Circulation 1995;92:2848-54.

30. Ho WO, Athey D, McNeil CJ. Amperometric detection of alkaline phosphatase activity at a horseradish peroxidase enzyme electrode based on activated carbon: potential application to electrochemical immunoassay. Biosens Bioelectron 1995;10:683-91.

31. Ivnitski D, Rishpon J. A one-step, separation-free amperometric enzyme immuno-sensor. Biosens Bioelectron 1996;11:409-17.

32. Schreiber A, Specht B, Pelsers MMAL, Glatz JFC, Borchers T, et al. Recombinant human heart-type fatty acid-binding protein as standard in immunochemical assays. Clin Chem Lab Med 1998;36:283-8.

33. Siegmann-Thoss C, Renneberg R, Glatz JFC, Spener F. Enzyme immunosensor for diagnosis of myocardial infarction. Sens Actuators B 1996;30:71-6.

34. Wodzig KWH, Pelsers MMAL, van der Vusse GJ, Roos W, Glatz JFC. One-step enzymelinked immunosorbent assay (ELISA) for plasma fatty acid-binding protein. Ann Clin Biochem 1997;34:263-8.

35. Kaptein WA, Korf J, Cheng S, Yang M, Glatz JFC, et al. On-line flow displacement immunoassay for fatty acid-binding protein. J Immunol Methods 1998;217:103-11.

36. Roos W, Eymann E, Symannek M, Duppenthaler J, Wodzig KWH, Pelsers MMAL, Glatz JFC. Monoclonal antibodies to human heart fatty acid-binding protein. J Immunol Methods 1995; 183:149-53.

37. van der Voort D, Pelsers MMAL, Korf J, Hermens WT, Glatz JFC. Development of a displacement immunoassay for human heart-type fatty acid-binding protein in plasma: the basic conditions. Biosens Bioelectron 2003;19:465-71.

38. de Groot MJM, Kragten HJA, Hermens WT, Glatz JFC. Assessment of coronary reperfusion by cardiac marker proteins in patients with myocardial infarction-a Review. Cardiovascular Rev Rep 2003;24:144-9.

39. Pelsers MMAL, Morovat A, Alexander GJ, Hermens WT, Trull AK, et al. Liver fatty acidbinding protein as a sensitive serum marker of acute hepatocellular damage in liver transplant recipients. Clin Chem 2002;48:2055-7.

40. Gok MA, Pelsers MMAL, Glatz JFC, Bhatti AA, Peaston R, et al. Comparison of perfusate activities of glutathione S-transferase, alanine aminopeptidase and fatty acid binding protein in the assessment of non-heart-beating donor kidneys. Ann Clin Biochem 2003;40:252-8. 
Chapter 6 


\section{Development of other rapid immunoassays for FABP based on electrochemical or optical transduction methods}

\subsection{Foreword}

As explained in detail in Chapters 2 and 3, the rapid measurement of heart-type fatty acid binding protein (FABP) in plasma of a patient with chest pain entering the emergency department, could be of great value. FABP can be used for detection or exclusion of acute myocardial infarction (AMI), for detection of re-infarction, and for estimation of the extent of tissue injury induced by ischemia. Further to several quantitative biosensor devices for the measurement of heart type-FABP already described in Chapter 4, two recently developed devices will be described here.

Ana Gallardo from Cambridge Life Sciences (CLS, Ely, United Kingdom) together with Calum McNeil from the Medical School of the University of Newcastleupon-Tyne (Newcastle upon-Tyne, United Kingdom) worked on the development of an immunosensor for FABP that uses a novel impedance detection technique. ${ }^{(1)}$ Since 2001 , we were involved in their project and also provided human plasma from AMI patients. Manufacturing problems with the electrodes and with the nitrocellulose membranes have seriously hampered the measurement of plasma samples. Therefore, only a brief description of the sensor and some preliminary results will be given below.

The second device that will be described here, is a lateral flow assay for FABP developed by Cangel Chan and Reinhard Renneberg at the Department of Chemistry, Biosensor and Bioelectronics Laboratory of Hong Kong University of Science and Technology (Hong Kong, China) in collaboration with the company 8sens.biognostic AG (Berlin, Germany). ${ }^{(2)}$ They developed a "credit-card-like" device with an incorporated lateral flow assay for FABP. This so-called CardioDetect ${ }^{(1)}$ card is a rapid chromatographic immunoassay designed for qualitative determination of $\mathrm{FABP}$ in whole blood samples, to be used by general practitioners, in the ambulance, or even by patients themselves. Our group was engaged to evaluate the performance of CardioDetect ${ }^{\otimes}$ cards in a laboratory setting as well as in the emergency department of the Academic hospital in Maastricht (AzM).

\subsection{FABP quantification by use of an $\mathrm{AC}$ impedance detection technique}

\subsubsection{Background}

Cambridge Life Sciences (CLS) together with the Medical School of the University of Newcastle-upon-Tyne developed a quantitative near-patient immunosensor technology to be used for myocardial infarction diagnosis and cardiac monitoring. The novel device enables rapid and quantitative prediction of infarction episodes as well as reliable cardiac monitoring by specialists in emergency units, paramedics, general practitioners, and other professionals. 


\subsubsection{Sensor Principle}

The sensor is a combination of a classical immuno-assay and a novel detection system that is based on capacitance measurements of enzyme-catalysed polymer degradation. Following the binding of the antigen to the immobilized antibody, an enzymatic reaction is started which causes that an insulating polymer film is gradually removed from its surface, thereby inducing capacitance changes measured by an electrode.

The device consists of a lateral flow strip test combined with an electrode. The electrode is coated with enteric polymer Eudragit S100 (Röhm Pharma) which degrades rapidly above $\mathrm{pH} 7.4$.

The sample pad of the lateral flow strip contains a blood separator, which prevents erythrocytes to enter the nitrocellulose membrane (Fig. 7.1). On the nitrocellulose membrane, FABP monoclonal antibody (Ab) has been deposited as a test line, and $A b$ conjugated with urease (Ab-urease) acts as a mobile phase. The soluble FABP, present in the blood or plasma sample, combines with both antibodies, thus fixing active urease at the capture line. After unbound Ab-urease is washed away, addition of a wash solution containing urea, which is rapidly hydrolyzed in the presence of urease, leads to a release of carbon dioxide and ammonia thereby increasing the local $\mathrm{pH}$ to values above eight. The polymer film starts degrading under these alkaline conditions, altering the insulating electrode coating and causing a measurable change in capacitance. Such a capacitance variation is directly related to the analyte concentration present in the sample, giving a quantifiable reading of FABP concentration in less than ten minutes.

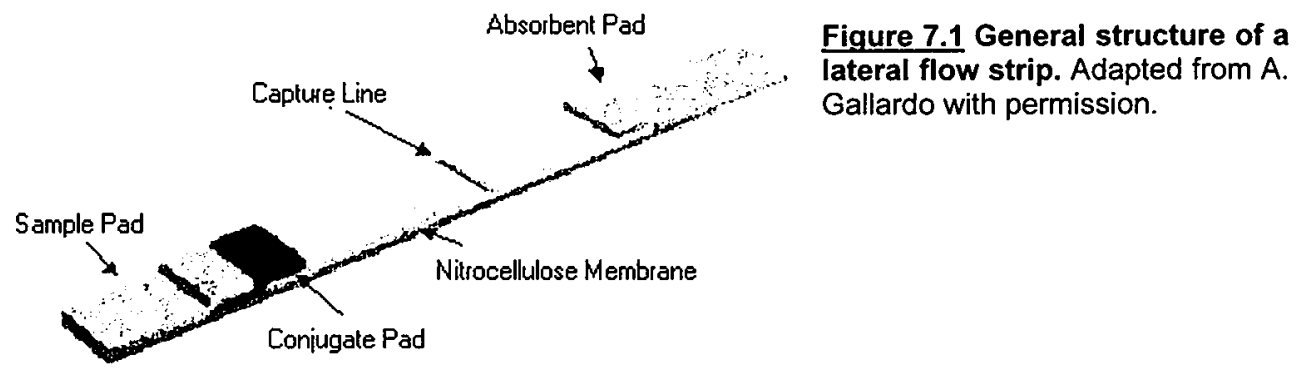

\subsubsection{Human plasma}

Plasma was obtained from patients with chest pain entering the Academic Hospital Maastricht (AzM). Inclusion criteria were (i) patient's hospital delay (i.e., timespan between onset of AMI symptoms and entrance at the emergency department) of less than $6 \mathrm{~h}$, (ii) patients did not receive heparine and/or thrombolytics before or during transportation to the hospital and (iii) patients did not receive thrombolytic therapy. AMI was confirmed by ST-segment elevation $>1 \mathrm{~mm}$, typical of AMI, and increased troponin T values within $24 \mathrm{~h} .10 \mathrm{ml}$ blood of these patients was collected in EDTA plasma-tubes, centrifuged $(1500 \mathrm{~g}, 10 \mathrm{~min})$ and stored at $-20^{\circ} \mathrm{C}$ till further use. All patients signed informed consent and the study was approved by the local Medical Ethical Committee. 


\subsubsection{Results}

Figure 7.2 presents the immunosensor response to different concentrations of FABP in plasma. The FABP concentration in plasma from two AMI patients was assayed by a standard ELISA method. ${ }^{(3)}$ Samples with 41.5 and $166 \mathrm{ng} / \mathrm{ml}$ FABP respectively were tested in duplicate with the sensor, to yield capacity readings during a certain timeinterval. Taking a specific time-point $(600 \mathrm{~s})$ the FABP concentration can be plotted against its accompanying capacitance (Fig. 7.3).

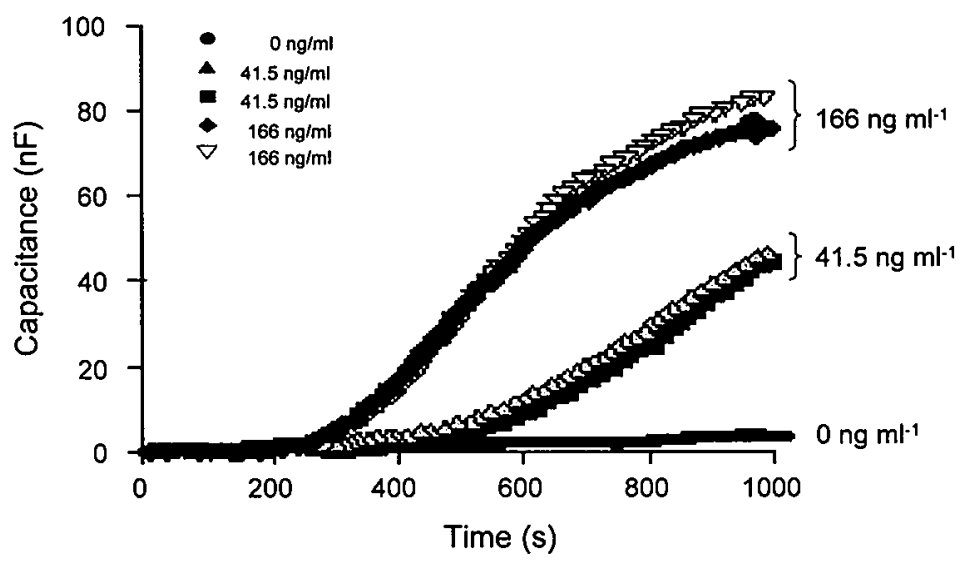

Figure 7.2 Immunosensor response to different concentra-tions of FABP in plasma.

Adapted from A. Gallardo with permission.

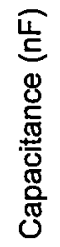

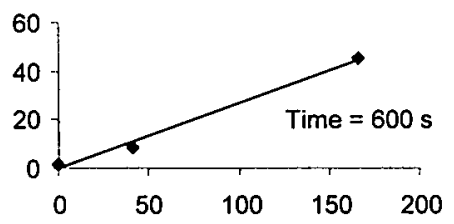

Figure 7.3 Immunosensor response after $600 \mathrm{~s}$ to different concentrations of FABP in plasma.

Abbreviations: $\mathrm{FABP}=$ fatty acid-binding protein, conc. $=$ concentration

$[\text { FABP conc. }]_{\text {plasma }}$

\subsubsection{Conclusion}

For the three samples tested here, the sensor gave reproducible results. Importantly, a clear distinction can be made between the different FABP concentrations and the control sample. From these preliminary data it is not yet clear whether there is a linear relationship between the plasma FABP concentration and the capacitance signal measured after a certain assay time. However, when a calibration curve is used, the sensor system is suitable for assay of FABP in whole blood.

Because the assay-time is only 10 minutes, this sensor seems to be very valuable for clinical application. Furthermore, the detection system offers the advantage of being easily applicable to the measurement by a similar sensor device of many other biomolecules that are produced or released in plasma as a result of a disease or abnormal condition. 


\subsection{CardioDetect $^{\circledR}$}

\subsubsection{Background}

The one-step FABP test, called CardioDetect ${ }^{\circledR}$, was derived from a recently described serum lateral-flow assay. ${ }^{(2,4)}$ This novel AMI rapid-test facilitates a reliable diagnosis as early as 35 minutes after the beginning of AMI. It is the only commercially available test worldwide that claims a truly early diagnosis of AMI. Two card types were developed, "CardioDetect ${ }^{\circledR}$ med" is suitable for all emergency units and institutions taking care of risk persons. The other card, "CardioDetect ${ }^{\circledast}$ self", is especially intended for persons with an elevated risk of myocardial infarction (Fig. 7.4). In case of non-specific symptoms such a person may perform the test for himself. The result of the test will then already be available when the emergency doctor arrives. As a result, the patient himself may help to shorten the critical time span between infarct and treatment onset.

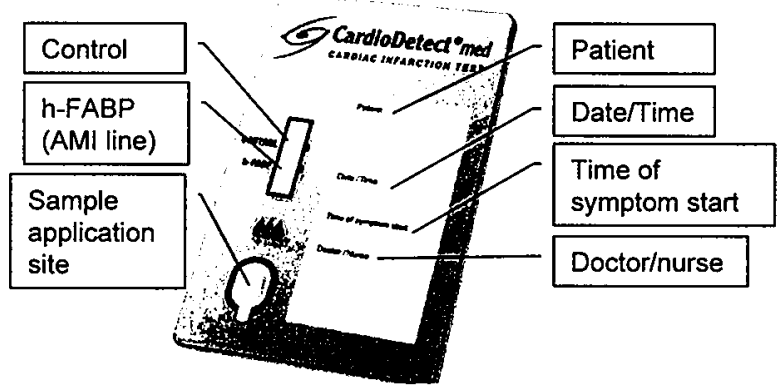

Figure 7.4 Presentation of the CardioDetect ${ }^{\oplus}$ med test.

Abbreviations: h-FABP = heart-type fatty acid-binding protein, $\mathrm{AMI}=$ acute myocardial infarction.

Adapted from www.rennesens.de with permission.

\subsubsection{Test principle}

The lateral flow assay used in the card is based on a blood separator instead of a sample pad, and the assay is based on an immuno-threshold principle.

After application of a few drops of blood, the plasma rapidly wets the entire test strip (within $15 \mathrm{~min}$ ), due to capillary action. Several monoclonal antibodies are placed on precisely defined positions of the strip. When plasma moves further, first the conjugate pad containing FABP antibodies conjugated with colloidal gold (Ab-CG) is wetted, and thereafter, these antibodies become solubilized. As the sample passes, FABP, when present in the blood, will become attached to this labeled antibody (Ab-CG) and forms a FABP-Ab-CG complex. Then, the zone (AMI line) where the capture antibody is immobilized is reached. The FABP-Ab-CG will bind to this antibody and within 15 minutes, a red line becomes visible. The remaining Ab-CG molecules not bound to FABP will reach anti-mouse IgG (present on the control line) which also produces a red line within 15 min (Fig. 7.5). 


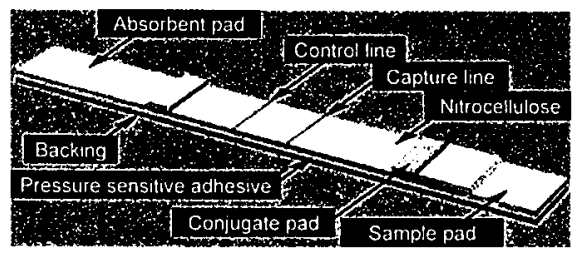

Figure 7.5 Schematic presentation of the test strip used as part of the CardioDetect ${ }^{\oplus}$ cards.

Adapted from www.rennesens.de with permission.

\subsubsection{Human samples}

Human blood used for the evaluation of this test in a laboratory setting was obtained from a healthy blood donor of the local blood bank. Blood was collected in heparin-tubes. After testing this blood for several diseases, it was stored at $4^{\circ} \mathrm{C}$ until use (performed within 8 hours).

Human plasma of AMI patients was obtained as described in section 7.2.3. At the time that blood was collected from these patients, the nurse at the emergency department immediately added three drops of fresh blood on the (pre-production) CardioDetect ${ }^{\circledR}$ card.

\subsubsection{Preliminary results}

In our laboratory, so far 18 cards were tested using fresh human blood spiked with 0,5 , $10,18,25,40,60,80$ or $100 \mu \mathrm{g} / \mathrm{L}$ FABP, respectively. There were no false positive and no false negative results, i.e., addition of plasma containing 0 or $5 \mu \mathrm{g} / \mathrm{L} \mathrm{FABP}$ did not resulted in a visible AMI line, whereas addition of plasma containing 10-100 $\mu \mathrm{g} / \mathrm{L}$ FABP did cause a visible AMI line. Taking a cut-off value of $6 \mu \mathrm{g} / \mathrm{L}$ FABP indicative for AMI, these results suggest a $100 \%$ sensitivity (i.e., proportion of positive subjects that are correctly identified by the test) as well as a $100 \%$ specificity (i.e., for the test proportion of negative subjects that are correctly identified by the test).

A second batch of cards was used at the emergency department of AzM. Three drops of fresh blood of patients who entered the emergency department with chest pain were used on the cards. Plasma of the same patient was also stored in heparin-tubes at $20^{\circ} \mathrm{C}$ to quantify the FABP concentration using a standard ELISA. ${ }^{(3)}$ From the 20 cards that could be tested so far, four cards did not show a control line $(20 \%)$, there was one false positive and one false negative result when compared to reference ELISA results and clinical diagnosis (AMI when FABP $>6 \mu \mathrm{g} / \mathrm{L}$ ).

\subsubsection{Conclusion and future studies}

Although the CardioDetect tests performed perfectly in a laboratory setting, the cards used at the emergency department produced less reliable results. A possible explanation for this discrepancy is the amount of blood that is used on the card and made us perform additional studies. It was found that an insufficient amount of blood will not cause complete wetting of the strip, and therefore bad or badly visible control lines, whereas when too much blood is applied, this can saturate the blood separator causing leakage of blood directly to the strip (data not shown). The fact that poorly trained nurses performed 
the test in an emergency setting may have caused poor control of the amount of blood applied to the card.

These findings led the company decide to do further studies with the test strips, and change specific details during the final developmental phase of the cards. Subsequent results of a batch of cards tested at the hospital of Bernau (Germany) ${ }^{(2)}$ are very promising, indicating their applicability for routine use in a clinical setting. However, more extensive evaluations at distinct hospitals are needed before the CardioDetect ${ }^{\mathbb{B}}$ self test can be commercialized for personal use.

\subsection{References}

1. Gallardo A, Rawson $\mathrm{K}, \mathrm{McNeil} \mathrm{C}$. Near patient testing: diagnosing a first world killer. The Chemical Engineer 2002; 734:30-2.

2. Chan CPY, Sum KW, Cheung KY, Glatz JFC, Sanderson JE, et al. Development of a quantitative lateral-flow assay for rapid detection of fatty acid-binding protein. J. Immunol Methods 2003; 279:91-100.

3. Wodzig KWH, Pelsers MMAL, van der Vusse GJ, Roos W, Glatz JFC. One-step enzymelinked immunosorbent assay (ELISA) for plasma fatty acid-binding protein. Ann Clin Biochem 1997;34:263-8.

4. Chan CPY, Cheng WS, Glatz JFC, van der Voort D, JE Sanderson, et al. Early diagnosis of acute myocardial infarction using immunosensors and immunotests. Anal Letters 2003; 36:1987-2004. 


\section{General discussion}

\subsection{The relevance of rapid diagnosis of cardiac injury}

Acute coronary syndromes (ACS) are the leading cause of morbidity and mortality in the Western world. Unstable angina, acute myocardial infarction and heart failure comprise a large part of patients with ACS and are emerging as a major public health problem. The incidence of cardiovascular disease in industrialized countries is expected to remain high. This high incidence is also caused by the fact that more patients can be kept alive during the acute phase of ischemic heart disease, and that these patients are prone to develop chronic heart disease such as heart failure. Secondly, the population is aging and, therefore, the numbers of patients with degenerative myocardial conditions increase.

Of all patients in Europe with chest pain, entering the emergency room, about $50 \%$ are identified as low risk (non-ischemic chest pain), and sent home (Fig. 8.1). ${ }^{(1)}$ Of the other half of patients, $40 \%$ have clear symptoms of AMI (i.e., a typical medical history and signs of persisting ischemia or necrosis in the electrocardiogram) and can rapidly be treated. ${ }^{(1)}$ If there are no contra-indications, these AMI patients will preferably be treated with thrombolytic therapy. If the latter is not possible, acute PTCA, or revascularisation (acute bypass surgery) are possible treatments. When the history is suspect but the electrocardiographic changes are not specific (the other $60 \%$ of patients), the patients are still admitted to the emergency department, but only $10 \%$ of these patients have AMI. Thus, if diagnosis could be performed properly, the remaining (nonAMI) patients could soon be discharged. Therefore, a more rapid and appropriate assessment or exclusion of AMI in this group of patients is strongly indicated for reasons of successful patient treatment, and of cost reduction as a result of early discharge. To enable rapid diagnosis or exclusion of AMI in this "hard-to-diagnose" patient population, cardiac marker proteins are commonly used. ${ }^{(2-4)}$ The need for cardiac marker measurements was emphasized when AMI was redefined by the ESC/ACC in 2000 and included the rise and fall of cardiac markers combined with e.g., clear electrocardiographic changes or ischemic symptoms (see Chapter 2). ${ }^{(5)}$ This resulted in a dual use of cardiac markers. On the one hand, when there are clear signs of cardiac infarction, the markers are used for confirmation of the diagnosis. On the other hand, when AMI signs are unclear, the markers are used to rule out myocardial infarction. Furthermore, the re-definition led to an extended role of cardiac marker testing into risk stratification and guidance of treatment decisions. ${ }^{(6,7)}$ After thrombolysis, for example, measurement of serial changes of plasma cardiac markers concentrations can be helpful for non-invasive assessment of successful coronary reperfusion. ${ }^{(8,9)}$

The new definition of AMI also raised several problems. Firstly, more patients are defined as suffering from AMI, partly due to the possibility of revealing micro-necrosis. Although this is of diagnostic and prognostic value for the patient, it also causes an increased amount of hospital admissions of patients formerly defined as non-AMI patients (Fig. 8.1). Secondly, the patient's diagnosis or exclusion of having AMI, is 
dependent on the type of cardiac marker that is used. Each marker has specific characteristics (see Chapter 2), but none of the markers alone can be used as an ideal marker of cardiac injury.

Before discussing the optimal set of markers for cardiac injury, some attention should be given to the definition of cardiac injury.

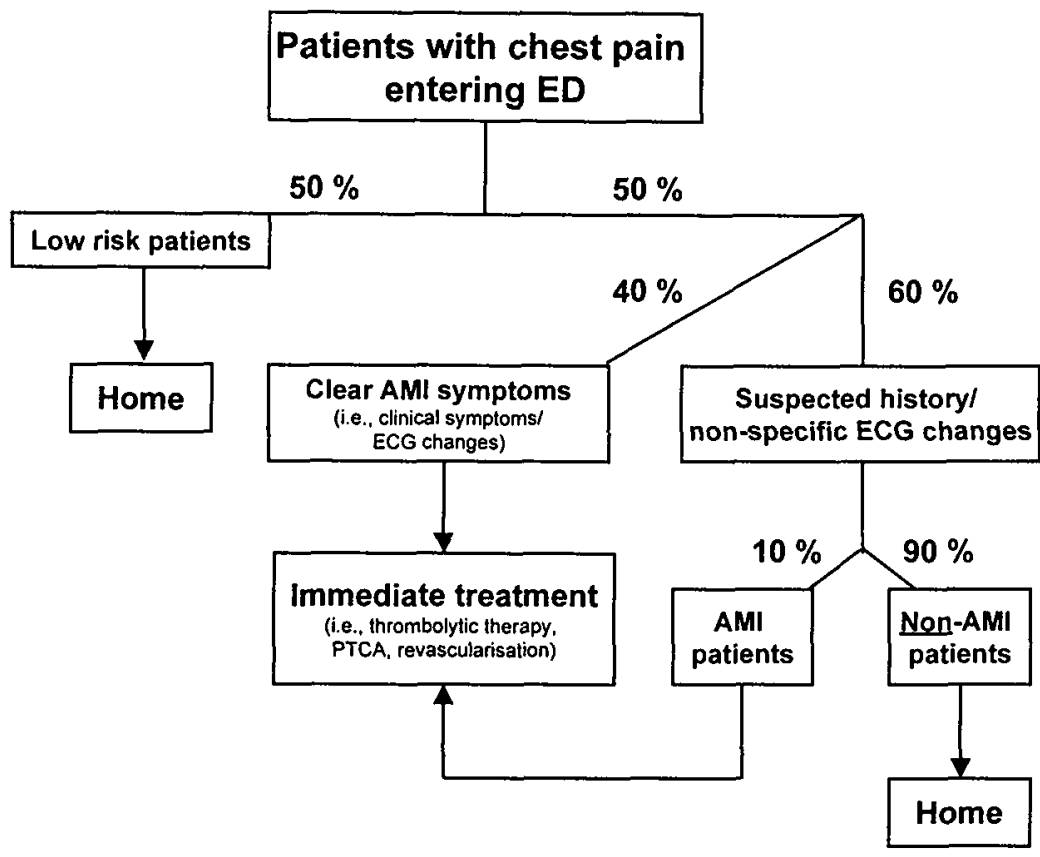

Figure 8.1 Flowchart of chest pain patients entering the emergency department

The diagnosis unstable angina pectoris (UAP) is not mentioned in this scheme because this is a controversial issue and is not subject of this thesis. Data obtained from reference 1.

Abbreviations: $E D$ = emergency department, $A M I$ = acute myocardial infarction, $E C G=$ electrocardiographic, PTCA = percutaneous transluminal coronary angioplasty .

\subsection{Apoptosis and necrosis may go together}

The amount of cardiac injury is dependent on the duration as well as the degree of reduced blood flow (see Chapter 2). However, only when the cell membrane of a cardiomyocyte is disrupted, cytoplasmic constituents, like cardiac proteins, can enter the interstitium. From there, the constituents will enter the circulation, and their presence and concentration can be assayed in blood, plasma or serum.

Rupture of the cell membrane is one of the characteristics of cell necrosis. If evolving ischemic injury results in necrosis, cell swelling occurs with organelle disruption, amorphous chromatin clumping, and eventually sarcolemmal breakdown. ${ }^{(10)}$ Recently, there has been an increasing interest in apoptosis, i.e., programmed cell death, which may occur in the ischemic and reperfused myocardium. ${ }^{(11,12)}$ During apoptosis, cell 
shrinkage occurs without the leakage of cytoplasmic constituents into the interstitium. Fragmentation of nuclear chromatin results in compacted, dense packages, which are closely associated with the nuclear membrane. The cell itself shrivels and cytoplasmic blebs are formed which round off into discrete (membrane-bound) apoptotic bodies. ${ }^{(10,13)}$ These bodies, containing densely packed, intact organelles, are engulfed and digested by macrophages or neighboring cells (Fig. 8.2). No leakage of cytosolic components and no inflammatory response occur. Once inside the macrophage, the apoptotic cell is quickly disassembled. ${ }^{(10,14)}$

(a)

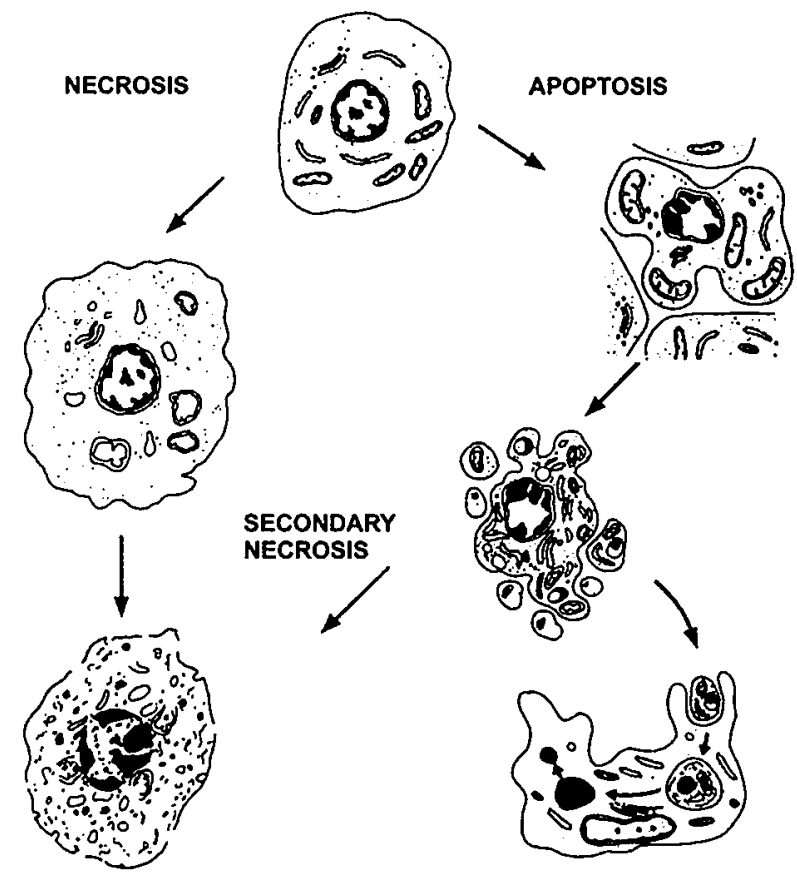

(c)

(d)

(e)

Figure 8.2 During necrosis the cell forms blebs, swells (a) and releases cytosolic constituents after permeabilisation of the plasma membrane (b), leading to an inflammation reaction in tissues. Apoptosis, also called "programmed cell death", is characterized by several specific morphological and biochemical aspects that are different from necrosis. An apoptotic cell shrinks, forms blebs, and detaches from its neighbours, while the plasma membrane and cellular organelles remain intact (c). In the nucleus, the chromatin condenses at the nuclear membrane. Finally, the cell disintegrates into apoptotic bodies (d) that are taken up by neighbouring cells (e). Only recently several techniques became available to identify this form of cell death in vitro. Figure adapted from reference 9 with permission

Apoptosis can be detected by specialized techniques that detect DNA fragmentation. Several studies revealed that apoptosis occurs during ischemia-reperfusion in addition to necrotic cell death. However, it is presently unclear to which extent and at what stage of cardiac injury apoptosis occurs in relation to necrosis due to conflicting results of several research groups. ${ }^{(11,15-17)}$ Furthermore, it is suggested that the apoptotic cell can also become necrotic. ${ }^{(18)}$ In such case, the cell membrane will eventually rupture 
and the constituents will still reach the interstitium. This process is sometimes referred to as secondary necrosis (Fig. 8.2). Thus, apoptosis may result in necrosis and these simultaneously occurring events make it difficult to assign cardiac cell death to one of these two processes only. However, from the agreement between the total amount of marker proteins released into circulation and lost from the heart it can be concluded that the contribution of pure apoptosis must be modest. ${ }^{(19)}$

\subsection{The optimal marker for cardiac injury}

As mentioned above, the patient's final diagnosis is dependent on the type of cardiac marker that is used. This is caused by the difference in marker characteristics and by the time-span between onset of AMI symptoms and entrance of the patient to the emergency department. When the time-span is known, the choice between measurement of an early or late marker can easily be made. However, when both types of markers are measured, the so-called diagnostic window can be extended. ${ }^{(20)}$ "Early" markers are useful to diagnose patients who enter the emergency department 1-6 h after onset of symptoms, but can also be used to indicate re-infarction at a later point of time. "Late" markers can be used to diagnose patients after $10 \mathrm{~h}$ or more after onset of AMI symptoms. Both types of markers can be used for estimation of the infarct size, which is important for better risk stratification, and for appropriate post-infarction treatment. ${ }^{(21-23)}$

The denomination of early versus late marker depends on the way the marker reaches the circulation after cardiac injury, as well as on the way they appear from the circulation. Small cardiac proteins, like myoglobin and FABP will enter the circulation mostly by diffusion into the micro-vessels, and partly by the lymphatic system (see Figure 2.1, Chapter 2). These small proteins are rapidly cleared by the kidneys and therefore, they disappear out of the circulation rather quickly. If the patient enters the hospital more than 12 hours after onset of AMI symptoms, the early maker may not be suitable for diagnosing AMI. However, when the patients develops a re-infarction within 24 hours after the first infarction, the early marker concentration will again be raised and therefore be measurable. Larger cardiac marker proteins like CK-MB and LDH will enter the circulation slower. Due to their size, their diffusion rate through the inter-endothelial clefts is limited. Intravasation will occur through wide clefts and via the lymphatic system. This causes a time gap between evolving cell death and elevation of marker concentrations in the circulation. The troponins are structural components of cardiac muscle and, apart of small cytosolic fractions, first have to be released from the tropomyosin complex, before entering into interstitium. This causes the relatively late time point at which their entrance into circulation can be measured, despite their small size $(21 \mathrm{kD})$. As a result, troponins are slowly released into the circulation and, due to their ongoing release, remain elevated during several days, which makes them suitable for late diagnosis. When a patient is suspected of reinfarction, this cannot be measured accurately by troponins because the level of troponin may still be elevated as a result of the first infarction. In conclusion, depending on the time that has passed after onset of symptoms and on the information required (i.e., reinfarction, reperfusion injury, or AMI), a different marker should be chosen. 
Currently, the troponins, due to their cardiac specificity, are generally accepted as the most suitable late markers. Whether troponin T or troponin I should be used is subject to investigation. There are several troponin I tests, which make the results of different studies (performed in different hospitals and with different tests) difficult to compare. Therefore, the cut-off value for AMI as well as the normal reference plasma value in healthy persons remains to be established. Because there is only one manufacturer of the troponin $\mathrm{T}$ test (Roche Diagnostics) the results of all studies of $\mathrm{TnT}$ are comparable worldwide. This TnT test measures troponin $\mathrm{T}$ as well as it fragments, and is therefore believed to be more sensitive than TnI-tests. Standardization of the troponin I tests however, should be achieved before this statement can be verified.

The choice of the most suitable early marker is important. Myoglobin is currently recommended as early cardiac marker. ${ }^{(5)}$ However, as stated in Chapter 3, FABP would be a better choice of early marker. Both myoglobin and FABP are eliminated from the plasma mainly by renal clearance. This may cause falsely high values in case of kidney malfunction. However, this can be overcome by the simultaneous measurement in plasma of creatinine to identify patients with renal insufficiency and to calculate a corrected FABP clearance rate. ${ }^{(22)}$ Another drawback of these early markers is their possible elevation due to skeletal muscle damage. On the other hand, the ratio between myoglobin and FABP can be used to distinguish skeletal from heart muscle damage. When the myoglobin:FABP ratio is $4-5$ only heart muscle cells are affected compared to a ratio of $20-70$ when skeletal muscle is affected. ${ }^{(3,24,25)}$

Although myoglobin was subject of many investigations, ${ }^{(26-28)}$ studies in which both myoglobin and FABP were measured showed better performance of FABP as early marker. ${ }^{(28-34)}$ However, FABP is not yet generally accepted as an early cardiac marker, which is probably due to the relative small amounts of patients with chest pain in which FABP has been tested.

A combination of FABP together with cardiac TnT or cardiac TnI, could well be the optimal set of biochemical markers of muscle necrosis for assessment of acute coronary syndromes.

\subsection{The continuous measurement of FABP}

To take full advantage of the characteristics of the early marker FABP, we set out to develop an on-line continuous measuring device. The ultimate FABP biosensor should be easy to use, allow rapid and sufficiently sensitive monitoring, i.e., allow to distinguish minor infarctions from unstable angina pectoris, and allow at least several hours of continuous monitoring. These requirements can probably best be met by a device based on the principle of immuno-displacement, as explained in Chapter 4.

Because none of the described biosensors were able to measure FABP rapidly, continuously and repeatedly, we attempted to develop a biosensor meeting all abovementioned requirements. The first experiments, described in Chapter 5, were aimed at testing the proof of principle of continuous immuno-displacement for assay of FABP. Reaction vials, which mimicked a semi-continuous measuring system, were filled with a specific matrix (containing immobilized-FABP bound to an antibody labeled with horseradish peroxidase (Ab-HRP)). After displacement of Ab-HRP by added FABP was 
proven, subsequent investigations were performed with the same matrix present in columns to study the immuno-displacement principle in relation with continuous flow (see Chapter 6).

In both systems, displacement of Ab-HRP by added FABP could be induced, and the sensitivity as well as the specificity of this assay principle were studied. Final experiments (see Chapter 6), in which human plasma of AMI patients was used, revealed the possible ability of the sensor for use as a continuous measuring device for FABP quantification in chest pain patients.

\subsection{Optimization of the FABP displacement sensor}

During the experiments performed with columns, it appeared that especially the flow through the column and the amount of matrix present, are major determinants of the sensitivity of the sensor. However, it appeared that the system in its current stage of development is not yet sufficiently sensitive to detect small infarctions or microinfarctions. In case of such infarctions plasma FABP is usually $10-20 \mu \mathrm{g} / \mathrm{L}$ (Chapter 3, Fig 3.3). Therefore, the above-mentioned parameters affecting the sensitivity of the sensor, will be discussed in more depth below, and suggestions for optimizing the displacement column will be given.

The first step in the displacement assay involves the binding of FABP to a Sepharose matrix. Then, Ab-HRP, is added to this matrix and incubated for two hours. It appeared that after the first washing step, about $50 \%$ of the anti-FABP-HRP was not bound to the matrix, either due to unspecific binding to the matrix or due to the rather high dissociation constant $\left(\mathrm{k}_{\mathrm{off}}\right)$ of the Ab-HRP complex. Therefore, increasing the amount of initially bound Ab-HRP plays a role in optimising the displacement column. When larger amounts of Ab-HRP would be used for displacement, we suspect that the displacement signal after addition of a specific amount of FABP will increase. Namely, this will lower the amount of FABP needed to induce displacement, and therefore, increase the sensitivity of the sensor. In addition, when more Ab-HRP is bound to the Sepharose-bound-FABP, the sensor could be used for a longer period of time. This would make the sensor more applicable in a clinical setting.

The amount of Sepharose, to which FABP is bound, was also investigated in relation to improvement of the assay sensitivity. Addition of equal amounts of FABP to two different types of columns (containing 50 or $200 \mu$ Sepharose matrix, respectively) resulted in a significantly higher release of Ab-HRP from the $50 \mu \mathrm{l}$ Sepharose column, than from the $200 \mu \mathrm{l}$ Sepharose column. Thus, the higher FABP/Sepharose ratio resulted in a higher Ab-HRP release. Apparently, a higher FABP/Sepharose ratio provides a better sensitivity, indicating that coupling density is one variable that could be optimized further.

Another parameter, worth investigating in order to optimize the displacement sensor, is flow velocity through the column. Our studies showed that when the flow was decreased from 30 to $15 \mu \mathrm{l} / \mathrm{min}$, the displacement signal (i.e., Ab-HRP release) increased. Lowering the flow increases the time in which displacement can occur, but could also cause a more pronounced concentration effect. Although a slow flow will increase the 
sensitivity of the sensor, it also increases assay time. Thus, optimization of the sensor would imply determination of the optimum between short assay time and high sensitivity.

Besides the optimization of the amount of bound Ab-HRP, flow and amount of Sepharose, several other parameters, such as antibody affinity and sample volume, are suggested to be important for increasing the sensitivity of the sensor. When the spontaneous release of Ab-HRP complex from the column can be reduced, the displacement signal will probably increase. Such release is affected by surface density of FABP on the Sepharose (as mentioned above) as well as by antibody affinity. However, when the affinity between antigen and antibody is too high, or becomes bivalent, no displacement will occur. When the affinity is too low, spontaneous release will dominate the displacement effect. Again, an optimum has to be assessed experimentally.

Antibodies are composed of two heavy and two light chains, and contain two antigen-binding sites. Papaine can be used to cleave the disulfide bridges between the two heavy chains, resulting in an antibody-complex containing only one Fab fragment (Fig. 8.3). ${ }^{(35)}$ After labelling this complex with HRP, it could be used in our displacement sensor instead of the full Ab-HRP complex. After addition of FABP, to induce displacement, the FABP molecule will immediately compete with the matrix-bound FABP instead of first occupying the empty antigen-binding site of the antibody complex. In that way, FABP can be used more efficiently and the displacement signal most likely will increase.

Antibodies can also be substituted by engineered antibodies if these are available. ${ }^{(36)}$ This could be an alternative approach to affect the affinity of the antibody, thereby increasing the sensitivity of the sensor.

Finally, the sensitivity of the sensor may be increased by changing the label of the antibody, in such manner, that the signal is amplified. When the antibody is attached to its label in a one-to-one fashion, amplification of the signal can be induced by the binding of more labels, for instance by coupling a biotinylated antibody to the Sepharose-bound FABP and subsequent addition of streptavidin-poly-HRP.

Apart from increasing the sensitivity of the sensor, the sensor could also be optimized by, for example, changing the procedure by which antigens or antibodies are immobilised to the matrix.

To make the sensor more applicable for use in a clinical setting, the detection method should be simplified. This could be performed, for instance, by using a fluorescent label (instead of HRP) which can directly be measured by fluorimetry in the sensor effluent.

Miniaturization to a small device will also be advantageous. Modern nanoscale technology makes such developments feasible and therefore, the principle of displacement could be applied on a biochip (a miniaturized single-sensor device containing all steps of the analytical process, i.e., "lab-on-a-chip"). ${ }^{(36)}$ 


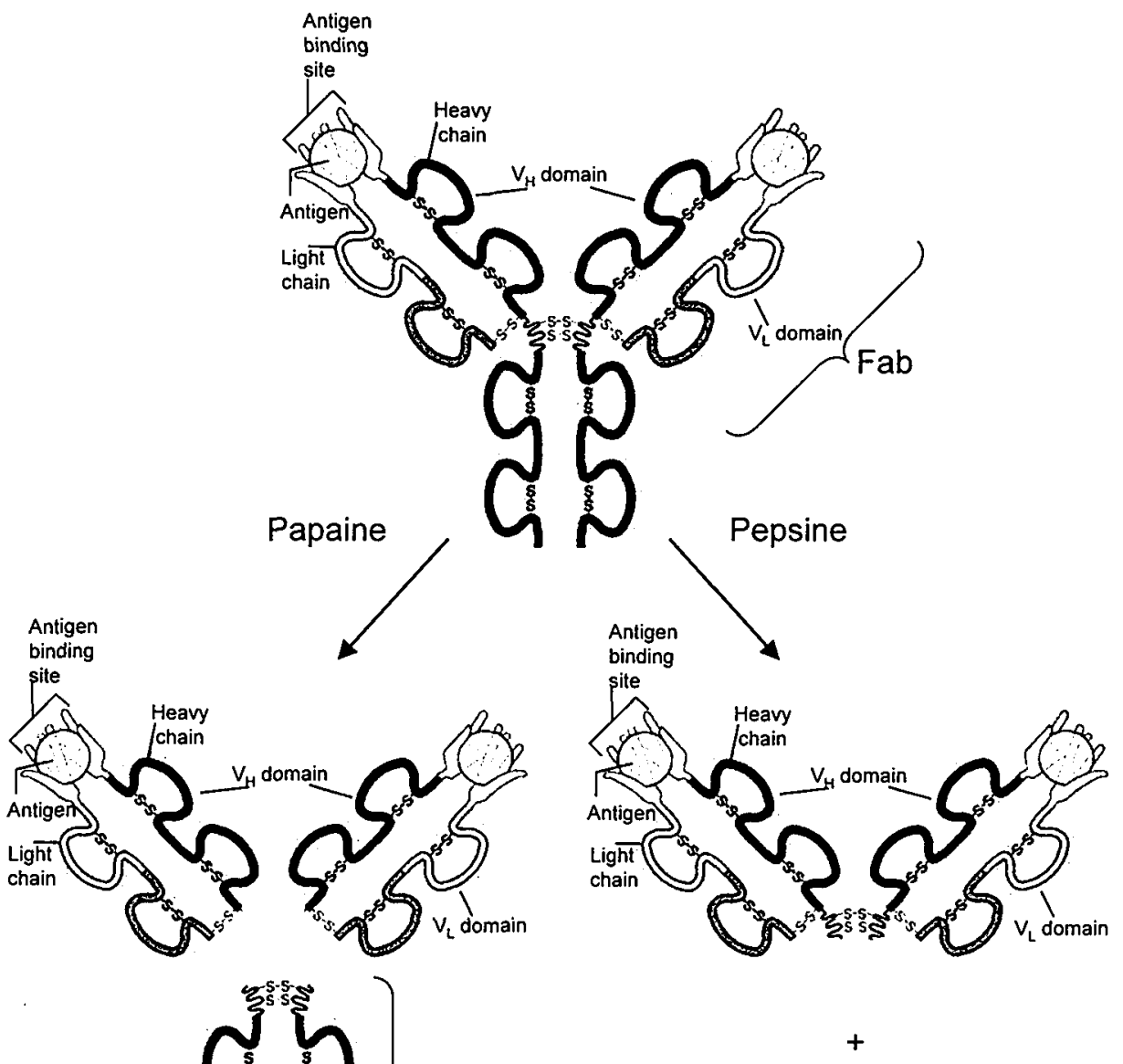

Fc fragments

Figure 8.3 General structure of an antibody and it cleavage sites

Schematic drawing of a typical antibody molecule. The protein (upper part) is $Y$-shaped and has two identical binding sites for its antigen, one on either arm of the complex. The protein is composed of four polypeptide chains (two identical heavy chains and two identical and smaller light chains) held together by disulfide bonds. Each chain is made up of several different domains, shaded in gray. The antigen-binding site is formed where a heavy chain variable domain (VH) and a light chain variable domain (VL) come close together. The lower part shows the result of cleavage due to of either papaine (resulting in two Fab fragments and one Fc fragment) or pepsine (resulting in two attached Fab fragments and Fc fragments). 


\subsection{Future perspectives}

When the above-described FABP displacement sensor would be optimized in such a manner that detection of micro-infarctions is possible, the sensor could be used for several applications. First, the sensor could be used in an emergency department. When patients with chest pain enter the emergency department, the sensor would allow rapid quantification of the concentration of FABP present in the patient's blood, so as to allow confirmation or exclusion of AMI. Furthermore, changes of the release pattern of FABP in the patient's plasma can be measured and the sensor may therefore also be applicable during open heart surgery, or for non-invasive detection of coronary reperfusion. ${ }^{(9)}$

By changing the antibody, the sensor principle could easily be made applicable for assay of other proteins in plasma. For instance, the displacement sensor could be used for estimation of the extent of damage to tissues other than heart muscle, exploiting the occurrence of other types of FABP in other organs. ${ }^{(37)}$ An example is a preliminary study that is part of the Groningen-Maastricht collaboration project (Chapter 1) and investigates several markers for brain-injury, including the novel marker B-FABP, which are released into liquor during mild trauma, cerebro-vascular attack (CVA) or during electroconvulsive therapy in depressed patients (Table 8.1 ) ${ }^{(38)}$ During this study, a novel ELISA was developed for the quantification of B-FABP, in collaboration with T. Hanhoff (University of Münster, Department of Biochemistry). The results of the study show that $\mathrm{B}-\mathrm{FABP}$ as well as H-FABP are more sensitive markers for brain injury than the current markers for brain injury (i.e., neuron specific enolase (NSE) and S100B). Therefore, both $\mathrm{H}-\mathrm{FABP}$ and B-FABP have recently been proposed as markers for brain-injury. ${ }^{(38-40)}$ Continuous monitoring of brain damage by use of a displacement sensor would be also of great importance during brain surgery. Furthermore, a recent study with transplantation patients, suggests Liver-FABP (L-FABP) as a promising biochemical marker for the early detection of hepatocellular injury. ${ }^{(41)}$ A L-FABP displacement sensor could be used to monitor patients undergoing liver transplantation and during their follow up to detect possible rejection of the transplanted liver. Another study, concerning transplantation of non heart beating donor (NHBD) kidneys reveals that H-FABP can be used to quantify renal injury in the perfusate of these NHBD kidneys. ${ }^{(42)}$ A H-FABP displacement sensor could be used to quantify kidney injury from the moment that kidneys are removed from their donor, until their transplantation to the receiver. The amount of H-FABP in the perfusate of these kidneys may indicate progressive deterioration of the kidney. In that way, unnecessary transplantation of kidneys with delayed- or non-function might be prevented. Further studies have to investigate FABP values in perfusate as a prognostic marker for kidney function after transplantation.

In view of the importance of monitoring the physiological status of patients in real-time, the displacement principle is not only useful in a biosensor setup for the detection of FABP (Figure 8.4), but also for the detection of hormones, drugs, other cardiac markers, plasma proteins etc.

In conclusion, after further optimization, the displacement sensor described in this thesis could become a powerful tool in different clinical applications. Not only for rapid 
detection of tissue injury, but also for estimation of the extent of damage, for monitoring patients who are prone to develop tissue injury or undergo surgery, and for risk stratification. Therefore, further studies are of great importance, and although optimization of all parameters will require time, a sensor that is able to measure micronecrosis in a fast and continuous manner, has great potential for many clinical purposes.

Table 8.1 Comparison of novel marker proteins for brain injury

\begin{tabular}{|l|c|c|c|}
\hline Marker & $\begin{array}{c}\text { Patients undergoing ECT } \\
(n=234)\end{array}$ & $\begin{array}{c}\text { Patients with MTBi } \\
(n=130)\end{array}$ & $\begin{array}{c}\text { Patients with CVA } \\
(n=30)\end{array}$ \\
\hline B-FABP & 15 & 88 & 0 \\
H-FABP & 39 & 91 & 4 \\
NSE & 0 & 66 & Not measured \\
S100B & 1 & 59 & Not measured \\
\hline
\end{tabular}

Summary of the results of several preliminary studies concerning brain injury. The number of patients with increased marker concentrations (i.e., concentrations above the cut-off value for brain injury) is given. In all three studies, H-FABP appears to be the marker that includes the highest number of patients with increased marker concentrations. This indicates that a H-FABP biosensor, capable of fast and continuous monitoring, might play an important role in the detection of brain injury. Results of the different studies are discussed in detail in references 38 and 43. Abbreviations: B-FABP = brain-type fatty acid-binding protein, $\mathrm{H}-\mathrm{FABP}=$ heart-type fatty acid-binding protein, NSE = neuron specific enolase, $\mathrm{ECT}=$ electroconvulsive therapy, $\mathrm{MTBi}=$ mild traumatic brain injury, CVA = cerebro-vascular attack 


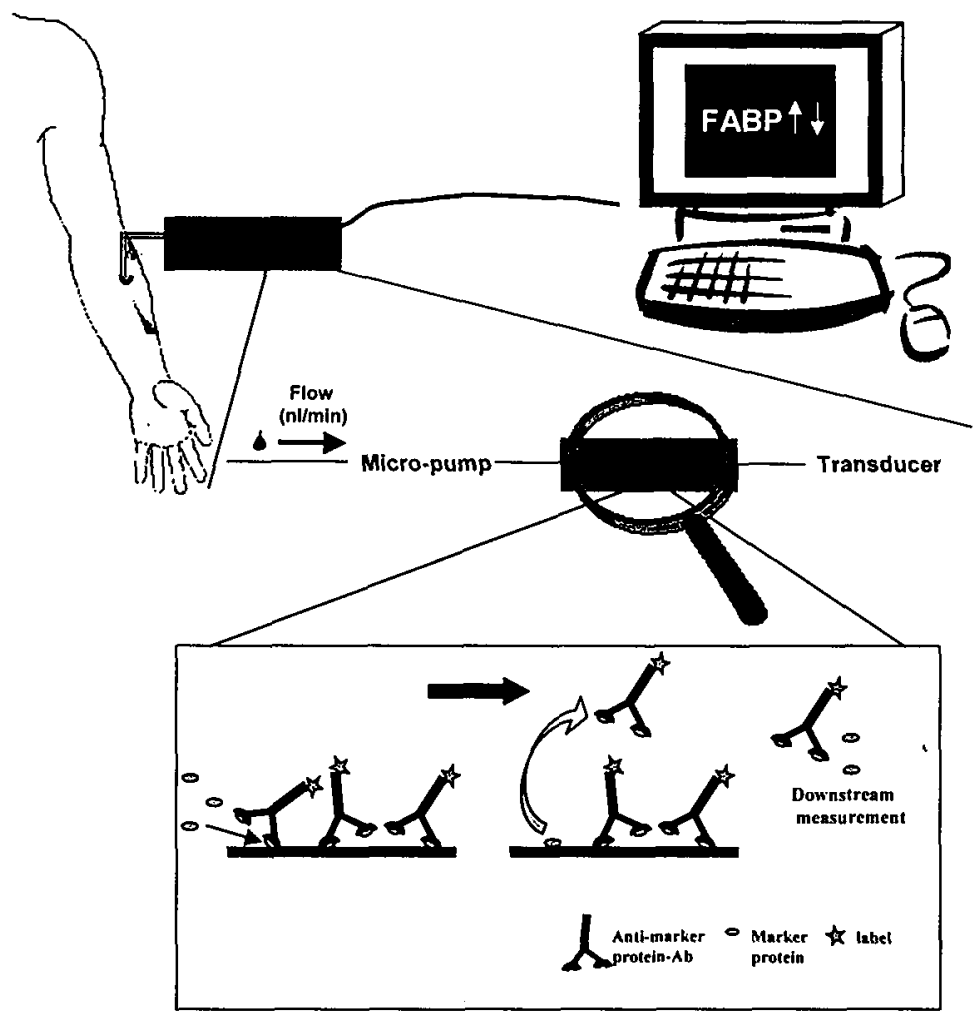

\section{Figure 8.4}

Futuristic example for an on-line biosensor setup for use in a clinical setting, illustrated for the quantification of FABP. A needle placed in the patients circulation is used in combination with a micro-pump to obtain a blood sample. The sample reaches the bioreceptor where FABP present in the sample can induce displacement of its labeled antibody. Subsequently, this label is measured downstream within the transducer unit, which transfers the signal to a computer for further processing.

\subsection{References}

1. Nyquist O. Acute coronary syndromes in Sweden: A survey. Läkartidningen 1996;93:1821-4.

2. Kragten JA. New myocardial proteins in acute myocardial infarction. Quantitative aspects. Assen, The Netherlands: Dekker \& van de Vegt;1998 (Thesis):chapter 6

3. Mair J. Progress in myocardial damage detection: new biochemical markers for clinicians. Crit Rev Clin Lab Sci 1997;34:1-66.

4. Lindahl B, Venge P, Wallentin L. Early diagnosis and exclusion of acute myocardial infarction using biochemical monitoring. Coron Artery Disease 1995;6:321-8.

5. Alpert JS, Thygesen K, Rydén L, Garson A. Myocardial infarction redefined-a consensus document of The Joint European Society of Cardiology/American College of Cardiology 
committee for the redefinition of myocardial infarction. The Joint European Society of Cardiology/ American College of Cardiology Committee. J Am Coll Cardiol 2000;36:95969.

6. Galvani $M$, Ferrini $D$, Ghezzi $F$, Ottani F. Cardiac markers and risk stratification: an integrated approach. Clin Chim Acta 2001;311:9-17.

7. Boden WE. In: Wu AHB. Cardiac Markers. Totowa, New Jersey: Humana Press; 2003. Foreword.

8. Fesmire FM. Improved identification of acute coronary syndromes with delta cardiac serum marker measurements during the emergency department evaluation of chest pain patients. Cardiov Toxicol 2001;01:117-123.

9. de Groot MJM, Kragten MJM, Hermens WT, Glatz JFC. Assessment of coronary reperfusion by cardiac marker proteins in patients with myocardial infarction: a review. Cardiovasc Rev Rep 2003;24:144-9.

10. Alberts B, Bray D, Lewis J, Raff M, Roberts K, et al. Molecular biology of the cell. $3^{\text {rd }}$ edition. New York and London: Garland publishing; 1994.

11. Fliss $\mathrm{H}$, Gattinger D. Apoptosis in ischemic and reperfused rat myocardium. Circ Res 1996;79:949-56.

12. Takashi E, Ashraf M. Pathologic assessment of myocardial cell necrosis and apoptosis after ischemia and reperfusion with molecular and morhpological markers. J Mol Cell Cardiol 2000;32:209-224.

13. Majno G, Joris I. Apoptosis, oncosis and necrosis: an overview of cell death. Am J Pathol 1995; 146:3-15.

14. Baxter GF. Cellular mechanisms of ischemic myocardial damage. In: Kaski JD, Holt DW. Myocardial damage early detection by novel biochemical markers. Dordrecht, The Netherlands: Kluwer academic publishers; 1998: chapter 1.

15. Olivetti G, Quaini F, Sala R, C. Lagrasta, Corradi D, et al. Acute myocardial infarction in humans is associated with activation of programmed myocyte death in the surviving portion of the heart. J Mol Cell Cardiol 1996;28:2005-16.

16. Saraste A, Pulkki K, Kallajoki M, Henriksen K, Parvinen M, et al. Apoptosis in human acute myocardial infarction. Circulation 1997;95:320-3.

17. Kajstura J, Cheng W, Reiss K, Clark WA, Sonnenblick EH, et al. Apoptotic and necrotic myocyte cell deaths are independent contributing variables of infarct size in rats. Lab Invest 1996;74:86-107.

18. Blom WM. Cell death in rat hepatocytes. Apoptosis-inducing and -protective mechanisms. Leiden, The Netherlands: Leiden University;2000 (Thesis).

19. Hermens WT, van der Veen FH, Willems GM, Reneman RS. Enzymatic infarct size and its significance for evaluation of thrombolytic therapy after acute myocardial infarction. Circulation 1990;81:1719-20.

20. Glatz JFC, van der Voort D, Hermens WT. Fatty acid-binding protein as the earliest available plasma marker of acute myocardial injury. J Clin Lig Assay 2002;25:167-177.

21. Licka $M$, Zimmermann R, Zehelein J, Dengler TJ, Katus HA, et al. Troponin T concentrations 72 hours after myocardial infarction as a serological estimate of infarct size. Heart 2002;87:520-4.

22. De Groot MJM, Wodzig KWH, Simoons ML, Glatz JFC, Hermens WT. Measurement of myocardial infarct size from plasma fatty acid-binding protein or myoglobin, using individually estimated clearance rates. Cardiovasc Res 1999;44:315-24.

23. van der Laarse A. Rapid estimation of myocardial infarct size. Cardiovasc Res 1999;44:247-8. 
24. van Nieuwenhoven FA, Kleine AH, Wodzig KWH, Hermens WT, Kragten HA, et al. Discrimination between myocardial and skeletal muscle injury by assessment of the plasma ratio of myoglobin over fatty acid-binding protein. Circulation 1995;92:2848-54.

25. Yoshimoto K, Tanaka T, Somiya K, Tsuji R, Okamoto F, et al. Human heart-type cytoplasmic fatty acid-binding protein as an indicator of acute myocardial infarction. Heart Vessels 1995;10:304-9.

26. Wu AHB, Apple FA, Gibler WB, Jesse RL, Warshaw MM, et al. National Academy of Clinical Biochemistry Standards on Laboratory Practice: Recommendations for the use of cardiac markers in coronary artery diseases. Clin Chem 1999;45:1 104-21.

27. Panteghini M, Apple FS, Christenson RH, Dati F, Mair J, et al. Use of biochemical markers in acute coronary syndromes. IFCC Scientific Division, Committee on Standardization of markers of Cardiac Damage. Clin Chem Lab Med 1999;37:687-93.

28. Storrow $\mathrm{AB}$, Gibler WB. The role of cardiac markers in the emergency department. Clin Chim Acta 1999;284:187-96.

29. Abe S, Saigo M, Yamashita T, et al. Heart fatty acid-binding protein is useful in early and myocardial-specific diagnosis of acute myocardial infarction. Circulation 1996;94:I323(abstract).

30. Ishii J, Wang $\mathrm{JH}$, Naruse $\mathrm{H}$, Taga $\mathrm{S}$, Kinoshita $\mathrm{M}$, et al. Serum concentrations of myoglobin vs human heart-type cytoplasmic fatty acid-binding protein in early detection of acute myocardial infarction. Clin Chem 1997;43:1372-8.

31. Kristensen SR, Haastrup B, Hørder M, et al. Fatty acid-binding protein: a new early marker of AMI. Scand J Clin Lab Invest 1996;56(suppl)225:36-7 (abstract).

32. Sanders GT, Schouten Y, De Winter RJ, et al. Evaluation of human heart type fatty acidbinding protein assay for early detection of myocardial infarction. Clin Chem 1998;44:A132(abstract).

33. Okamoto F, Sohmiya K, Ohkaru Y, Kawamura K, Asayama K, et al. Human heart-type cytoplasmic fatty acid-binding protein (H-FABP) for the diagnosis of acute myocardial infarction. Clinical evaluation of H-FABP in comparison with myoglobin and creatine kinase isoenzyme MB. Clin Chem Lab Med 2000;38:231-8.

34. Ghani F, Wu AHB, Graff L, Petry C, Armstrong G, et al. Role of heart-type fatty acidbinding protein in early detection of acute myocardial infarction. Clin Chem 2000;46:7189.

35. Tijssen P. Laboratory techniques in biochemistry and molecular biology. Amsterdam, The Netherlands: Elsevier Science Publishers B.V.; 985 Chapter 6.

36. Luppa PB, Sokoll LJ, Chan DW. Immunosensors-principles and applications to clinical chemistry. Clin Chim Acta 2001;314:1-26.

37. Glatz JFC, van der Vusse GJ. Cellular fatty acid-binding proteins: their function and physiological significance. Prog Lip Res 1997;35:243-282.

38. Pelsers MMAL, Honig A, Peters M, Hanhoff T, Ponds R, et al. Comparison of serum concentrations of B-FABP, H-FABP and S100B in patients undergoing electroconvulsive therapy. 2003 Lund congress (abstract).

39. Guillaume E, Zimmermann C, Burkhard PR, Hochstrasser DF, Sanchez JC. A potential cerebrospinal fluid and plasmatic marker for the diagnosis of Creutzfeldt-Jakob disease. Proteom 2003;3:1495-9.

40. Pelsers MMAL, Hanhoff $T$, van der Voort D, de Kruijk JR, Twijstra A, et al. Tissue specific types of fatty acid-binding protein, B- and H-FABP, as novel plasma markers of human brain injury. 2003 Lund congress (abstract). 
41. Pelsers MMAL, Morovat A, Alexander GJ, Hermens WT, Trull AK, et al. Liver fatty acidbinding protein as a sensitive serum marker of acute hepatocellular damage in liver transplant recipients. Clin Chem 2002;48:2055-7.

42. Gok MA, Pelsers MMAL, Glatz JFC, Bhatti AA, Peaston R, et al. Comparison of perfusate activities of glutathione $S$-transferase, alanine aminopeptidase and fatty acid binding protein in the assessment of non-heart-beating donor kidneys.Ann Clin Biochem 2003;40:252-8.

43. de Kruijk JR. Mild traumatic brain injury. Maastricht, The Netherlands: University Maastricht;2001 (Thesis): chapter 4. 


\section{Chapter 9}

\section{Summary}

This thesis, which was part of the project entitled "Intravenous biosensor systems for the continuous biochemical monitoring of heart and brain damage" (a collaborative project of the universities of Groningen and Maastricht and supported by the Dutch Technology Foundation, NWO-STW grant nr. GGN 4680), describes the development of a biosensordevice based on the principle of immuno-displacement. The device was developed in order to quantify heart-type fatty acid-binding protein (H-FABP) in a fast continuous manner. Since this protein was first suggested as a plasma marker of acute myocardial infarction (AMI) in 1988, several studies revealed the suitability of FABP especially for early diagnosis of AMI. However, to make such early diagnosis possible, a quantification method is necessary that is more rapid than the currently available commercial enzymelinked immunosorbent assay (ELISA) method, which shows an assay time of approximately one hour. When AMI can be diagnosed more rapidly, early initiation of appropriate therapy will be facilitated. Furthermore, low-risk patients, i.e., patients without cardiac ischemia, can safely be sent home.

Therefore, the studies described in this thesis aimed at developing a more rapid device for the quantification of FABP in blood samples obtained from patients entering the emergency department, or undergoing cardiac surgery.

Chapter 1 provides a brief overview of the importance of diagnosing AMI and summarises briefly all subsequent aspects described in this thesis. Chapter two, the general introduction, provides background information on several topics described in this thesis. First, the causes of cellular injury, and especially myocardial injury, are discussed. When coronary arterial flow supplies insufficient oxygen to meet the demands of the myocardium, myocardial ischemia will occur. Myocytes can sustain ischemia of less than 15 minutes, however ischemia of longer duration usually results in irreversible injury so that the myocyte will die. This process is characterised by disruption of the cell membrane resulting in release into the circulation of several cellular constituents, including specific cardiac marker-proteins. Depending on the type and release characteristics of the different markers, their concentration increase in plasma or serum may provide an indication of the extent of myocardial damage.

Because the new definition of AMI, formulated in 1999, includes the rise and fall of biomarkers in plasma, an overview of characteristics of several markers, including aspartate aminotransferase, creatine kinase, lactate dehydrogenase, troponin, myoglobin and FABP is given in Chapter 2. To monitor a patient in the emergency department, continuous measurements of cardiac proteins would be beneficial. Therefore, the sample should be obtained from the patient in a continuous manner. Continuous sampling techniques include microdialysis, ultrafiltration, and direct intravenous sampling, and 
could ideally be combined with the measurement of marker protein concentrations in a biosensor device.

Chapter 3 represents an extensive review concerning the cardiac marker FABP. The characteristic features of this marker are described in more detail because, at present, it is regarded the most suitable early marker for the detection of AMI. FABP is not cardio-specific, but is expressed in relatively low amounts in skeletal muscle. The release and plasma kinetics of FABP closely resemble those of myoglobin, i.e., a rise is detectable as early as 1 to 3 hours after AMI onset, peak values are reached at 6 to 8 hours, and the plasma level returns to normal within 24 to 36 hours. Several clinical studies have unanimously revealed a significantly better performance of FABP over myoglobin for early AMI detection as well as early estimation of infarct size. This superior performance of FABP relates to its relatively low plasma reference concentration. Preliminary evidence suggests that FABP also detects minor myocardial injury and may serve as a prognostic marker for patients with unstable angina pectoris. It is concluded that FABP appears to be an excellent marker for early confirmation or exclusion of AMI. The results are discussed in relation to the recently formulated recommendations for use of marker proteins in the emergency room.

If FABP is used as early marker for the detection of AMI, a biosensor for fast, continuous quantification should be very helpful. Before a description is given of the development of an FABP sensor (Chapter 4), a review is presented on the basic principles of biosensors. Because most biosensors are based on antigen-antibody reactions that are highly sensitive and specific, they are of great value for use in a clinical setting. Furthermore, it becomes more and more important to measure specific compounds in biological matrices (i.e., blood or plasma), in a fast continuous manner. Continuous measurement of proteins (such as FABP) could be established by use of the principle of immuno-displacement. In our case, such displacement can be defined as the breaking of the binding between antigen and antibody when free antigen is added.

For the measurement of FABP several immunoassays and immunosensors already have been developed. An overview of these devices, which include amperometric, optical, grating coupler and flow displacement sensors, is presented in this chapter. The different biosensors are displayed in chronological order and the main features are given. Till now, no biosensor is capable of repeated continuous quantification of FABP in plasma. Therefore, a new biosensor was being developed in our lab. A previous preliminary study already provided proof of principle of immuno-displacement for FABP in buffer.

Chapter 5 describes the first steps in the development of our FABP immunosensor. Continuous measurement of FABP was first mimicked in a discontinuous manner, by repeated addition of FABP-containing solutions to a reaction vial containing a specific matrix, (i.e., the medium containing the analyte), followed by several washing steps. The matrix consisted of Sepharose-bound-FABP to which horseradish peroxidase labeled anti-FABP antibody (Ab-HRP) was coupled. In the presence of free FABP, the 
enzyme-labeled antibodies dissociated and were subsequently quantified. Significant displacement in the presence of free FABP was observed in both buffer and human plasma, for duration of at least $9 \mathrm{~h}$. The amount of displaced Ab-HRP from plasma was higher than that from buffer. Therefore, lower FABP concentrations could be measured in plasma compared to buffer ( $\geq 20 \mu \mathrm{g} / \mathrm{L}$ and $\geq 40 \mu \mathrm{g} / \mathrm{L}$ respectively). From this study the principle of displacement was proven for FABP in buffer as well as in plasma samples. These results show the feasibility of a sensor based on the displacement principle to be used for the diagnosis of AMI in emergency medicine.

To further investigate the principle of displacement and more closely approach the use of the immunosensor in the intensive care unit, a continuous flow system was developed (Chapter 6). During this subsequent study, with slightly different matrix conditions, displacement of FABP in columns, in which a continuous flow was present, could also be proven. To our knowledge, this is the first time that displacement of AbHRP was induced by a continuous flow of human plasma from a patient suffering from AMI. A correlation coefficient of 0.96 was found in comparison with the standard ELISA. Although the system is semi-continuous in the way that the amount of displaced Ab-HRP in the samples is measured after finishing the experiment, the column can be used in a continuous measuring device.

The current displacement sensor is not yet able to detect FABP concentrations found in plasma following small infarctions. Therefore, several optimisation experiments, varying the flow velocity as well as the amount of matrix to which the FABP was bound, were performed. It was found that the lower the flow, the more sensitive was the sensor. However, on the other hand, a lower flow results in an increased assay time. An optimum between these two parameters should be determined in future studies.

In Chapter 7, two current other attempts of early diagnosis of AMI using FABP are described. The group of dr. C. McNeil (University of Newcastle upon Tyne, Newcastle, United Kingdom) developed a biosensor based on impedance measurements for FABP quantification. The principle of this sensor is explained and preliminary results are given. Due to several technical problems, this sensor is not yet operational. Moreover, it will not allow continuous measurement of FABP.

In collaboration with the company 8 sens.diagnostic AG (Berlin, Germany) we tested several so-called Cardio-Detect ${ }^{(3)}$ cards. These cards contain a qualitative measuring device for FABP. The precise mechanism underlying this method as well as the first results, are given. The first cards that were tested by a nurse of the coronary care unit showed unreliable results in $30 \%$ of cases. A second batch of cards was, after slightly changing several parameters, tested in the hospital of Bernau (Germany). The results of these latter studies are promising. However, more extensive evaluations at distinct hospitals are needed before the Cardio-Detect ${ }^{\circledR}$ self-test can be commercialized for personal use.

Finally, Chapter 8 comprises a general discussion of this thesis and provides suggestions for future investigations. The importance of a rapid diagnosis of cardiac injury is discussed as well as the most optimal marker for AMI. Several suggestions for 
optimization of the displacement sensor (such as reduction of flow, increase of amount of FABP coupled to its matrix, and increase of the amount of Ab-HRP) as well as future developments (for measurement of liver, kidney or brain damage) of this sensor are given. It is concluded that the displacement sensor described in this thesis could become a powerful tool in different clinical applications. Not only for rapid detection of tissue damage, but also for estimation of the extent of injury, for monitoring patients who are prone to develop injury or undergo surgery, and for risk stratification. Taken together, further studies are of great importance, and although optimization will require time, a sensor that is able to measure micro-necrosis in a fast and continuous manner, has great potential for various purposes. 


\section{Samenvatting}

Dit proefschrift is een beschrijving van het onderzoek waar ik mij de afgelopen vier jaar mee heb mogen bezighouden. Het project, opgesteld door een samenwerkingsverband van de universiteiten van Groningen en Maastricht, had als titel: "Intraveneuze biosensor systemen voor de continue biochemische monitoring van hart- en hersenschade". Vrij vertaald gaat het over de ontwikkeling van een apparaat, een biosensor, waarmee de hoeveelheid van bepaalde stoffen (zoals eiwitten) in het bloed continue kan worden gemeten. Het werkingsprincipe van deze biosensor berust op het fenomeen van zogenaamde immuno-displacement. Later in dit hoofdstuk kom ik daar nog op terug.

Het eiwit waarvan wij de hoeveelheid in bloed willen bepalen en dat centraal staat in het onderzoek is een relatief klein $(14 \mathrm{kD})$ vetzuurbindend eiwit doorgaans aangeduid met de Engelse naam fatty acid binding protein (FABP). Dit FABP komt in vrijwel alle cellen van ons lichaam voor. Er bestaan verschillende typen FABP en het in hart-cellen aanwezige FABP noemt men "hart-type-FABP". Wanneer een cel sterft, bijvoorbeeld als gevolg van zuurstoftekort, breekt de cel open en komt onder andere het FABP buiten de cel terecht. Bij een hartinfarct heeft een deel van de hartspier eveneens een tekort aan zuurstof en zullen meer of minder hartspiercellen afsterven waarbij er meer of minder FABP vrij komt. Dit FABP komt na enige tijd in de bloedbaan terecht. In 1988 is er voor het eerst beschreven dat een verhoogde concentratie van het (hart-type) FABP in de bloedbaan aantoont dat er ergens in het hart schade moet zijn (of recent moet zijn geweest). Met name op hoge leeftijd komen er nogal eens kleine infarcten voor die aanvankelijk weinig of geen specifieke klachten veroorzaken. Deze patienten klagen bijvoorbeeld over vermoeidheid. Als er tijdens een onderzoek bij dergelijke patiënten wordt vastgesteld dat er een verhoogde concentratie FABP in de bloedbaan aanwezig is, dan betekent dat wel, dat er met het hart iets aan de hand is.

In de loop van de tijd zijn er verschillende methoden ontwikkeld om de hoeveelheid FABP in bloed te meten. Tot nu toe bestaat er echter nog geen methode die de hoeveelheid FABP in het bloed snel (binnen enkele minuten) en continue kan bepalen. Het snel kunnen meten van FABP is van belang voor een snelle diagnose (zoals bij een hartinfarct), zodat de medische behandeling dan direct kan worden ingesteld. Een continue meting, ookwel "on-line" meting genoemd, kan bijvoorbeeld van belang zijn voor patiënten op de eerste (hart)hulp. In het geval van een zich ontwikkelende nieuwe hartschade, zou men dit direct, op een monitor, kunnen waarnemen. Ook zou het met een continue meting mogelijk zijn het verloop van de schade in de tijd te vervolgen. Op deze manier kan het beloop van de ziekte zo goed mogelijk worden vervolgd en kan er bij verslechtering van de toestand op tijd worden ingegrepen. Dit proefschrift beschrijft ondermeer de ontwikkeling van een snelle meetmethode voor FABP.

In het eerste hoofdstuk staat globaal omschreven wat er in het proefschrift aan bod komt, en wordt uitgelegd waarom en wanneer het belangrijk is om vast te stellen of en in welke mate een patiënt hartschade heeft. Hoofdstuk 2 geeft een overzicht van de achtergrondkennis van de onderwerpen van dit proefschrift. Er staat beschreven wat 
hartschade is, hoe het ontstaat en welke stoffen er vrijkomen bij een infarct. Vanzelfsprekend zijn er naast FABP nog andere stoffen die in de bloedbaan terecht komen als hartcellen afsterven en de belangrijkste worden in hoofdstuk 2 genoemd. Een aantal van deze stoffen kunnen net als FABP gebruikt worden om aan te tonen dat een patiënt hartschade heeft of om dit juist uit te sluiten. Welke van deze stoffen hiervoor het meest geschikt zijn, de zogenoemde hartschademerkstoffen (hartschade markers), is afhankelijk van de eigenschappen van die stof. Zo blijken grote stoffen in het algemeen trager in de bloedbaan terecht te komen dan kleine stoffen; voor een snelle diagnose ligt het dus voor de hand te zoeken naar bruikbare kleine stoffen. Sommige stoffen komen slechts in één type cel voor, en zijn dus celspecifiek, andere stoffen komen in meerdere soorten cellen voor en zijn dus niet celspecifiek. Welke eigenschappen van een stof aangeven of die stof een geschikte marker kan zijn voor hartschade staat ook beschreven in hoofdstuk 2.

Het gebruik van een methode die de concentratie van een stof snel en continu kan bepalen, vereist dat er continue bloed van de patiënt beschikbaar moet zijn (de patiënt moet 'on-line' zijn). Hiervoor bestaan verschillende technieken, zoals microdialyse of ultrafiltratie. Hoe deze technieken precies werken staat eveneens beschreven in hoofdstuk 2.

Hoofdstuk 3 beschrijft diverse eigenschappen van het eiwit FABP, en waarom deze stof momenteel het meest geschikt is als vroege marker voor hartschade. Tot nu toe werd wereldwijd aangenomen dat het eiwit myoglobine de beste vroege marker is voor hartschade. In dit hoofdstuk staat beschreven waarom FABP wellicht een betere vroege hartschademarker is dan myoglobine.

Gesteld dat FABP gebruikt wordt als vroege marker voor een infarct, dan is het erg nuttig te kunnen beschikken over een FABP-biosensor. In hoofdstuk 4 wordt uitgelegd wat een biosensor precies is, en hoe ze in verschillende groepen kunnen worden onderverdeeld. Biosensoren maken meestal gebruik van de unieke binding tussen een antilichaam en zijn bijbehorende stof. Bij elke stof in het menselijk lichaam hoort namelijk een apart antilichaam; en dit antilichaam bindt zich specifiek aan zijn bijbehorende stof. Zoals boven beschreven is het belangrijk en wordt het steeds belangrijker om in het ziekenhuis bepaalde stoffen in bloed of in plasma snel, continue en makkelijk te kunnen meten.

Er bestaan reeds biosensoren die FABP kunnen meten, maar deze sensoren zijn of heel traag, of maar voor één meting te gebruiken, of ze kunnen FABP niet in bloed meten. Alle tot nu toe in de literatuur beschreven biosensoren voor FABP staan kort beschreven in hoofdstuk 4. In dit hoofdstuk staat ook vermeld welk type biosensor wij hebben ontwikkeld en waarom wij vinden dat dit type wel geschikt is voor het gebruik in, bijvoorbeeld, een ziekenhuis.

In hoofdstuk 5 staan de eerste stappen van de ontwikkeling van onze biosensor beschreven. In het kort volgt hier enige uitleg. In eerste instantie gebruikten we zogenaamde cupjes (kleine kunstof reactie vaatjes), met daarin bepaalde korrels waaraan FABP werd gebonden. Vervolgens werd het antilichaam tegen FABP toegevoegd. Dit antilichaam (met daaraan een label, een chemisch kenmerk) bond zich aan FABP. 
Antilichamen die zich niet stevig of niet goed vast hechtten aan FABP werden vervolgens weggewassen. Bij het opnieuw toevoegen van een oplossing met FABP (dit noemen we "vrij-FABP"), liet een bepaalde hoeveelheid van de antilichamen van de korrels los en hechtte aan het "vrije FABP" (en dit fenomeen heet displacement). Het "vrije" FABP was opgelost in een buffervloeistof, of in plasma. Na het centrifugeren van het cupje konden we dit FABP, en de daaraan gebonden antilichamen, uit het cupje halen en, omdat de antilichamen waren gelabeld, konden we de hoeveelheid antilichamen gebonden aan het vrije FABP, meten. Zowel in een buffervloeistof als in plasma trad displacement op, maar in plasma bleek dat er meer antilichamen werden gebonden aan het vrije FABP.

Andere onderzoekers hebben eerder het displacement fenomeen beschreven voor grote eiwitten. In hoofdstuk 5 hebben we beschreven dat het fenomeen ook optreedt bij de hier beschreven meetmethode van een klein eiwit zoals FABP.

Het bepalen van een hoeveelheid van een stof in een cupje is niet erg praktisch in een ziekenhuis. Zoekend naar verbetering hebben we in de verdere ontwikkeling van de biosensor (hoofdstuk 6) de cupjes vervangen door kleine $(6-10 \mathrm{~cm})$ smalle $(2 \mathrm{~mm})$ glazen buisjes (kolommen). Door deze kolommen werd met behulp van een pomp, continu vloeistof gezogen. De korrels met FABP met daaraan de antilichamen, die we al gebruikten in de cupjes, hebben we eveneens gebruikt in de kolommen. Daarna onderzochten we of in deze kolommen, in buffer zowel als in plasma, displacement kon optreden. Om displacement te verkrijgen in een kolom bleken minder korrels en minder antilichamen nodig te zijn dan in de cupjes.

Aanvankelijk gebruikten we in de experimenten plasma van een gezonde donor, waaraan we zelf FABP hadden toegevoegd. Om te kunnen onderzoeken of de kolom geschikt zou zijn voor het meten van FABP in "ziek" plasma, hebben we ook het plasma van patiënten met een hartinfarct aan de kolommen toegevoegd. Zoals hierboven beschreven, bevat het bloed van een patiënt met een hartinfarct FABP. Dit FABP induceerde, net als het "vrije" FABP in "gezond" plasma, ook displacement. Hoe meer FABP er in het plasma aanwezig was, hoe meer displacement er optrad.

Het gebruik van een kolom in plaats van een cupje is niet alleen makkelijker en sneller, er is ook minder materiaal voor nodig.

Voor zover wij weten is dit de eerste keer dat er onderzoek werd verricht met plasma van een patiënt met een hartinfarct om in een kolom displacement op te wekken. De kolom is nog niet geschikt om in het ziekenhuis te worden gebruikt, en we kunnen er kleine infarcten nog niet mee aantonen. De kolom moet dus worden verbeterd. Inmiddels weten we al wel dat we kleinere hoeveelheden van FABP kunnen meten als we de vloeistof langzamer door de kolom zuigen. Voorlopig is het nadeel hiervan echter dat de meting langer duurt. Omdat snelheid geboden is moet voor dit probleem een oplossing gezocht worden.

In hoofdstuk 7 staat beschreven dat we betrokken zijn geweest bij het onderzoek van twee andere onderzoeksgroepen. De groep van C. McNeil uit Newcastle, Engeland, probeert een andere biosensormethode uit om FABP snel te kunnen meten. Welke methode dit precies is en hoe het werkt staat beschreven in hoofdstuk 7. Tijdens hun eerdere experimenten traden er enkele problemen op waarvoor nog geen oplossing werd 
gevonden. De Engelse biosensor werkt nog niet goed, kan maar één meting doen, en is dus niet geschikt voor continue metingen.

De tweede groep waarmee is samnegewerkt, is die van R. Renneberg in Berlijn, Duitsland. $\mathrm{Zij}$ hebben een 'testkaartje' ontwikkeld waarmee FABP gemeten kan worden. Het testkaartje heeft de grootte van een creditcard en de werking lijkt op die van een zwangerschapstest. Als er bloed op de juiste plaats op het kaartje wordt gedruppeld, wordt er een streepje zichtbaar indien de betrokken patiënt een infarct heeft.

De eerste kaartjes die wij hebben getest met bloed van hartinfarct-patiënten werkten niet optimaal. Er waren te veel fout-negatieve resultaten (d.w.z. er ontstond geen streepje als er bloed met FABP erin werd toegevoegd). Het bedrijf heeft de kaartjes daarna kunnen verbeteren en een onderzoeksgroep in Bernau heeft de nieuwe testkaartjes getoetst. De nieuwe resultaten zagen er goed uit. Voordat dit type testkaartje op de markt kan worden gebracht, moet er in verschillende ziekenhuizen nader onderzoek naar de kwaliteit ervan worden verricht. De indicatie voor het gebruik van een testkaartje is anders dan die voor het gebruik van een on-line biosensor; zo spreekt het voor zich dat het kaartje niet geschikt is voor continue metingen.

In hoofdstuk 8 staat de beschouwing en discussie over het onderzoek en wordt er beschreven wat er in de directe toekomst gedaan kan en zou moeten worden om de FABP biosensor verder te ontwikkelen. De discussie gaat met name over de noodzaak om tot een snellere diagnostische methode te komen, waarom een snelle diagnose van hartschade belangrijk is en welke marker daarvoor het meest geschikt zou zijn. Er staat beschreven hoe we denken de functie van de biosensor te verbeteren en waarom dit type biosensor niet alleen geschikt is voor het meten van hartschade, maar ook is te gebruiken voor het meten van schade aan de lever, nieren of hersenen. De belangrijkste conclusie luidt dat de biosensor die we ontwikkeld hebben van grote betekenis kan zijn voor diverse toepassingen. We zijn ons bewust dat er nog veel onderzoek moet worden verricht om de biosensor te verbeteren tot een biosensor die kleine weefselschade snel en continu kan bepalen. 


\section{Dankwoord}

Zonder hulp van anderen had ik niet kunnen promoveren. En daarom wil ik op deze plek iedereen bedanken die op welke manier dan ook heeft bijgedragen aan dit boekje.

Allereerst natuurlijk mijn promotor en co-promotors, de bedenkers en begeleiders van het project: Jaap Korf (Groningen), Jan Glatz en Wim Hermens (Maastricht). Het was een enorme uitdaging om als net afgestudeerd medisch biologe aan een vrij technisch promotie-onderzoek te beginnen. Jaap, je was vooral mijn begeleider in het eerste jaar, toen ik in Groningen woonde. Je enthousiasme was aanstekelijk, en ideëen waren er genoeg (het was immers altijd erg "lollig" om iets anders uit te proberen). Jan bedankt voor alle telefoontjes en de kopjes koffie die in het eerste jaar altijd voor me klaarstonden als ik 3,5 uur had gereden.

Gea, collega AIO, kamergenoot in het eerste jaar, sportmaatje en medespreekster tijdens de STW bijeenkomsten, ik heb altijd veel respect gehad voor je nuchtere, ongecompliceerde kijk op sommige zaken, en je hebt me menigmaal laten inzien dat er ook andere dingen bestonden naast het werk op de universiteit. Je verdient hier een zeer speciaal bedankje, ook voor je aanwezigheid op 20 maart 2001.

Alle andere groningse AIO's: Andrea, Christel en Renger, jullie zijn mij allemaal al voorgegaan. Folkert, Ger, Kor (de "handy man" met het baardje), Ria, Rikje, Tineke, Tineke, Willie, bedankt voor de gezellige koffiepauzes (met en zonder taart).

In augustus 2000 "mocht" ik naar Hong Kong, Helma, bedankt voor alles wat je me daar hebt geleerd, je instructies hebben absoluut een bijdrage geleverd aan de inhoud van dit boekje. Reinhard, thank you very much for giving me the opportunity to stay at the Hong Kong University of Science and Technology.

$\mathrm{Na}$ Hong Kong zette ik mijn project voort in Maastricht. Jan, ik noem je hier nogmaals, en dan als begeleider. Bedankt voor je steun voor en tijdens de overgang naar Maastricht en de begeleiding tot het eind. Je zeer nauwkeurige manier van nakijken, heeft menig rode streep opgeleverd. Beste Wim, na ruim een jaar werd je mijn derde begeleider. Je wist me altijd veel proeven te laten doen...en had altijd tijd om "even" te brainstormen. Bedankt voor je interesse in het project en het helpen met de schrijverijen, zeker aan het eind! En ja, er was nog een begeleider... Maurice. Je leerde me ELISA's en vertelde me een hoop achtergrond informatie over hèt eiwit. Je onderzocht het in eekhoorns, ganzen, paarden en zalm maar ook in darm, brein, lever en nier, nee als het over FABP ging, was niets je te gek. Je komt verderop nogmaals aan bod.

Dear Ana (Life Sciences, Ely, UK) and Calum (University of Newcastle Upon Tyne, $\mathrm{UK})$, thank you for teaching me about your sensor.

Beste collega promovendi van fysiologie: Danny, Debby, Joep, Karin, Kristel, Maurice, Pascal, Roy en Susan, heel veel succes met jullie promotie en/of verdere carrière. Nog 
een woord van dank voor alle andere collega's en (oud)-medewerkers van Fysiologie, waaronder Anita, Claire, Hans, Ger, Karin, Linda, Marc, Martijn, Mirjam, Jodil, Joost, Jos, Lilian, Peter, Theo, Veerle, Will en iedereen die ik vergeten ben (sorry). En dan mijn allerlaatste kamergenoot, Benjamin, bedankt voor alle rust tijdens de laatste weken.

In juni 2003 verhuisde een deel van de vakgroep fysiologie naar de vakgroep moleculaire genetica. Er kwamen een boel collega's bij. Ondanks dat ik niet echt de kans heb gehad om jullie goed te leren kennen, wil ik ook jullie hier bedanken. Het dagje uit was geweldig!!

Geachte heren van de gebruikerscommissie, bedankt voor het aanhoren van mijn presentaties, het stellen van vragen, en het geven van al die waardevolle suggesties.

Zonder de expertise van mevrouw Leonie had ik die laatste "puntjes op de i" niet kunnen vinden, bedankt voor Uw tijd, super!

- En dan "the family", waar jullie ook waren (America, Frankrijk of Nederland), ik was altijd thuis. Papa, bedankt voor je monnikkenwerk.

Lieve Maurice, van samen werken tot samen promoveren en sinds kort ook samenwonen. Bedankt voor al je inbreng, steun en troost. Laten we zó, saampjes èn met z'n vieren, verder gaan.

Op naar ons feest! 


\section{Curriculum Vitae}

De Schrijfster van dit proefschrift, Daniëlle van der Voort, werd geboren op 12 januari 1976 te Hoensbroek als tweede dochter van Danny en Toos, en zusje van Marjolein. Na haar eindexamen VWO in 1995 startte ze enthousiast haar opleiding medische biologie aan de Universiteit van Amsterdam. De keuze beviel goed en binnen 4 jaar behaalde zij haar doctoraal examen. In september 1999 begon ze als assistent in opleiding (AIO) op de afdeling biologische psychiatrie te Groningen haar promotieonderzoek, een project gecombineerd met de afdeling fysiologie te Maastricht. Na een jaar in Groningen te hebben doorgebracht verhuisde ze naar Maastricht om daar, na een twee weken durend werkbezoek aan de universiteit van Hong Kong in augustus 2000 haar onderzoek naar de ontwikkeling van een biosensor voor fatty acid-binding protein voort te zetten. Ze volgde diverse cursussen, behaalde o.a. de CARIM-status en werd de artikel 9 status volgens de wet op de dierproeven toegekend. Naast het bezoeken van congressen te Aken, Berlijn, Cambridge, Dijon, Eindhoven, Lund, Maastricht, Münster en Parijs legde ze ook een werkbezoek af aan de universiteit van Newcastle Upon Tyne, en het bedrijf Life Sciences te Ely (UK). Naast haar onderzoek was Daniëlle actief als organisatrice van sportieve en recreatieve evenementen in en buiten Limburg. In september 2003 rondde ze haar proefschrift af en sindsdien is ze zich aan het oriënteren op de arbeidsmarkt. 


\section{$\underline{\text { Publicaties }}$}

- de Graaf IA, van der Voort D, Brits JH, Koster HJ. Increased post-thaw viability and phase I and II biotransformation activity in cryopreserved rat liver slices after improvement of a fast-freezing method. Drug Metab Dispos. 2000 Sep;28(9):1100-6.

- van der Voort DJM, van der Voort D, Geusens PP, Dinant GJ. Aging and social and socio-economic determinant of osteoporosis, studied in healthy postmenopausal women. In: Detectie en determinanten van osteoporosis in de eerste lijn, Maastricht, The Netherlands, university Maastricht; 2000 (thesis):chapter 7

- Glatz JFC, van der Voort D, Hermens WT. Fatty acid-binding protein as the earliest available plasma marker of acute myocardial injury. J Clin Ligand Assay 2002;25:167-77

- Chan CPY, Cheng WS, Glatz JFC, van der Voort D, Sanderson JE, Hempel A, Lehmann M, Renneberg I, Renneberg R. Early diagnosis of acute myocardial infarction using immunosensors and immunotests. Anal let 2003;36:1987-2004

- Van der Voort D, Pelsers MMAL, Korf J, Hermens WT, Glatz JFC. Development of a displacement immunoassay for human heart-type fatty acid-binding protein in plasma: the basic conditions. Biosens Bioelectron 2003;19:465-71

- Van der Voort D, McNeil CA, Renneberg R, Korf J, Hermens WT, Glatz JFC. Biosensors: basic features and application for fatty acid-binding protein, an early plasma marker of myocardial injury. Sens Actuators 2003; accepted for publication

- Van der Voort D, Pelsers MMAL, Korf J, Hermens WT, Glatz JFC. A displacement immunoassay for human heart-type fatty acid-binding protein in plasma. $\mathrm{J}$ immunol Methods 2003; submitted 